\title{
Benzofuran-derived Cyclic $\beta$-Amino Acid Scaffold for Building a Diverse Set of Flavonoid-like Probes and the Discovery of a Cell Motility Inhibitor
}

Jyoti P. Nandy, ${ }^{1}$ Bojana Rakic, ${ }^{1,3}$ Bugga V. N. B. Sarma, ${ }^{1}$ Nallareddy Babu, ${ }^{1}$ Marc Lefrance, ${ }^{3}$ Gary D. Enright, ${ }^{1}$ Donald M. Leek, ${ }^{1}$ Kate Daniel, ${ }^{4}$ Luc A. Sabourin ${ }^{4, *}$ and Prabhat Arya ${ }^{1,2,{ }^{*}}$

(1) Steacie Institute for Molecular Sciences, National Research Council of Canada, 100 Sussex Drive, Ottawa, Ontario, K1A 0R6

(2) Ontario Institute for Cancer Research, MaRS Centre, South Tower, 101 College Street, Toronto, Ontario, M5G $1 L 7$

(3) Department of Chemistry, University of Ottawa, Ottawa, Ontario, K1N 6N5

(4) Ottawa Health Research Institute, 503 Smyth Road, Ottawa, Ontario, K1H 8L6 
Table of Contents

1) General Methods (Chemical synthesis)

2) Synthetic Procedures

Synthesis of compounds 3a and 4

Synthesis of compounds $4 a$ and 5

Synthesis of compounds 6 and 7

Synthesis of compounds $7 \mathbf{a}$ and $7 \mathbf{b}$

Synthesis of compounds 7c and 9

Synthesis of compounds $9 \mathbf{a}$ and 10

Synthesis of compounds 10a and 11

Synthesis of compounds $\mathbf{1 2 a}$ and $\mathbf{1 2 b}$

Synthesis of compounds 12c, 9b and 9c

Synthesis of compounds $9 \mathrm{~d}$ and $9 \mathrm{e}$

Synthesis of compound 13

Synthesis of compounds 13a and 15

Synthesis of compounds 14 and 14a

Synthesis of compound 16

3) Procedure to Obtain Compound 18.

Synthesis of compound $\mathbf{8}$

Synthesis of compounds $\mathbf{8 a}, \mathbf{8 b}$ and 17

Synthesis of compound 17a

Synthesis of compounds $17 b$ and $17 c$

Synthesis of compounds $17 d$ and $17 e$

Synthesis of compound $\mathbf{1 8}$

4) X-ray Crystallographic Data for Compound 8.

5) Biological Assays

Wound-healing assay

Chamber Cell migration assay

Immunostaining experiment

6) $1 \mathrm{D}$ and $2 \mathrm{D}$ NMR Spectra

Compound 15

Compound $\mathbf{1 6}$

Compound 12 


\section{Compound 18}

\section{General methods (Chemical synthesis):}

All reactions were carried out in flame-dried glassware under an Argon atmosphere. Thin-layer chromatography (TLC) was done on EMD (Art. 5715-7) precoated silica gel $60 \mathrm{~F}_{254}$ glass plates (layer thickness $0.25 \mathrm{~mm}$ ). Visualisation was affected with a UV lamp $(254 \mathrm{~nm})$ and/or by staining with $\mathrm{KMnO}_{4}$ solution or ammonium molybdate/ceric sulfate solution. Flash column chromatography was performed using silica gel 60 (40-63 $\mu \mathrm{m}$, Silicycle) or Biotage Horizon Flash Chromatography System. Solvents were purified as follows: trace amounts of water and oxygen from tetrahydrofuran (THF), dymethylformamide (DMF) and dichloromethane (DCM) were removed using columns containing activated alumina and copper under $\mathrm{N}_{2}$. Triethylamine (TEA), pyridine, $\mathrm{N}, \mathrm{N}-$ diisopropylethylamine (DIPEA), diethyl ether, acetonitrile and toluene were obtained from commercial suppliers $\left(\mathrm{EMD}^{\circledR}\right.$ and $A$ Adrich $\left.{ }^{\circledR}\right)$ and used without further purification. NMR spectra were recorded on a Bruker DRX $400 \mathrm{MHz}$ spectrometer. All chemical shifts are reported in parts per million $(\delta) .{ }^{1} \mathrm{H}$ NMR $(400 \mathrm{MHz})$ spectra were recorded at room temperature in $\mathrm{CDCl}_{3}$ or $\mathrm{C}_{6} \mathrm{D}_{6}$ solutions and referenced to residual $\mathrm{CHCl}_{3}(7.27$ ppm) or $\mathrm{C}_{6} \mathrm{H}_{6}(7.16 \mathrm{ppm})$. Fully decoupled ${ }^{13} \mathrm{C}$ NMR (100 MHz) spectra were recorded in $\mathrm{CDCl}_{3}$ or $\mathrm{C}_{6} \mathrm{D}_{6}$ solutions. The center peaks of $\mathrm{CDCl}_{3}(77.0 \mathrm{ppm})$ and $\mathrm{C}_{6} \mathrm{D}_{6}(128.7$ ppm) were used as the internal reference. Mass spectra were carried out on a VG Quattro I (Micromass) mass spectrometer equipped with a pneumatically assisted electrospray ionization source, operating in positive mode. HPLC were performed using a HewlettPackard (Agilent) 1100 Series equipped with a diode array detector and a NovaPack C18 $(3.9 \times 300 \mathrm{~mm})$ column. The enantiomeric excess was determined by chiral HPLC, using a Hewlett-Packard (Agilent) 1090 Series II Liquid Chromatograph equipped with a diode array detector and a CHIRACEL-OD column.

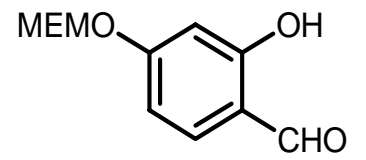

To a solution of 2,4-dihydroxybenzaldehyde $3(10.0 \mathrm{~g}, 72.3 \mathrm{mmol})$ in DCM $(100 \mathrm{~mL})$ at $-5{ }^{\circ} \mathrm{C}$ was added DIPEA $(12.50 \mathrm{~mL}, 72.3$ 
mmol) over a 5 minute period dropwise. The following mixture was stirred for 5 minutes followed by the addition of 2-methoxyethoxymethyl chloride $(8.20 \mathrm{~mL}, 72.3 \mathrm{mmol})$. The solution was stirred at $-5^{\circ} \mathrm{C}$ for 6 hours. The reaction was then quenched with water $(50$ $\mathrm{mL})$ at $0{ }^{\circ} \mathrm{C}$ and extracted with $\mathrm{DCM}(3 \times 100 \mathrm{~mL})$, dried over anhydrous $\mathrm{MgSO}_{4}$, filtered and concentrated in vacuo to produce yellowish oil. Purification by flash chromatography (ethyl acetate/hexane 50\%) afforded 3a (14.9 g, 91\%) as a colorless oil. ${ }^{1} \mathrm{H}$ NMR: $\left(400 \mathrm{MHz}, \mathrm{CDCl}_{3}\right) \delta=11.32(\mathrm{~s}, 1 \mathrm{H}), 9.68(\mathrm{~s}, 1 \mathrm{H}), 7.40(\mathrm{~d}, J=8.7 \mathrm{~Hz}, 1 \mathrm{H})$, 6.62 (dd, $J=2.1,8.6 \mathrm{~Hz}, 1 \mathrm{H}), 6.56$ (d, $J=2.1 \mathrm{~Hz}, 1 \mathrm{H}), 5.27$ (s, 1H), 3.78 (t, $J=4.6 \mathrm{~Hz}$, $2 \mathrm{H}), 3.51$ (t, $J=4.6 \mathrm{~Hz}, 2 \mathrm{H}), 3.33$ (s, 3H); ${ }^{13} \mathrm{C}-\mathrm{NMR}:\left(100 \mathrm{MHz}, \mathrm{CDCl}_{3}\right) \delta=195.1$, 164.7, 164.5, 132.8, 116.3, 109.4, 103.9, 93.5, 71.9, 68.7, 59.5; MS: (EI) $\mathrm{m} / \mathrm{z}=227$ $(\mathrm{M}+1)$, HPLC purity $(>99 \%)$.

MEMO

4

To a solution of 3a $(14.9 \mathrm{~g}, 69.08 \mathrm{mmol})$ in acetone $(200 \mathrm{~mL})$ at room temperature was added $\mathrm{K}_{2} \mathrm{CO}_{3}(38.19 \mathrm{~g}, 276.35 \mathrm{mmol})$. The suspension was stirred for 5 minutes followed by the subsequent addition of benzyl bromide $(8.22 \mathrm{~mL}, 69.08 \mathrm{mmol})$. The reaction mixture was stirred for 12 hours at room temperature and then filtered through a $5 \mathrm{~cm}$ celite pad and concentrated in vacuo to produce yellowish oil. Purification by flash chromatography (30\% ethyl acetate in hexane) afforded $4(18.8 \mathrm{~g}, 90 \%)$ as a colorless oil. ${ }^{1} \mathrm{H}$ NMR: (400 $\left.\mathrm{MHz}, \mathrm{CDCl}_{3}\right) \delta=10.41(\mathrm{~s}, 1 \mathrm{H}), 7.82(\mathrm{~d}, J=8.4 \mathrm{~Hz}, 1 \mathrm{H}), 7.46-7.33(\mathrm{~m}, 5 \mathrm{H}), 6.73(\mathrm{~s}, 1 \mathrm{H})$, $6.72(\mathrm{~d}, J=8.7 \mathrm{~Hz}, 1 \mathrm{H}), 5.31(\mathrm{~s}, 2 \mathrm{H}), 5.16(\mathrm{~s}, 2 \mathrm{H}), 3.82(\mathrm{t}, J=4.6 \mathrm{~Hz}, 2 \mathrm{H}), 3.55(\mathrm{t}, J=$ $4.7 \mathrm{~Hz}, 2 \mathrm{H}), 3.38(\mathrm{~s}, 3 \mathrm{H}) ;{ }^{13} \mathrm{C} \mathrm{NMR}:\left(100 \mathrm{MHz}, \mathrm{CDCl}_{3}\right) \delta=188.8,164.1,163.1,136.3$, 130.7, 129.0, 128.8, 127.7, 120.4, 109.1, 101.6, 93.6, 72.0, 70.9, 68.5, 59.5; MS: (ES+) $\mathrm{m} / \mathrm{z}=317(\mathrm{M}+1)$, HPLC purity $(>99 \%)$.

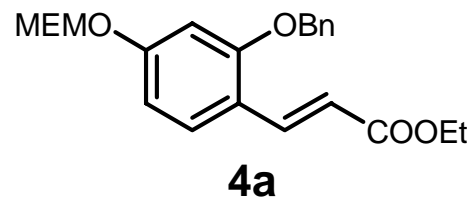

To a suspension of $\mathrm{NaH}(2.87 \mathrm{~g}, 61.1 \mathrm{mmol})$ in dry THF $\left(\begin{array}{ll}100 & \mathrm{~mL}\end{array}\right)$ at $\quad 0 \quad{ }^{\circ} \mathrm{C}$ was slowly added triphenylphosphinoethyl acetate $(10.91 \mathrm{~mL}, 55.01 \mathrm{mmol})$

for 5 minutes. The reaction mixture was then allowed to stir for 30 minutes at $0{ }^{\circ} \mathrm{C}$ and then aldehyde 4 (15 g, $47.4 \mathrm{mmol})$ dissolved in dry THF $(50 \mathrm{~mL})$ was added to it slowly. 
After being stirred for 5 hours at $0{ }^{\circ} \mathrm{C}$ under the $\mathrm{N}_{2}$ atmosphere the reaction mixture was quenched with water very slowly at $0{ }^{\circ} \mathrm{C}$ and extracted with ethyl acetate, washed with brine, dried over anhydrous $\mathrm{MgSO}_{4}$, and concentrated in vacuo. Purification by flash chromatography (30\% ethyl acetate in hexane) afforded 4a $(E: Z=99: 1)(17.5 \mathrm{~g}, 95 \%$ yield) as a white solid. ${ }^{1} \mathrm{H}-\mathrm{NMR}$ : $\left(400 \mathrm{MHz}, \mathrm{CDCl}_{3}\right) \delta=8.03(\mathrm{~d}, J=16.1 \mathrm{~Hz}, 1 \mathrm{H}), 7.49$ $7.28(\mathrm{~m}, 6 \mathrm{H}), 6.70-6.67(\mathrm{~m}, 2 \mathrm{H}), 6.46(\mathrm{~d}, J=16.1 \mathrm{~Hz}, 1 \mathrm{H}), 5.28(\mathrm{~s}, 2 \mathrm{H}), 5.16(\mathrm{~s}, 2 \mathrm{H})$, 4.26 (q, $J=7.1 \mathrm{~Hz}, 2 \mathrm{H}), 3.82$ (t, $J=4.5 \mathrm{~Hz}, 2 \mathrm{H}), 3.57$ (t, $J=4.7 \mathrm{~Hz}, 2 \mathrm{H}), 3.39$ (s, 3H), $1.34(\mathrm{t}, J=7.1 \mathrm{~Hz}, 3 \mathrm{H}) ;{ }^{13} \mathrm{C}$ NMR: $\left(100 \mathrm{MHz}, \mathrm{CDCl}_{3}\right) \delta=168.2,160.5,159.0,139.1$, 138.8, 130.3, 129.0, 128.4, 127.7, 118.5, 117.1, 108.9, 101.9, 93.8, 71.9, 70.8, 68.2, 60.6, 59.5, 14.8; LRMS: $\left(\mathrm{ES}^{+}\right) \mathrm{m} / \mathrm{z}=387(\mathrm{~m}+1)$, HPLC purity $(>99 \%)$.

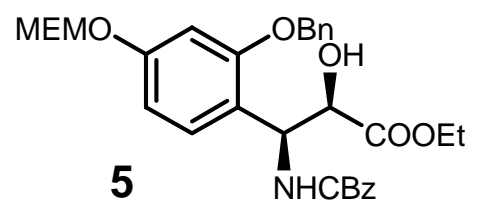

additions of the freshly prepared ${ }^{t} \mathrm{BuOCl}(10.7 \mathrm{~mL}, 93.3 \mathrm{mmol})$, and the solution of (DHQ) 2 PHAL ligand (1.240 g, $1.59 \mathrm{mmol}$ in $108 \mathrm{~mL}$ of $n$-propanol) at $0{ }^{\circ} \mathrm{C}$. The reaction mixture was stirred at room temperature for 5 minutes, and then $4 \mathbf{a}(12 \mathrm{~g}, 31.1 \mathrm{mmol}$ in $30 \mathrm{~mL}$ of $n$-propanol) was added followed by the addition of the osmium catalyst $\left(\mathrm{K}_{2} \mathrm{OsO}_{2}(\mathrm{OH})_{4}, 480 \mathrm{mg} 1.30 \mathrm{mmol}\right)$. The resulting mixture was stirred for 3 hours at room temperature. The solution turned from a dark green to a dark yellow over the period. Once reaction completed, the reaction mixture was extracted with ethyl acetate. The organic extracts were combined, washed with brine, dried over anhydrous $\mathrm{MgSO}_{4}$ and concentrated to dark brown oil. Purification by flash chromatography (40\% ethyl acetate in hexane) afforded 5 (11.2 g, 64\%yield, enantiomeric excess $>95 \%$ in ethanol/hexane) as a colorless oil. ${ }^{1} \mathrm{H}$-NMR: $\left(400 \mathrm{MHz}, \mathrm{CDCl}_{3}\right) \delta=7.49(\mathrm{t}, J=7.1 \mathrm{~Hz}$, $2 \mathrm{H}), 7.43$-7.22 (m, 10H), 6.97-6.69 (m, 1H), 6.07-5.60 (m, 2H), 5.30-5.25 (m, 2H), 5.19$5.02(\mathrm{~m}, 2 \mathrm{H}), 5.08(\mathrm{~s}, 2 \mathrm{H}), 4.85-4.56(\mathrm{~m}, 1 \mathrm{H}), 4.18(\mathrm{q}, J=7.2,2 \mathrm{H}), 3.88-3.80(\mathrm{~m}, 2 \mathrm{H})$, $3.56(\mathrm{t}, J=5.8 \mathrm{~Hz}, 2 \mathrm{H}), 3.38(\mathrm{~s}, 3 \mathrm{H}), 1.21(\mathrm{t}, J=7.2 \mathrm{~Hz}, 3 \mathrm{H}) ;$ LRMS: $\left(\mathrm{ES}^{+}\right) \mathrm{m} / \mathrm{z}=554$ $(\mathrm{m}+1)$, HPLC purity $(99 \%)$. 


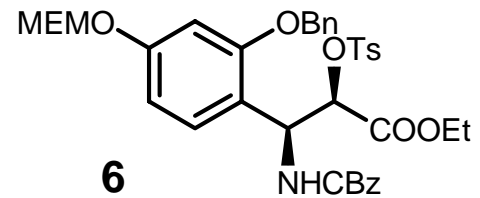

Tosyl chloride (4.55 g, $23.9 \mathrm{mmol})$ was added to a stirred solution of 5 (11 g, $19.9 \mathrm{mmol})$ and DMAP (3.64 g, 29.9 mmol) in DCM $(100 \mathrm{~mL})$ at room temperature. The reaction mixture was refluxed for 12 hours at $40{ }^{\circ} \mathrm{C}$. After solution $(3 \times 20 \mathrm{~mL})$ and combined organic layer was extracted with DCM, washed with brine, dried over anhydrous $\mathrm{MgSO}_{4}$ and concentrated in vacuo. Purification by flash chromatography (40\% ethyl acetate in hexane) afforded 6 (13.4 g, 95\% yield) as a white solid. ${ }^{1} \mathrm{H}$-NMR: (400 MHz, $\left.\mathrm{CDCl}_{3}\right) \delta=7.47-7.32(\mathrm{~m}, 12 \mathrm{H}), 7.07(\mathrm{~d}, J=8.0 \mathrm{~Hz}, 2 \mathrm{H})$, $6.97(\mathrm{~d}, J=8.4 \mathrm{~Hz}, 1 \mathrm{H}), 6.55(\mathrm{dd}, J=1.7,8.4 \mathrm{~Hz}, 1 \mathrm{H}),$,6.49 (d, $J=1.7 \mathrm{~Hz}, 1 \mathrm{H},), 5.65-$ $5.54(\mathrm{~m}, 2 \mathrm{H}), 5.28-5.21(\mathrm{~m}, 3 \mathrm{H}), 5.11-4.90(\mathrm{~m}, 4 \mathrm{H}), 4.08(\mathrm{q}, J=7.1=\mathrm{Hz}, 2 \mathrm{H}),$, (t, $J=4.4 \mathrm{~Hz}, 2 \mathrm{H}), 3.58(\mathrm{t}, J=4.8 \mathrm{~Hz}, 2 \mathrm{H}$ ), $3.40(\mathrm{~s}, 3 \mathrm{H}), 2.38(\mathrm{~s}, 3 \mathrm{H}), 1.23$ (t, $J=7.1$ $\mathrm{Hz}, 3 \mathrm{H}) ;{ }^{13} \mathrm{C} \mathrm{NMR}:\left(100 \mathrm{MHz}, \mathrm{CDCl}_{3}\right) \delta=167.1,158.9,156.5,155.8,145.0,136.7$, $136.5,132.8,129.8,129.1,129.0,128.9,128.8,128.6,128.5,128.4,128.2$, 127.8, 127.6, $118.4,108.0,101.5,93.9,78.5,71.9,70.6,68.2,67.4,62.3,59.5,52.9,22.0,14.6,14.5$, 14.3; LRMS: $\left(\mathrm{ES}^{+}\right) \mathrm{m} / \mathrm{z}=708(\mathrm{~m}+1)$, $\operatorname{HPLC}$ purity $(>97 \%)$.

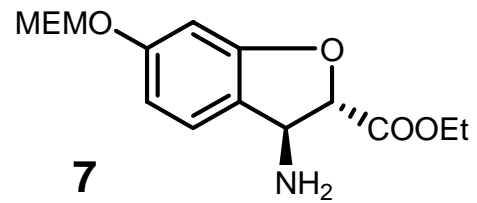

To a stirred solution of compound 6 (13 g, $18.4 \mathrm{mmol})$ in $95 \%$ ethanol $(130 \mathrm{~mL})$ was added $10 \% \mathrm{Pd} / \mathrm{C}(1.3 \mathrm{~g})$ followed by the addition of anhydrous $\mathrm{K}_{2} \mathrm{CO}_{3}(5.1 \mathrm{~g}, 36.8$ mmol). The solution was stirred under $\mathrm{H}_{2}$ atmosphere for 48 hours at room temperature. The reaction mixture was then filtered through a celite pad $(5 \mathrm{~cm})$ and concentrated into pale yellow oil. Purification by flash chromatography (90\% ethyl acetate in hexane) afforded yellowish oil 7 (4.23 g, 74\%). ${ }^{1} \mathrm{H}-\mathrm{NMR}$ : (400 MHz, $\left.\mathrm{CDCl}_{3}\right) \delta=7.22$ (d, $J=8.8$ $\mathrm{Hz}, 1 \mathrm{H}), 6.66-6.68(\mathrm{~m}, 2 \mathrm{H}), 5.24(\mathrm{~s}, 2 \mathrm{H}), 4.84(\mathrm{~d}, J=4.9,1 \mathrm{H}),, 4.72(\mathrm{~d}, J=4.8 \mathrm{~Hz}$, $1 \mathrm{H},), 4.28$ (q, $J=7.1 \mathrm{~Hz}, 2 \mathrm{H}), 3.82$ (t, $J=4.5 \mathrm{~Hz}, 2 \mathrm{H}$ ), 3.56 (t, $J=4.7 \mathrm{~Hz}, 2 \mathrm{H}), 3.38$ (s, $3 \mathrm{H}), 2.8($ broad s, $2 \mathrm{H}), 1.33(\mathrm{t}, J=7.1 \mathrm{~Hz}, 3 \mathrm{H}) ;{ }^{13} \mathrm{C}-\mathrm{NMR}\left(100 \mathrm{MHz}, \mathrm{CDCl}_{3}\right) \delta=170.3$, $160.5,159.6,125.3,110.3$, 99.6, 94.0, 89.3, 71.9, 68.1, 62.1, 59.4, 58.7, 14.5; LRMS: $\left(\mathrm{ES}^{+}\right) \mathrm{m} / \mathrm{z}=312(\mathrm{~m}+1)$, HPLC purity $(>99 \%)$. 


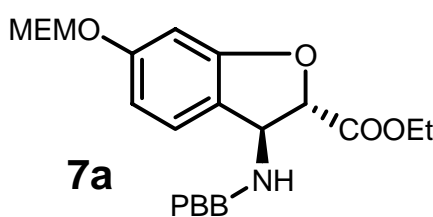

To a solution of compound 7 ( $2.0 \mathrm{~g}, 6.43 \mathrm{mmol})$ in dry $\mathrm{MeCN}$ $(140 \mathrm{~mL})$ was added $p$-bromobenzyl bromide (1.6g, 6.4 $\mathrm{mmol})$ and anhydrous $\mathrm{K}_{2} \mathrm{CO}_{3}(887 \mathrm{mg}, 6.43 \mathrm{mmol})$ at room temperature. After 5 hours stirring at room temperature the reaction mixture was filtered through a celite pad $(5 \mathrm{~cm})$ and concentrated in vacuo into pale yellow oil. Purification by flash chromatography (30\% ethyl acetate in hexane) afforded yellowish oil 7a (1.850 gm, $60 \%$ yield). ${ }^{1} \mathrm{H}-\mathrm{NMR}$ : $\left(400 \mathrm{MHz}, \mathrm{CDCl}_{3}\right) \delta=7.46$ $(\mathrm{d}, J=8.2 \mathrm{~Hz}, 2 \mathrm{H}), 7.28(\mathrm{~d}, J=3.6 \mathrm{~Hz}, 2 \mathrm{H}), 7.18(\mathrm{~d}, J=8.1 \mathrm{~Hz}, 1 \mathrm{H}), 6.70(\mathrm{~s}, 1 \mathrm{H}), 6.65$ (dd, J = 8.1, 1.9 Hz, 1H), 5.25 (dd, $J=7.0,2.4 \mathrm{~Hz}, 2 \mathrm{H}), 5.04(\mathrm{~d}, J=3.3 \mathrm{~Hz}, 1 \mathrm{H}), 4.54$ (d, $J=3.2 \mathrm{~Hz}, 1 \mathrm{H}), 4.25$ (q, $J=7.1 \mathrm{~Hz}, 2 \mathrm{H}), 3.88$ (s, 2H), 3.83 (t, $J=4.4 \mathrm{~Hz}, 2 \mathrm{H}), 3.57$ (t, $J$ $=4.8 \mathrm{~Hz}, 2 \mathrm{H}), 3.39(\mathrm{~s}, 3 \mathrm{H}), 1.29(\mathrm{t}, J=7.1 \mathrm{~Hz}, 3 \mathrm{H}) ;{ }^{13} \mathrm{C}-\mathrm{NMR}\left(100 \mathrm{MHz}, \mathrm{CDCl}_{3}\right) \delta=$ 170.7, 161.1, 159.8, 138.9, 131.9, 130.3, 125.9, 121.4, 120.2, 110.1, 99.6, 94.0, 86.0, 71.9, 68.1, 64.2, 62.1, 59.4, 49.9, 14.6; LRMS: $\left(\mathrm{ES}^{+}\right) \mathrm{m} / \mathrm{z}=480(\mathrm{~m}+1)$ and $482(\mathrm{~m}+2)$, HPLC purity $(>97 \%)$.

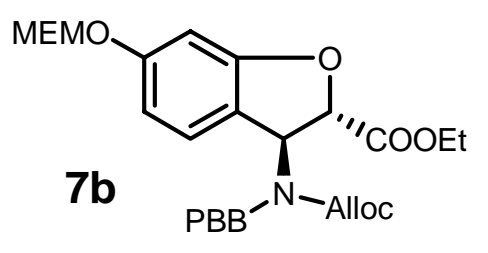

To a solution of compound $7 \mathrm{a}(1.5 \mathrm{~g}, 3.1 \mathrm{mmol})$ in dry DCM $(80 \mathrm{~mL})$ at $0{ }^{\circ} \mathrm{C}$ was added DIPEA $(485 \mathrm{mg}, 3.7$ $\mathrm{mmol}$ ) and the reaction mixture was stirred for 5 minutes. Allyloxy chloroformate $(331 \mu \mathrm{L}, 3.1 \mathrm{mmol})$ was added slowly and the reaction mixture was stirred for 12 hours at room temperature. The reaction mixture was quenched by addition of water and extracted with DCM, dried over anhydrous $\mathrm{MgSO}_{4}$ and concentrated in vacuo. Purification by flash chromatography (30 $\%$ ethyl acetate in hexane) afforded pure compound of $7 \mathbf{b}$ ( $1.6 \mathrm{~g}, 90 \%$ yield) as a white solid. ${ }^{1} \mathrm{H}$-NMR: $\left(400 \mathrm{MHz}, \mathrm{CDCl}_{3}\right) \delta=7.38(\mathrm{~d}, J=8.2 \mathrm{~Hz}, 2 \mathrm{H}), 7.01(\mathrm{~d}, J=7.8 \mathrm{~Hz}$, 2H), $6.87(\operatorname{broad~s}, 1 \mathrm{H}), 6.66(\mathrm{~d}, J=1.6 \mathrm{~Hz}, 1 \mathrm{H}), 6.57(\mathrm{dd}, J=6.4 \mathrm{~Hz}, 1.8 \mathrm{~Hz}, 1 \mathrm{H}), 5.96$ - $5.86(\mathrm{~m}, 2 \mathrm{H}), 5.31-5.22(\mathrm{~m}, 4 \mathrm{H}), 4.86(\mathrm{~d}, J=3.6 \mathrm{~Hz}, 1 \mathrm{H}), 4.67(\mathrm{~d}, J=5.4 \mathrm{~Hz}, 2 \mathrm{H})$ $4.46-4.43$ (m, 1H), 4.24 (q, $J=6.9,2 \mathrm{H}), 4.12$ (d, $J=16.0 \mathrm{~Hz}, 1 \mathrm{H}), 3.83$ (t, $J=4.4 \mathrm{~Hz}$, $2 \mathrm{H}), 3.58(\mathrm{t}, J=4.8 \mathrm{~Hz}, 2 \mathrm{H}), 3.40(\mathrm{~s}, 3 \mathrm{H}), 1.30$ (t, $J=7.1 \mathrm{~Hz}, 3 \mathrm{H}) ;{ }^{13} \mathrm{C}-\mathrm{NMR}(100 \mathrm{MHz}$, $\left.\mathrm{CDCl}_{3}\right) \delta=169.9,161.7,160.2,156.2,137.7,132.7,131.9,129.8,126.2,121.6,118.4$, 116.6, 110.4, 99.5, 94.0, 84.4, 71.9, 68.2, 67.1, 62.5, 62.3, 59.5, 47.5, 14.5; LRMS: (ES $\left.{ }^{+}\right)$ $\mathrm{m} / \mathrm{z}=564(\mathrm{~m}+1)$ and $566(\mathrm{~m}+2)$, HPLC purity $(>97 \%)$. 


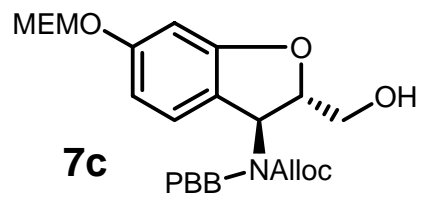

To a stirred solution of compound $\mathbf{7 b}(1.6 \mathrm{~g}, 2.84 \mathrm{mmol})$ in dry THF $(70 \mathrm{~mL})$ was added a solution of $2 \mathrm{M} \mathrm{LiBH}_{4}$ in THF of $(1.42 \mathrm{~mL}, 1.42 \mathrm{mmol})$ at $0{ }^{\circ} \mathrm{C}$. The reaction was allowed to warm to room temperature and stirred for 3 hours. The reaction mixture was quenched by addition of a saturated aqueous ammonium chloride, extracted with ethyl acetate, washed with brine, dried over anhydrous $\mathrm{MgSO}_{4}$ and concentrated in vacuo. Purification by flash chromatography (40\% ethyl acetate in hexane) afforded compound $7 \mathrm{c}(1.4 \mathrm{~g}, 95 \%)$ as a dense liquid. ${ }^{1} \mathrm{H}-\mathrm{NMR}$ : $\left(400 \mathrm{MHz}, \mathrm{CDCl}_{3}\right) \delta=7.36(\mathrm{~d}, J=8.2 \mathrm{~Hz}, 2 \mathrm{H}), 6.89$ (broad s, $3 \mathrm{H}), 6.55$ - $6.52(\mathrm{~m}, 2 \mathrm{H}), 5.98-5.88(\mathrm{~m}, 1 \mathrm{H}), 5.66($ broad s,1H $), 5.31-5.24(\mathrm{~m}, 4 \mathrm{H})$, 4.69 (d, $J=5.4 \mathrm{~Hz}, 2 \mathrm{H}), 4.48-4.39$ (m, 2H), $4.19-4.08$ (m, 2H), 3.83 (t, $J=4.4 \mathrm{~Hz}$, 2H), 3.74 (broad s, 2H), 3.58 (t, $J=4.8 \mathrm{~Hz}, 2 \mathrm{H}), 3.39$ (s, 3H); ${ }^{13} \mathrm{C}-\mathrm{NMR}(100 \mathrm{MHz}$, $\left.\mathrm{CDCl}_{3}\right) \delta=160.1,132.7,131.8,129.5,127.1,121.5,118.7,109.8,99.3,94.0,89.0,71.9$, 68.2, 67.2, 64.1, 59.4, 47.1, 31.3; LRMS: (ES+) $\mathrm{m} / \mathrm{z}=522(\mathrm{M}+1)$ and $524(\mathrm{~m}+2)$, HPLC purity $(95 \%)$.

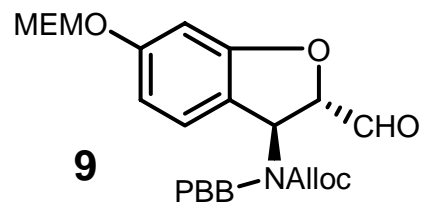

To a stirred solution of alcohol compound 7c (700 mg, 1.34 $\mathrm{mmol})$ in dry DCM was added anhydrous $\mathrm{NaHCO}_{3}(677 \mathrm{mg}$, $8.06 \mathrm{mmol}$ ) followed by Dess-Martin Periodinane $(712 \mathrm{mg}$, $1.68 \mathrm{mmol}$ ) at room temperature. The reaction mixture was stirred at room temperature for 1.5 hours and then quenched by addition of $10 \%$ aqueous solution $\mathrm{Na}_{2} \mathrm{~S}_{2} \mathrm{O}_{3}(10 \mathrm{~mL})$. The reaction mixture was stirred for additional 10 minutes until the solution turned out clear, then extracted with $\mathrm{DCM}$, washed with saturated $\mathrm{NaHCO}_{3}$ solution, dried with anhydrous $\mathrm{MgSO}_{4}$ and concentrated in vacuo. Purification by flash chromatography (40\% ethyl acetate in hexane) afforded compound 9 (550 mg, 79\% yield). ${ }^{1} \mathrm{H}-\mathrm{NMR}:(400 \mathrm{MHz}$, $\left.\mathrm{CDCl}_{3}\right) \delta=9.66(\mathrm{~s}, 1 \mathrm{H}), 7.38(\mathrm{~d}, 2 \mathrm{H}, J=8.2 \mathrm{~Hz}), 6.98(\mathrm{~d}, 2 \mathrm{H}, J=7.0 \mathrm{~Hz}), 6.89(\mathrm{~d}, 1 \mathrm{H}, J$ $=7.8 \mathrm{~Hz}), 6.60-6.56(\mathrm{~m}, 2 \mathrm{H}), 6.05-5.92(\mathrm{~m}, 2 \mathrm{H}), 5.29-5.24(\mathrm{~m}, 4 \mathrm{H}), 4.77-4.70(\mathrm{~m}$, $3 \mathrm{H}), 4.54-4.44(\mathrm{~m}, 1 \mathrm{H}), 4.15-4.06(\mathrm{~m}, 1 \mathrm{H}), 3.84(\mathrm{t}, 2 \mathrm{H}, J=4.4 \mathrm{~Hz}), 3.58(\mathrm{t}, 2 \mathrm{H}, J=4.8$ $\mathrm{Hz}), 3.40(\mathrm{~s}, 3 \mathrm{H}) ;{ }^{13} \mathrm{C}-\mathrm{NMR}\left(100 \mathrm{MHz}, \mathrm{CDCl}_{3}\right) \delta=199.0,160.4,156.2,137.6,132.6$, 
$131.9,129.7,126.7,121.7,118.7,110.9,99.5,99.1,94.0,90.8,71.9,68.3,67.3,59.7$, 59.5, 47.7; LRMS: $(\mathrm{ES}+) \mathrm{m} / \mathrm{z}=520(\mathrm{~m}+1)$ and $522(\mathrm{~m}+2)$, HPLC purity $(>93 \%)$.

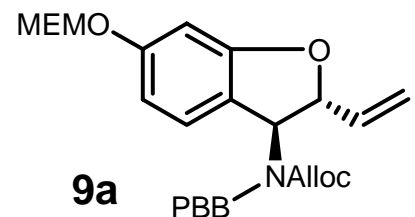

temperature and was stirred for 1 hour. The reaction mixture was then cooled to $0{ }^{\circ} \mathrm{C}$ and a solution of 9 (64 mg, $0.12 \mathrm{mmol})$ in THF $(5.0 \mathrm{~mL})$ was added to it. Reaction mixture was stirred at room temperature for additional 2 hours and then quenched by addition of brine $(15 \mathrm{~mL})$, extracted with ethyl acetate $(3 \times 20 \mathrm{~mL})$, dried over $\mathrm{MgSO}_{4}$ and concentrated to oil. Purification by flash chromatography (50\% ethyl acetate in hexane) afforded 9a (32 mg, 52\% yield) as a clear oil. ${ }^{1} \mathrm{H}-\mathrm{NMR}$ : $\left(400 \mathrm{MHz}, \mathrm{CDCl}_{3}\right) \delta=7.37$ (d, $J=8.3 \mathrm{~Hz}, 2 \mathrm{H}), 6.95-6.87$ (m, 3H), 6.59 (d, $J=1.97 \mathrm{~Hz}, 1 \mathrm{H}), 6.53$ (dd, $J=8.3 \mathrm{~Hz}, 2.2 \mathrm{~Hz}$, $1 \mathrm{H}), 6.00-5.80(\mathrm{~m}, 2 \mathrm{H}), 5.70-5.50(\mathrm{~m}, 1 \mathrm{H}), 5.38-5.19(\mathrm{~m}, 6 \mathrm{H}), 4.85-4.82(\mathrm{~m}, 1 \mathrm{H}), 4.70$ (m, 2H), 4.40-4.25 (m, 1H), 4.16 (d, $J=15.9 \mathrm{~Hz}, 1 \mathrm{H}), 3.84$ (t, $J=4.75,2 \mathrm{H}), 3.59$, (t, $J=3.2$ $\mathrm{Hz}, 2 \mathrm{H}), 3.40$ (s, 3H); ${ }^{13} \mathrm{C}-\mathrm{NMR}\left(100 \mathrm{MHz}, \mathrm{CDCl}_{3}\right) \delta=162.0,161.2,156.6,138.1$, 135.6, 132.8, 131.7, 129.9, 129.3, 127.0, 121.3, 118.4, 117.1, 116.8, 109.7, 99.3, 94.0, 88.8, 72.0, 68.2, 67.0, 63.8, 59.5; MS: (ES+) m/z $=349(\mathrm{M}+1)$, HPLC purity ( $>96 \%)$.

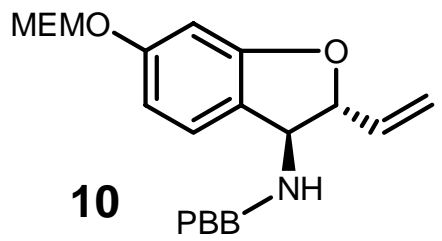

To a solutin of N-Alloc protected compound 9a (180 mg, 0.35 mmol $)$ in dry DCM $(5 \mathrm{~mL})$ at $0{ }^{\circ} \mathrm{C}$ was added morpholine $(60$ $\mathrm{mg}, \quad 0.69 \mathrm{mmol})$ followed by addition of tetrakis(triphenylphosphine)palladium (0) catalyst $(80 \mathrm{mg}$, $0.0069 \mathrm{mmol})$. The solution was stirred for 1 hour at room temperature and then filtered through a celite pad and concentrated to oil. Purification by flash chromatography ( $40 \%$ ethyl acetate in hexane) afforded $\mathbf{1 0}$ (130 mg, 86\% yield) as a colorless oil. ${ }^{1} \mathrm{H}-\mathrm{NMR}$ : $\left(400 \mathrm{MHz}, \mathrm{CDCl}_{3}\right) \delta=7.46(\mathrm{~d}, J=8.3 \mathrm{~Hz}, 2 \mathrm{H}), 7.26(\mathrm{~d}, J=8.3 \mathrm{~Hz}, 2 \mathrm{H}), 7.20(\mathrm{~d}, J=8.0$ Hz, 1H), 6.63-5.59 (m, 2H), 5.91 (ddd, $J=17.0 \mathrm{~Hz}, 10.4 \mathrm{~Hz}, 6.5 \mathrm{~Hz}, 1 \mathrm{H}), 5.39$ (d, $J=$ 17.1, 1H), 5.26, (s, 2H), 5.25 (d, $J=10.4 \mathrm{~Hz}, 1 \mathrm{H}), 5.0(\mathrm{dd}, J=6.4 \mathrm{~Hz}, 4.0 \mathrm{~Hz}, 1 \mathrm{H}), 4.19$ (d, $J=3.9 \mathrm{~Hz}, 1 \mathrm{H}), 3.83-3.80(\mathrm{~m}, 4 \mathrm{H}), 3.58(\mathrm{t}, J=4.5 \mathrm{~Hz}, 2 \mathrm{H}), 3.40(\mathrm{~s}, 3 \mathrm{H}) .{ }^{13} \mathrm{C}-\mathrm{NMR}$ $\left(100 \mathrm{MHz}, \mathrm{CDCl}_{3}\right) \delta=161.0,159.6,139.3,136.5,132.6,132.5,131.9,130.3,125.9$, 
$121.5,121.3,117.2,109.3,99.4,94.0,90.6,72.0,68.1,65.2,59.5,50.2 ; \mathrm{MS}:(\mathrm{ES}+) \mathrm{m} / \mathrm{z}=$ $434(\mathrm{M}+1), 435(\mathrm{M}+2)$, HPLC purity $(>97 \%)$.

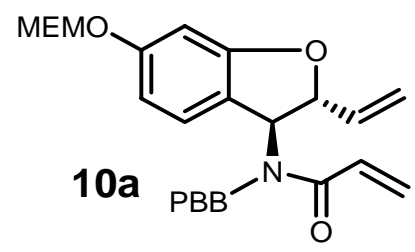

anhydrous $\mathrm{MgSO}_{4}$, filtered and concentrated in vacuo. Purification by flash chromatography (60\% hexane in ethyl acetate) afforded 10a (130 $\mathrm{mg}, 89 \%$ yield) as a colorless oil. ${ }^{1} \mathrm{H}-\mathrm{NMR}: \quad\left(400 \mathrm{MHz}, \mathrm{CDCl}_{3}\right) \delta=7.41-7.34(\mathrm{~m}, 3 \mathrm{H}), 6.94-6.68(\mathrm{~m}, 3 \mathrm{H})$, 6.60-6.39 (m, 4H), 6.06-6.02 (m, 1H), 5.76-5.63 (m, 1H), 5.36 (d, $J=18.0 \mathrm{~Hz}, 1 \mathrm{H}), 5.23-$ $5.15(\mathrm{~m}, 3 \mathrm{H}), 4.89($ broad s, $1 \mid \mathrm{H}), 4.25(\mathrm{~d}, J=7.1 \mathrm{~Hz}, 2 \mathrm{H}), 3.82($ broad s, $2 \mathrm{H}), 3.58(\mathrm{t}, J=$ $4.4 \mathrm{~Hz}, 2 \mathrm{H}), 9.99$ (s, 3H); ${ }^{13} \mathrm{C}-\mathrm{NMR}\left(100 \mathrm{MHz}, \mathrm{CDCl}_{3}\right) \delta=167.7,162.4,160.2,137.3$, 135.5, 132.0, 131.7, 130.6, 130.0, 128.1, 127.3, 121.6, 117.0, 116.7, 109.7, 99.3, 94.0, 88.9, 71.9, 68.2, 62.0, 59.5, 47.4; MS: (ES+) m/z = $488(\mathrm{M}+1), 490(\mathrm{M}+3)$, HPLC purity $(95 \%)$.

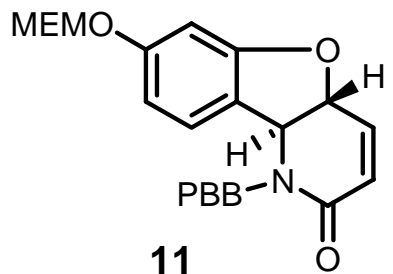

To a stirred solution of compound 10a $(21 \mathrm{mg}, 0.04 \mathrm{mmol})$ in dry DCM $(5 \mathrm{~mL})$ was added slowly a solution of tricyclohexylphosphine [1,3-bis[2,4,6-tri[benzyline] ruthenium (IV) dichloride $(7 \mathrm{mg}, 20 \% \mathrm{~mol})$ in DCM $(1 \mathrm{~mL})$. The reaction was refluxed for 3 hours, then concentrated to an oil and purified by flash chromatography ( $40 \%$ ethyl acetate in hexane) to afford $11(15 \mathrm{mg}, 76 \%)$ as a white solid. ${ }^{1} \mathrm{H}-\mathrm{NMR}:\left(400 \mathrm{MHz}, \mathrm{CDCl}_{3}\right) \delta=7.48(\mathrm{~d}, J=8.4 \mathrm{~Hz}, 2 \mathrm{H}), 7.27(\mathrm{~s}, 1 \mathrm{H}), 7.20(\mathrm{~d}, J$ $=8.3 \mathrm{~Hz}, 2 \mathrm{H}), 7.03(\mathrm{~d}, J=8.4 \mathrm{~Hz}, 1 \mathrm{H}), 6.70(\mathrm{~d}, J=2.2 \mathrm{~Hz}, 1 \mathrm{H}), 6.62(\mathrm{dd}, J=8.4 \mathrm{~Hz}, 2.2$ Hz, 1H), 6.12 (dd, $J=10.0 \mathrm{~Hz}, 1.8 \mathrm{~Hz}, 1 \mathrm{H}), 5.23$ (s, 2H), 5.18 (d, $J=16.0,1 \mathrm{H}), 5.00$ (s, 2H), $4.81(\mathrm{~d}, J=15 \mathrm{~Hz}, 1 \mathrm{H}), 3.81$ (t, $J=4.7 \mathrm{~Hz}, 2 \mathrm{H}), 3.56$ (t, $J=4.5 \mathrm{~Hz}, 2 \mathrm{H}), 3.39$ (s, $3 \mathrm{H}) ;{ }^{13} \mathrm{C}-\mathrm{NMR}\left(100 \mathrm{MHz}, \mathrm{CDCl}_{3}\right) \delta=166.7,162.0,158.9,140.9,136.5,132.0,128.8$, 126.2 , 124.7, 121.6, 119.1, 109.9, 101.5, 93.8, 84.5, 71.9, 68.2, 64.4, 59.4, 46.9; MS: $(\mathrm{ES}+) \mathrm{m} / \mathrm{z}=460(\mathrm{M}+1) 462(\mathrm{M}+3)$, HPLC purity $(98 \%)$. 


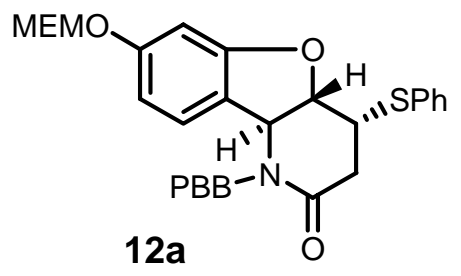

To a stirred solution of compound $11(46 \mathrm{mg}, 0.1 \mathrm{mmol})$ in THF $(5 \mathrm{~mL})$ was added phenyl thiol $(33 \mathrm{mg}, 0.3 \mathrm{mmol})$ followed by the addition of $\mathrm{Et}_{3} \mathrm{~N}(30 \mathrm{mg}, 0.3 \mathrm{mmol})$ at $0{ }^{\circ} \mathrm{C}$. Reaction mixture was allowed to gradually reach room temperature and stirred for additional 2 hours at room temperature. Reaction mixture was then concentrated in vacuo. Purification by flash chromatography ( $40 \%$ ethyl acetate in hexane) afforded 12a (33 mg, 60\%) as a colorless oil.

${ }^{1} \mathrm{H}-\mathrm{NMR}:\left(400 \mathrm{MHz}, \mathrm{CDCl}_{3}\right) \delta=7.56-7.50(\mathrm{~m}, 4 \mathrm{H}), 7.38-7.3(\mathrm{~m}, 3 \mathrm{H}), 7.19(\mathrm{~d}, J=8.4$ $\mathrm{Hz}, 2 \mathrm{H}), 7.08$ (dd, $J=8.4 \mathrm{~Hz}, 0.7 \mathrm{~Hz}, 1 \mathrm{H}), 6.65$ (d, $J=2.2 \mathrm{~Hz}, 1 \mathrm{H}), 6.60$ (dd, $J=8.4 \mathrm{~Hz}$, $2.2 \mathrm{~Hz}, 1 \mathrm{H}), 5.54$ (d, $J=11.3 \mathrm{~Hz}, 1 \mathrm{H}), 5.15(\mathrm{~m}, 3 \mathrm{H}), 4.82-4.73(\mathrm{~m}, 2 \mathrm{H}), 4.20-4.17$ (m, $1 \mathrm{H}), 3.80$ (t, $J=4.8 \mathrm{~Hz}, 2 \mathrm{H}), 3.56$ (t, $J=4.5 \mathrm{~Hz}, 2 \mathrm{H}), 3.38$ (s, $3 \mathrm{H}), 3.18$ (dd, $J=18.5 \mathrm{~Hz}$, $7.6 \mathrm{~Hz}, 1 \mathrm{H}), 2.96(\mathrm{dd}, J=18.5 \mathrm{~Hz}, 2.2 \mathrm{~Hz}, 1 \mathrm{H}) ;{ }^{13} \mathrm{C}-\mathrm{NMR}\left(100 \mathrm{MHz}, \mathrm{CDCl}_{3}\right) \delta=169.8$, 161.7, 159.1, 136.2, 135.1, 133.4, 133.1, 132.4, 129.6, 128.8, 128.7, 128.3, 125.7, 121.6, $118.7,110.2,101.1,93.9,87.7,71.9,68.2,60.8,59.4,59.0,47.2,42.7,39.2 ;(E S+) \mathrm{m} / \mathrm{z}=$ $570(\mathrm{M}+1)$, HPLC purity $(96 \%)$.

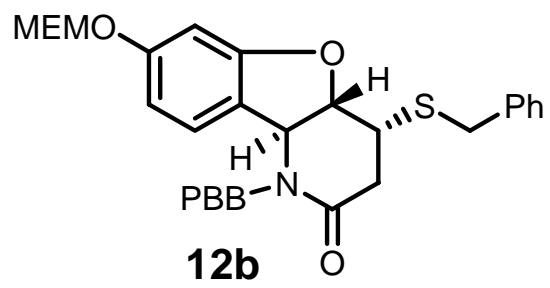

To a stirred solution of compound 11 (32 $\mathrm{mg}, 0.07$ $\mathrm{mmol})$ in THF $(5 \mathrm{~mL})$ was added benzyl thiol $(25 \mathrm{mg}$, $0.2 \mathrm{mmol})$ followed by the addition of $n$-BuLi $(90 \mu \mathrm{L}$, $2.5 \mathrm{M}$ in hexane, $0.23 \mathrm{mmol}$ ) at $-78{ }^{\circ} \mathrm{C}$. Reaction mixture was allowed to gradually reach room temperature and stirr for additional 3 hours at room temperature. Reaction mixture was then cooled to $0{ }^{\circ} \mathrm{C}$ and quenched with saturated $\mathrm{NH}_{4} \mathrm{Cl}$ solution. THF was evaporated and reaction mixture extracted with DCM, washed with brine, dried over anhydrous $\mathrm{MgSO}_{4}$ and concentrated in vacuo. Purification by flash chromatography ( $40 \%$ ethyl acetate in hexane) afforded $\mathbf{1 2 b}(28 \mathrm{mg}$, 69\%) as a colorless oil. ${ }^{1} \mathrm{H}-\mathrm{NMR}$ : $\left(400 \mathrm{MHz}, \mathrm{CDCl}_{3}\right) \delta=7.48(\mathrm{~d}, J=8.4 \mathrm{~Hz}, 2 \mathrm{H}), 7.42$ $7.28(\mathrm{~m}, 6 \mathrm{H}), 7.15(\mathrm{~d}, J=8.3 \mathrm{~Hz}, 2 \mathrm{H}), 7.05(\mathrm{dd}, J=8.4 \mathrm{~Hz}, 0.8 \mathrm{~Hz}, 1 \mathrm{H}), 6.72(\mathrm{~d}, J=2.2$ $\mathrm{Hz}, 1 \mathrm{H}), 6.59$ (dd, $J=8.3 \mathrm{~Hz}, 3.4 \mathrm{~Hz}, 1 \mathrm{H}), 5.58(\mathrm{~d}, J=11.2 \mathrm{~Hz}, 1 \mathrm{H}), 5.25-5.20(\mathrm{~m}, 3 \mathrm{H})$, 4.75-4.69 (m, 2H), 4.07 (d, $J=13.3 \mathrm{~Hz}, 1 \mathrm{H}), 3.84-3.81$ (m, $3 \mathrm{H}), 3.65$ (ddd, $J=8.2 \mathrm{~Hz}$, 
$4.0 \mathrm{~Hz}, 2.2 \mathrm{~Hz}, 1 \mathrm{H}), 3.57$ (t, $J=4.7 \mathrm{~Hz}, 2 \mathrm{H}), 3.39$ (s, 3H), 3.15 (dd, $J=18.6 \mathrm{~Hz}, 8.2 \mathrm{~Hz}$, $1 \mathrm{H}), 2.68(\mathrm{dd}, J=18.6 \mathrm{~Hz}, 2.2 \mathrm{~Hz}, 1 \mathrm{H}) ;{ }^{13} \mathrm{C}-\mathrm{NMR}\left(100 \mathrm{MHz}, \mathrm{CDCl}_{3}\right) \delta=169.8,161.7$, 159.0, 137.8, 136.3, 132.3, 129.6, 129.5, 129.0, 128.8, 128.7, 127.7, 125.8, 121.5, 118.8, $110.2,100.9$, 93.9, 89.4, 71.9, 68.2, 59.5, 58.5, 47.1, 38.3, 37.0, 36.5; MS: (ES+) m/z = $584(\mathrm{M}+1) 586(\mathrm{M}+3)$, HPLC purity $(94 \%)$.

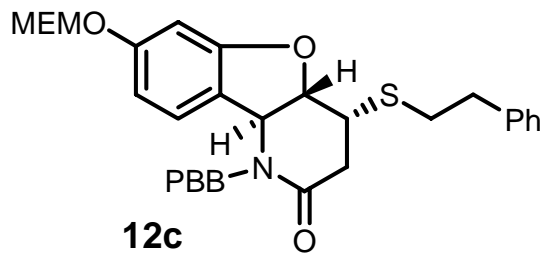

To a stirred solution of compound 11 (20 mg, 0.04 $\mathrm{mmol})$ in THF $(2 \mathrm{~mL})$ was added phenyl ethylthiol (16 $\mu \mathrm{L}, 0.12 \mathrm{mmol})$ followed by the addition of $n$-BuLi (24 $\mu \mathrm{L}, 2.5 \mathrm{M}$ in hexane, $0.06 \mathrm{mmol}$ ) at $-78^{\circ} \mathrm{C}$. Reaction mixture was allowed to gradually reach room temperature and stirred for additional 3 hours at room temperature. Reaction mixture was then cooled to $0{ }^{\circ} \mathrm{C}$ and quenched with saturated $\mathrm{NH}_{4} \mathrm{Cl}$ solution. THF was evaporated and reaction mixture extracted with DCM, washed with brine, dried over anhydrous $\mathrm{MgSO}_{4}$ and concentrated in vacuo. Purification by flash chromatography (40\% ethyl acetate in hexane) afforded 12c (16 mg, 67\%) as a colorless oil. ${ }^{1} \mathrm{H}-\mathrm{NMR}:\left(400 \mathrm{MHz}, \mathrm{CDCl}_{3}\right) \delta=7.49(\mathrm{~d}, J=8.3 \mathrm{~Hz}, 2 \mathrm{H}), 7.34-$ $7.19(\mathrm{~m}, 5 \mathrm{H}), 7.17(\mathrm{~d}, J=8.2 \mathrm{~Hz}, 2 \mathrm{H}), 7.03(\mathrm{~d}, J=8.2 \mathrm{~Hz}, 1 \mathrm{H}), 6.66$ (d, $J=2.1 \mathrm{~Hz}, 1 \mathrm{H})$, $6.59(\mathrm{dd}, J=8.4 \mathrm{~Hz}, 2.1 \mathrm{~Hz}, 1 \mathrm{H}), 5.47$ (d, $J=11.2 \mathrm{~Hz}, 1 \mathrm{H}), 5.23-5.2$ (m, 3H), 4.78- 4.70 (m, 2H), 3.83-3.81 (m, 3H), $3.56(\mathrm{t}, J=4.7 \mathrm{~Hz}, 1 \mathrm{H}), 3.38(\mathrm{~s}, 3 \mathrm{H}), 3.25$ (dd, $J=18.6 \mathrm{~Hz}$, $7.9 \mathrm{~Hz}, 1 \mathrm{H}), 3.1-2.91(\mathrm{M}, 4 \mathrm{H}), 2.66$ (dd, $J=18.6 \mathrm{~Hz}, 1.8 \mathrm{~Hz}, 1 \mathrm{H})$; MS: (ES+) m/z = 598 $(\mathrm{M}+1) 600(\mathrm{M}+3)$, HPLC purity $(>95 \%)$.
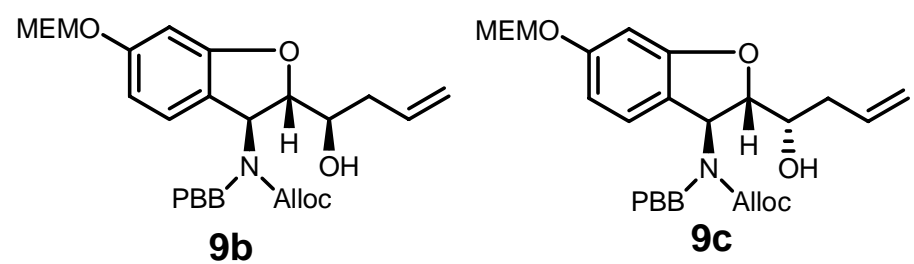

To a stirred solution of Zinc chloride $(3.08 \mathrm{~mL}$ of $1.0 \mathrm{M}$ solution in ether, $3.08 \mathrm{mmol}$ ) in $10 \mathrm{~mL}$ of dry THF, aldehyde $\mathbf{9}$ (400 mg, $0.77 \mathrm{mmol}$ ), pre-dissolved in $8 \mathrm{~mL}$ of dry THF were added at $0{ }^{\circ} \mathrm{C}$. After 30 min stirring at $0{ }^{\circ} \mathrm{C}$, Allyl magnesium bromide $(4.62 \mathrm{~mL}$ of $1.0 \mathrm{M}$ solution in ether, 4.62 mmol) was added to the solution at the same temperature. The mixture was stirred at $0{ }^{\circ} \mathrm{C}$ for 2 hours. The reaction was quenched at $0{ }^{\circ} \mathrm{C}$ with a solution of saturated ammonium chloride. Organic phase were washed with ammonium chloride and aqueous phases were 
washed with ethyl acetate. The combined organic phases were dried over anhydrous $\mathrm{MgSO}_{4}$ and the crude compound was concentrated under vacuum. The purification by column chromatography on silica gel (30\% ethyl acetate/hexane) afforded a dense colourless oil 9b (220 mg, 50\%) and 9c (160 mg, 37\%) with an overall yield of the reaction was $87 \%$.

For 9b: ${ }^{1} \mathrm{H}-\mathrm{NMR}:\left(400 \mathrm{MHz}, \mathrm{CDCl}_{3}\right) \delta=7.36(\mathrm{~d}, J=8.3 \mathrm{~Hz}, 2 \mathrm{H}), 6.91-6.86(\mathrm{~m}, 3 \mathrm{H})$, 6.55 - $6.50(\mathrm{~m}, 2 \mathrm{H}), 5.92-5.83(\mathrm{~m}, 3 \mathrm{H}), 5.29-5.14(\mathrm{~m}, 6 \mathrm{H}), 4.69$ (d, J=4.5 Hz, $2 \mathrm{H})$, 4.37 - 4.15 (m, 3H), 3.83 (t, $J=4.4 \mathrm{~Hz}, 2 \mathrm{H}) 3.71($ broad s, $1 \mathrm{H}), 3.58(\mathrm{t}, J=4.4 \mathrm{~Hz}, 2 \mathrm{H})$, $3.40(\mathrm{~s}, 3 \mathrm{H}), 2.48$ (broad m, 1H), $2.30-2.55(\mathrm{~m}, 1 \mathrm{H}) ;{ }^{13} \mathrm{C}-\mathrm{NMR}:\left(100 \mathrm{MHz}, \mathrm{CDCl}_{3}\right) \delta=$ 160.7, 134.4, 132.6, 131.7, 129.5, 126.9, 121.4, 118.7, 118.4, 116.5, 109.7, 99.0, 94.0, 90.7, 71.9, 71.6, 68.2, 67.2, 61.6, 59.4, 47.1, 37.5; LRMS: (ES+) $\mathrm{m} / \mathrm{z}=562(\mathrm{~m}+1)$ and $564(\mathrm{~m}+3)$, HPLC purity $(>97 \%)$.

For 9c: ${ }^{1} \mathrm{H}-\mathrm{NMR}:\left(400 \mathrm{MHz}, \mathrm{CDCl}_{3}\right) \delta=7.36(\mathrm{~d}, J=8.3 \mathrm{~Hz}, 2 \mathrm{H}), 6.91-6.86(\mathrm{~m}, 3 \mathrm{H})$, $6.57-6.51(\mathrm{~m}, 2 \mathrm{H}), 5.92-5.83(\mathrm{~m}, 3 \mathrm{H}), 5.29-5.03(\mathrm{~m}, 6 \mathrm{H}), 4.68(\mathrm{~d}, J=5.0,2 \mathrm{H}), 4.34$ (broad t, 2H), $4.16(\mathrm{~d}, J=15.9 \mathrm{~Hz}, 1 \mathrm{H}), 3.84(\mathrm{t}, J=4.4 \mathrm{~Hz}, 2 \mathrm{H}) 3.76-3.66$ (broad s, $1 \mathrm{H}), 3.59$ (t, $J=4.4 \mathrm{~Hz}, 2 \mathrm{H}), 3.40(\mathrm{~s}, 3 \mathrm{H}), 2.39$ (broad m, 1H) and $2.31-2.29(\mathrm{~m}, 1 \mathrm{H})$; ${ }^{13} \mathrm{C}-\mathrm{NMR}:\left(100 \mathrm{MHz}, \mathrm{CDCl}_{3}\right) \delta=160.0,137.9,134.3,132.7,131.7,130.0,129.4,126.7$, 121.4, 118.7, 109.8,109.7, 99.1, 94.0, 90.1, 71.9, 68.2, 67.1, 60.5, 61.6, 59.4, 47.1, 37.2; LRMS: $(\mathrm{ES}+) \mathrm{m} / \mathrm{z}=562(\mathrm{~m}+1)$ and $564(\mathrm{~m}+3)$, HPLC purity $(>97 \%)$.

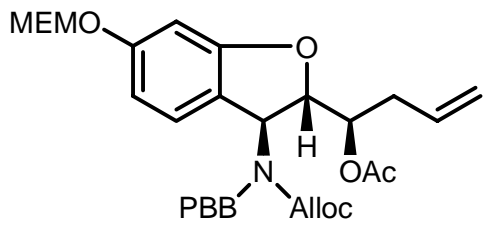

9d

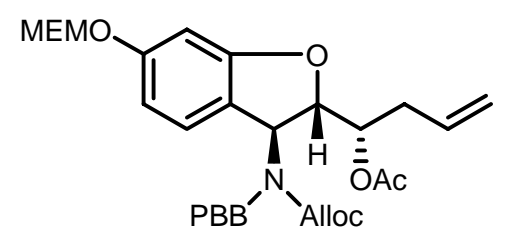

$9 e$

To a solution of compound 9b (250 $\mathrm{mg}, 0.45 \mathrm{mmol})$ in $25 \mathrm{~mL}$ of distilled DCM were added successively DMAP (65 $\mathrm{mg}, 0.53 \mathrm{mmol})$ and freshly distilled acetic anhydride $(99 \mu \mathrm{L}, 0.89 \mathrm{mmol})$. The mixture was stirred during 2 hrs at room temperature under $\mathrm{N}_{2}$ and quenched with aqueous ammonium chloride. After few extractions with dichloromethane organic phases were dried over anhydrous $\mathrm{MgSO}_{4}$. Then, after filtration, the crude was concentrated under vacuum and was purified by column chromatography on silica gel (30\% ethyl acetate/hexane) to afford 9d as a 
colourless oil (95\%, $255 \mathrm{mg}) .{ }^{1} \mathrm{H}-\mathrm{NMR}:\left(400 \mathrm{MHz}, \mathrm{CDCl}_{3}\right) \delta=7.35(\mathrm{~d}, J=8.3 \mathrm{~Hz}, 2 \mathrm{H})$, 6.92 (broad s, 3H), 6.55 - $6.50(\mathrm{~m}, 2 \mathrm{H}), 5.92$ (broad s, 1H) 5.70 - $5.68(\mathrm{~m}, 1 \mathrm{H}), 5.28$ $5.24(\mathrm{~m}, 4 \mathrm{H}), 5.10$ - $5.05(\mathrm{~m}, 3 \mathrm{H}), 4.69$ (broad s, $2 \mathrm{H}), 4.57(\mathrm{~s}, 1 \mathrm{H}), 4.45(\mathrm{~s}, 1 \mathrm{H}), 4.27$ 4.23 (broad s, 1H), $4.10(\mathrm{~d}, J=15.9,1 \mathrm{H}), 3.84$ (t, $J=4.4 \mathrm{~Hz}, 2 \mathrm{H}) 3.59$ (t, $J=4.4 \mathrm{~Hz}$, 2H), $3.40(\mathrm{~s}, 3 \mathrm{H}), 2.47-2.39(\mathrm{~m}, 2 \mathrm{H}), 1.90(\mathrm{~s}, 3 \mathrm{H})$; LRMS: (ES+) m/z = $604(\mathrm{~m}+1)$ and $606(\mathrm{~m}+3)$, HPLC purity $(>98 \%)$.

To a solution of compound 9c $(140 \mathrm{mg}, 0.25 \mathrm{mmol})$ in $10 \mathrm{~mL}$ of distilled DCM was added successively DMAP (37 mg, $0.3 \mathrm{mmol}$ ) and freshly distilled acetic anhydride (47 $\mu \mathrm{L}, 0.5 \mathrm{mmol}$ ). The mixture was stirred during $2 \mathrm{hrs}$ at room temperature and quenched with aqueous ammonium chloride. After few extractions with dichloromethane, organic phases were dried over anhydrous $\mathrm{MgSO}_{4}$. Then, after filtration, the crude was concentrated under vacuum and was purified by column chromatography on silica gel (30 $\%$ ethyl acetate / hexane) to afford 9e as a colorless oil (140 mg, $93 \%) .{ }^{1} \mathrm{H}-\mathrm{NMR}$ : (400 $\left.\mathrm{MHz}, \mathrm{CDCl}_{3}\right) \delta=7.36(\mathrm{~d}, J=8.3 \mathrm{~Hz}, 2 \mathrm{H}), 6.93-6.86($ broad s, $3 \mathrm{H}), 6.55-6.49(\mathrm{~m}, 2 \mathrm{H})$, $5.93($ broad s, 1H) 5.77 - $5.66(\mathrm{~m}, 2 \mathrm{H}), 5.27$ - $5.25(\mathrm{~m}, 4 \mathrm{H}), 5.12$ - $5.05(\mathrm{~m}, 3 \mathrm{H}), 4.69(\mathrm{~d}$, $J=4.9,2 \mathrm{H}), 4.12-4.08($ broad s, 2H), $4.11(\mathrm{~d}, J=15.9,1 \mathrm{H}), 3.84(\mathrm{t}, J=4.4 \mathrm{~Hz}, 2 \mathrm{H})$ $3.59(\mathrm{t}, J=4.4 \mathrm{~Hz}, 2 \mathrm{H}), 3.40(\mathrm{~s}, 3 \mathrm{H}), 2.46-2.36(\mathrm{~m}, 2 \mathrm{H}), 1.90(\mathrm{~s}, 3 \mathrm{H}) ; \mathrm{MS}:(\mathrm{ES}+) \mathrm{m} / \mathrm{z}=$ $604(\mathrm{M}+1)$ and $606(\mathrm{~m}+3)$, HPLC purity $(>97 \%)$.

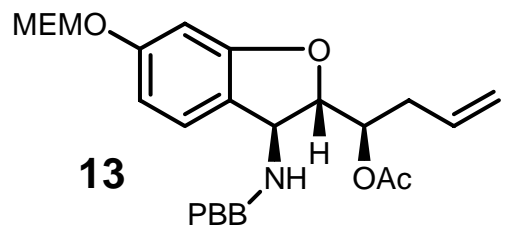

To a solution of compound 9d (100 $\mathrm{mg}, 0.17 \mathrm{mmol})$ in $3 \mathrm{~mL}$ of distilled DCM were added under $\mathrm{N}_{2}$ at 0 ${ }^{\circ} \mathrm{C}$ temperature morpholine $(29 \mu \mathrm{L}, 0.33 \mathrm{mmol})$ and tetrakis (triphenylphosphine) palladium catalyst (19 $\mathrm{mg}, 0.017 \mathrm{mmol}$ ). The flash was covered with a tinfoil and the mixture was stirred for 2 hour. The reaction was quenched with aqueous ammonium chloride and extracted three times with dichloromethane. The combined organic phases were dried with anhydrous $\mathrm{MgSO}_{4}$, filtered and concentrated under vacuum. The crude was purified by column chromatography on silica gel (40\% ethyl acetate/hexane) to give yellow oil $13(81.2 \mathrm{mg}$, 92\%). ${ }^{1} \mathrm{H}-\mathrm{NMR}:\left(400 \mathrm{MHz}, \mathrm{CDCl}_{3}\right) \delta=7.46(\mathrm{~d}, J=8.3 \mathrm{~Hz}, 2 \mathrm{H}), 7.27$ (d, $J=8.0 \mathrm{~Hz}$, 2H), $7.20(\mathrm{~d}, J=8.1 \mathrm{~Hz}, 1 \mathrm{H}), 6.45-6.58(\mathrm{~m}, 2 \mathrm{H}), 5.77-5.73(\mathrm{~m}, 1 \mathrm{H}), 5.25(\mathrm{~s}, 2 \mathrm{H}), 5.13$ 
- $5.04(\mathrm{~m}, 2 \mathrm{H}), 5.02(\mathrm{q}, 1 \mathrm{H}), 4.62(\mathrm{t}, J=3.5 \mathrm{~Hz}, 1 \mathrm{H}), 4.23(\mathrm{~d}, J=3.3,1 \mathrm{H}), 3.84-3.82$ (m, 4H), $3.58(\mathrm{t}, J=3.1 \mathrm{~Hz}, 2 \mathrm{H}), 3.40$ (s, 3H), $2.44-2.39$ (m, 2H), 1.98 (s, 3H); LRMS: $(\mathrm{ES}+) \mathrm{m} / \mathrm{z}=520(\mathrm{~m}+1)$ and $522(\mathrm{~m}+3), \operatorname{HPLC}$ purity $(>98 \%)$.

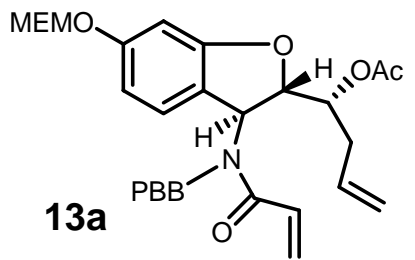

To a solution of compound $13(75 \mathrm{mg}, 0.144 \mathrm{mmol})$ in $4 \mathrm{~mL}$ of freshly distilled DCM was added $\mathrm{Et}_{3} \mathrm{~N}(30 \mu \mathrm{L}, 0.216$ mmol). The reaction mixture was cooled down at $0{ }^{\circ} \mathrm{C}$ and acryloyl chloride was added $(14 \mu \mathrm{L}, 0.173 \mathrm{mmol})$. The reaction was allowed to stir at room temperature for $5 \mathrm{hrs}$ under $\mathrm{N}_{2}$. Reaction was quenched with aqueous ammonium chloride, extracted with dichloromethane and the organic phases were dried over anhydrous $\mathrm{MgSO}_{4}$, filtered and concentrated. The crude was purified by column chromtogarphy on silica gel (30\% ethyl acetate/hexane) to afford a pale yellowish oil 13a (70.2 mg, $85 \%$ ). ${ }^{1} \mathrm{H}-\mathrm{NMR}:\left(400 \mathrm{MHz}, \mathrm{CDCl}_{3}\right) \delta=7.73$ (d, $J=7.3 \mathrm{~Hz}, 2 \mathrm{H}), 7.52(\mathrm{~d}, J=7.3 \mathrm{~Hz}, 2 \mathrm{H}), 6.94(\mathrm{~d}, J=7.8 \mathrm{~Hz}, 2 \mathrm{H}), 6.53-6.34$ (m, $4 \mathrm{H}), 5.74-5.72(\mathrm{~m}, 2 \mathrm{H}), 5.22-5.01(\mathrm{~m}, 5 \mathrm{H}), 4.47(\mathrm{~s}, 1 \mathrm{H}), 4.37-4.26(\mathrm{~m}, 2 \mathrm{H}), 3.82$ (broad s, 2H), 3.58 (broad s, 2H), 3.39 (s, 3H), 2.50 - 2.43 (m, 2H), 1.96 (s, 3H); LRMS: $(\mathrm{ES}+) \mathrm{m} / \mathrm{z}=574(\mathrm{~m}+1)$ and $576(\mathrm{~m}+3)$, HPLC purity $(>97 \%)$.

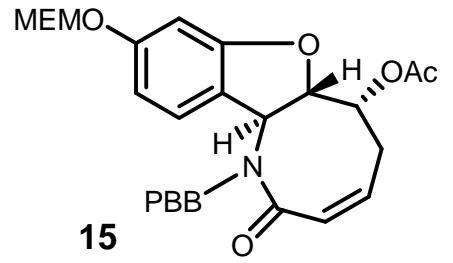

To a solution of compound 13a ( $75 \mathrm{mg}, 0.130 \mathrm{mmol}$ ) in 25 $\mathrm{mL}$ of freshly distilled DCM was added $20 \mathrm{~mol} \%$ of Grubbs $2^{\text {nd }}$ generation catalyst $(22 \mathrm{mg}, 0.026 \mathrm{mmol})$. The solution was stirred at room temperature for $2 \mathrm{hrs}$ under $\mathrm{N}_{2}$ then the solution was concentrated under vacuum and the crude was purified by column chromatography on silica gel (50\% ethyl acetate/hexane). The 8 -membered ring was obtained as a dark brown solid 15 (68 mg, $95 \%)$. ${ }^{1} \mathrm{H}-\mathrm{NMR}$ : $\left(400 \mathrm{MHz}, \mathrm{CDCl}_{3}\right) \delta=7.38$ (d, $J=8.3 \mathrm{~Hz}, 2 \mathrm{H}), 6.98(\mathrm{~d}, J=8.3 \mathrm{~Hz}, 2 \mathrm{H}), 6.82$ (d, $J=8.2 \mathrm{~Hz}, 1 \mathrm{H}), 6.58$ (dd, $1 \mathrm{H}, J=$ 8.2 and $2.0 \mathrm{~Hz}), 6.55(\mathrm{~d}, 1 \mathrm{H}, J=2.0 \mathrm{~Hz}), 6.30(\mathrm{~d}, 1 \mathrm{H}, J=9.0 \mathrm{~Hz}) 6.27(\mathrm{~d}, J=11.8 \mathrm{~Hz}$, 1H), $5.92-5.85(\mathrm{~m}, 1 \mathrm{H}), 5.29(\mathrm{dd}, J=2.8$ and $8.2 \mathrm{~Hz}, 1 \mathrm{H}), 5.26(\mathrm{~s}, 2 \mathrm{H}), 5.06(\mathrm{~d}, J=14.6$ $\mathrm{Hz}, 1 \mathrm{H}), 4.40$ (d, $J=14.7 \mathrm{~Hz}, 1 \mathrm{H}), 4.08(\mathrm{dd}, J=2.9$ and $9.2 \mathrm{~Hz}, 1 \mathrm{H}), 3.85(\mathrm{t}, J=3.5 \mathrm{~Hz}$, 2H), 3.59 (t, $J=3.1 \mathrm{~Hz}, 2 \mathrm{H}), 3.40(\mathrm{~s}, 3 \mathrm{H}), 2.95-2.87(\mathrm{~m}, 1 \mathrm{H}), 2.21-2.15(\mathrm{~m}, 1 \mathrm{H}), 2.02$ 
(s, 3H); ${ }^{13} \mathrm{C}-\mathrm{NMR}:\left(100 \mathrm{MHz}, \mathrm{CDCl}_{3}\right) \delta=170.4,169.8,160.9,159.7,138.0,132.2,130.8$, $129.7,128.4,126.8,122.0,115.9,109.6,99.7,94.1,87.7,72.0,68.3,64.9,60.2,59.4$, 44.8, 27.1, 21.2; LRMS: $(\mathrm{ES}+) \mathrm{m} / \mathrm{z}=546(\mathrm{M}+1)$ and $548(\mathrm{~m}+3)$, HPLC purity $(>99 \%)$.

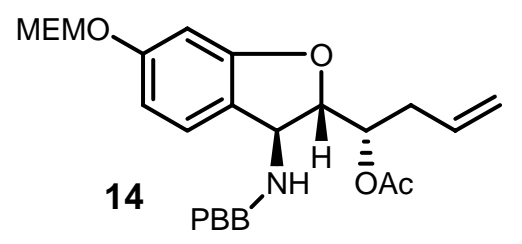

To a solution of compound $9 \mathrm{e}(100 \mathrm{mg}, 0.165 \mathrm{mmol})$ in 5 $\mathrm{mL}$ of distilled $\mathrm{DCM}$ were added under $\mathrm{N}_{2}$ at $0^{\circ} \mathrm{C}$ temperature 2 eq of morpholine $(29 \mu \mathrm{L}, 0.331 \mathrm{mmol})$ and 0.1 eq of tetrakis (triphenylphosphine) palladium catalyst (19 $\mathrm{mg}, 0.0165 \mathrm{mmol})$. The flash was covered with an aluminium foil and the mixture was stirred for 2 hours. The reaction was quenched with aqueous ammonium chloride and extracted three times with dichloromethane. The combined organic phases were dried with anhydrous $\mathrm{MgSO}_{4}$, filtered and concentrated under vacuum. The crude was purified by column chromatography on silica gel ( $40 \%$ ethyl acetate / hexane) to give yellow oil 14 (78 mg, 91\%). ${ }^{1} \mathrm{H}-\mathrm{NMR}:\left(400 \mathrm{MHz}, \mathrm{CDCl}_{3}\right) \delta=7.46(\mathrm{~d}, J=8.3 \mathrm{~Hz}, 2 \mathrm{H}), 7.24$ (d, $J=$ $8.2 \mathrm{~Hz}, 2 \mathrm{H}), 7.17$ (d, $J=8.0 \mathrm{~Hz}, 1 \mathrm{H}), 6.62-6.58$ (m, 2H), $5.80-5.73(\mathrm{~m}, 1 \mathrm{H}), 5.27$ (s, $2 \mathrm{H}), 5.18-5.10(\mathrm{~m}, 3 \mathrm{H}), 4.55(\mathrm{t}, J=4.0 \mathrm{~Hz}, 1 \mathrm{H}), 4.26(\mathrm{~d}, J=3.7,1 \mathrm{H}), 3.87-3.76(\mathrm{~m}$, $4 \mathrm{H}), 3.58(\mathrm{t}, J=3.1 \mathrm{~Hz}, 2 \mathrm{H}), 3.40(\mathrm{~s}, 3 \mathrm{H}), 2.52-2.39(\mathrm{~m}, 2 \mathrm{H})$ and $1.95(\mathrm{~s}, 3 \mathrm{H})$; LRMS: $(\mathrm{ES}+) \mathrm{m} / \mathrm{z}=520(\mathrm{M}+1)$ and $522(\mathrm{~m}+3)$, HPLC purity $(99 \%)$.

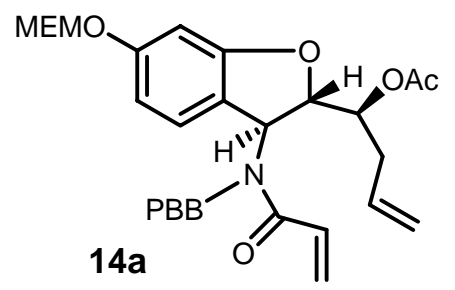

To a solution of compound 14 (75 $\mathrm{mg}, 0.144 \mathrm{mmol})$ in $5 \mathrm{~mL}$ of freshly distilled DCM was added $\mathrm{Et}_{3} \mathrm{~N}(30 \mu \mathrm{L}, 0.216$ mmol). The reaction mixture was cooled down at $0{ }^{\circ} \mathrm{C}$ and acryloyl chloride was added $(14 \mu \mathrm{L}, 0.173 \mathrm{mmol})$. The reaction was allowed to stir at room temperature for $5 \mathrm{hrs}$ under $\mathrm{N}_{2}$. Reaction was quenched with aqueous ammonium chloride, extracted with dichloromethane and the organic phases were dried over anhydrous $\mathrm{MgSO}_{4}$, filtered and concentrated. The crude was purified by column chromatography on silica gel (30\% ethyl acetate/hexane) to afford 14a as a pale yellowish oil (70 mg, 85\%). ${ }^{1} \mathrm{H}-\mathrm{NMR}$ : (400 MHz, $\left.\mathrm{CDCl}_{3}\right) \delta=7.73(\mathrm{~d}, J=7.3 \mathrm{~Hz}, 2 \mathrm{H}), 7.41$ (broad d, $\left.3 \mathrm{H}, J=7.3 \mathrm{~Hz}\right), 6.54-6.42(\mathrm{~m}, 4 \mathrm{H})$, $5.74(\mathrm{~d}, J=9.7 \mathrm{~Hz}, 2 \mathrm{H}), 5.23-5.05(\mathrm{~m}, 5 \mathrm{H}), 4.48(\mathrm{~s}, 1 \mathrm{H}), 4.37-4.31(\mathrm{~m}, 2 \mathrm{H}), 3.83$ 
(broad s, 2H), $3.58($ broad s, 2H), $3.40(\mathrm{~s}, 3 \mathrm{H}), 2.53-2.42(\mathrm{~m}, 2 \mathrm{H})$ and $1.95(\mathrm{~s}, 3 \mathrm{H})$; LRMS: $(\mathrm{ES}+) \mathrm{m} / \mathrm{z}=574(\mathrm{~m}+1)$ and $576(\mathrm{~m}+3)$, HPLC purity $(>97 \%)$.

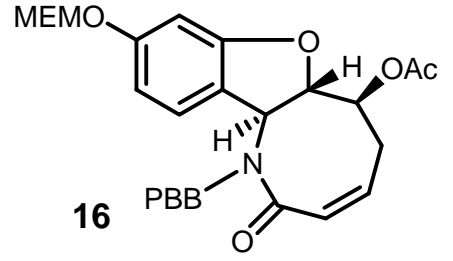

To a solution of compound 14a (55 mg, $0.095 \mathrm{mmol}$ ) in 10 $\mathrm{mL}$ of freshly distilled DCM was added $20 \mathrm{~mol} \%$ of Grubbs $2^{\text {nd }}$ generation catalyst $(16 \mathrm{mg}, 0.0019 \mathrm{mmol})$. The solution was stirred at room temperature for $2 \mathrm{hrs}$ under $\mathrm{N}_{2}$ then the solution was concentrated under vacuum and the crude was purified by column chromatography on silica gel (50\% ethyl acetate/ hexane). The 8-membered ring 16 was obtained as a dark brown solid (51 mg, 95\%). ${ }^{1} \mathrm{H}-\mathrm{NMR}$ : $\left(400 \mathrm{MHz}, \mathrm{CDCl}_{3}\right) \delta=7.40$ (d, $J$ $=8.3 \mathrm{~Hz}, 2 \mathrm{H}), 6.01(\mathrm{~d}, J=8.3 \mathrm{~Hz}, 2 \mathrm{H}), 6.59-6.56(\mathrm{~m}, 2 \mathrm{H}), 6.23-6.15(\mathrm{~m}, 2 \mathrm{H}), 6.01(\mathrm{~d}$, $J=4.7 \mathrm{~Hz}, 1 \mathrm{H}), 6.24(\mathrm{~s}, 2 \mathrm{H}), 5.11(\mathrm{~d}, J=14.7 \mathrm{~Hz}, 1 \mathrm{H}), 4.93(\mathrm{dt}, J=4.0$ and $9.6 \mathrm{~Hz}, 1 \mathrm{H})$, $4.44(\mathrm{~d}, J=14.7 \mathrm{~Hz}, 1 \mathrm{H}), 4.15$ (t, $J=9.7 \mathrm{~Hz}, 1 \mathrm{H}), 3.82$ (t, $J=3.5 \mathrm{~Hz}, 2 \mathrm{H}), 3.57$ (t, $J=$ $3.1 \mathrm{~Hz}, 2 \mathrm{H}), 3.39(\mathrm{~s}, 3 \mathrm{H}), 2.43-2.33(\mathrm{~m}, 2 \mathrm{H}), 2.02(\mathrm{~s}, 3 \mathrm{H}) ;{ }^{13} \mathrm{C}-\mathrm{NMR}:(100 \mathrm{MHz}$, $\left.\mathrm{CDCl}_{3}\right) \delta=170.5,169.5,160.3,159.7,137.8,132.2,130.9,130.8,128.1,126.5,122.0$, $115.7,109.9,99.8,94.0,86.9,71.9,70.2,68.2,63.5,59.4,44.9,31.2$ and 21.6; MS: $(\mathrm{ES}+) \mathrm{m} / \mathrm{z}=546(\mathrm{~m}+1)$ and $548(\mathrm{~m}+3)$, HPLC purity $(99 \%)$.

\section{Procedure to Obtain Compound 18:}




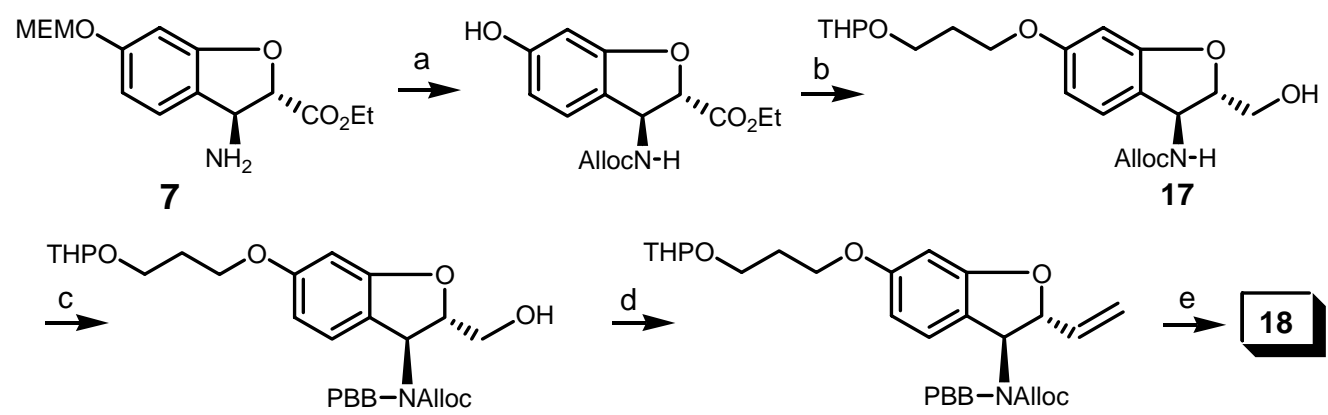

(a) (i) Allyl chloroformae, DIPEA, DCM, $0{ }^{\circ} \mathrm{C}-\mathrm{RT}$ (ii) PTSA, EtOH, $50{ }^{\circ} \mathrm{C}$ (b) (i) $\mathrm{LBH}$, THF, $0{ }^{\circ} \mathrm{C}-\mathrm{RT}$ (ii) ${ }^{\mathrm{THPO}} \mathrm{OTs}, \mathrm{Cs}_{2} \mathrm{CO}_{3}, \mathrm{DMF}, \mathrm{RT}$ (c) (i) $\mathrm{Pd}\left(\mathrm{PPh}_{3}\right)_{4}, \mathrm{AcOH}, \mathrm{Bu}_{3} \mathrm{SnH}$, DCM, $0{ }^{\circ} \mathrm{C}$-RT (ii) $p$-Bromobenzyl bromide, $\mathrm{K}_{2} \mathrm{CO}_{3}$, DMF, RT (iii) Allyl chloroformate, DIPEA, acetonitrile, $0{ }^{\circ} \mathrm{C}-\mathrm{RT}$ (d) (i) Dess-Martin Periodinate, $\mathrm{NaHCO}_{3}, \mathrm{DCM}$, RT (ii) (Methyl)triphenylphosphonium bromide, NaHMDS, THF, $0{ }^{\circ} \mathrm{C}-\mathrm{RT}$ (e) PPTS, EtOH, 50 ${ }^{\circ} \mathrm{C}$.

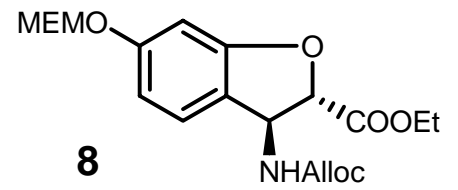

To a solution of $7(12.5 \mathrm{~g}, 40.2 \mathrm{mmol})$ in DCM $(100 \mathrm{~mL})$ at 0 ${ }^{\circ} \mathrm{C}$ was added slowly diisopropylethylamine $(7.7 \mathrm{~mL}, 5.7 \mathrm{~g}$, $44.2 \mathrm{mmol}$ ) and stirred for $2 \mathrm{~min}$. Allyl chloroformate was then added to the mixture and the solution was stirred for $12 \mathrm{hrs}$ at room temperature. The reaction was quenched by addition of water $(50 \mathrm{~mL})$, extracted with DCM (3X60 $\mathrm{mL}$ ), dried over $\mathrm{MgSO}_{4}$ and concentrated to a pale yellow solid. Purification by flash chromatography (70\% hexane/ethyl acetate) afforded afford 8 (10.7 g, 67\%) as a cream colored solid. ${ }^{1} \mathrm{H}-\mathrm{NMR}:\left(400 \mathrm{MHz}, \mathrm{CDCl}_{3}\right) \delta=7.16(\mathrm{~d}, J=8.1 \mathrm{~Hz}, 1 \mathrm{H}), 6.64(\mathrm{~s}, 1 \mathrm{H})$, $6.63(\mathrm{~d}, J=7.6 \mathrm{~Hz}, 1 \mathrm{H}), 5.93-5.86(\mathrm{~m}, 1 \mathrm{H}), 5.45$ (s, 1H), 5.41 (s, 1H), 5.29 (d, $J=16.9$, $1 \mathrm{H}), 5.27-5.21(\mathrm{~m}, 1 \mathrm{H}), 5.21(\mathrm{~s}, 2 \mathrm{H}), 4.91(\mathrm{~d}, J=3.5 \mathrm{~Hz}, 1 \mathrm{H}), 4.52(\mathrm{~s}, 2 \mathrm{H}), 4.24(\mathrm{q}, J=$ $6.9 \mathrm{~Hz}, 2 \mathrm{H}) 3.78(\mathrm{t}, J=4.5 \mathrm{~Hz}, 2 \mathrm{H}), 3.53(\mathrm{t}, J=4.5 \mathrm{~Hz}, 2 \mathrm{H}), 3.34(\mathrm{~s}, 3 \mathrm{H}), 1.29(\mathrm{t}, J=7.1$ $\mathrm{Hz}, 3 \mathrm{H}) ;{ }^{13} \mathrm{C}-\mathrm{NMR}:\left(100 \mathrm{MHz}, \mathrm{CDCl}_{3}\right) \delta=169.6,161.1,160.1,155.6,133.1,125.8$, $118.4,110.5,99.6,93.9,87.0,71.9,68.1,66.3,62.3,59.4,57.3,14.5 ; \mathrm{MS}:(\mathrm{ES}+) \mathrm{m} / \mathrm{z}=$ $396(\mathrm{M}+1)$, HPLC purity (>99\%).

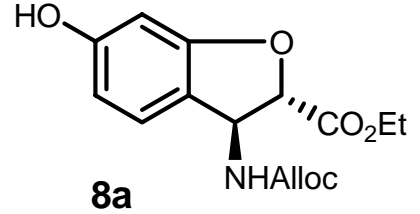

To a solution of $8(572 \mathrm{mg}, 1.44 \mathrm{mmol})$ in anhydrous ethanol $(10 \mathrm{ml})$, was added p-toluensulfonic acid monohydrate (300 
$\mathrm{mg}, 1.58 \mathrm{mmol})$. The reaction mixture was stirred for 7 hours at $50{ }^{\circ} \mathrm{C}$. Saturated solution of sodium bicarbonate was added and $\mathrm{pH}$ was adjusted to 7 . Solvent was evaporated and resulting mixture was diluted with ethyl acetate and washed with brine, dried over anhydrous magnesium sulfate, filtered and concentrated. Purification by flash chromatography (40\% ethyl acetate in hexane) afforded $\mathbf{8 a}(383 \mathrm{mg}, 86 \%)$ as a white solid. ${ }^{1} \mathrm{H}-\mathrm{NMR}:\left(400 \mathrm{MHz}, \mathrm{CDCl}_{3}\right) \delta=7.11(\mathrm{~d}, J=8.0 \mathrm{~Hz}, 1 \mathrm{H}), 6.46-6.42(\mathrm{~m}, 2 \mathrm{H})$, 6.37 (broad s, 1H), 5.97-5.90 (m, 1H), 5.44 (broad s, 2H), 5.33 (d, $J=16.2 \mathrm{~Hz}, 1 \mathrm{H}), 5.25$ (d, $J=9.9 \mathrm{~Hz}, 1 \mathrm{H}), 4.97(\mathrm{~d}, J=3.2 \mathrm{~Hz}, 1 \mathrm{H}), 4.63($ broad d, $J=3.5 \mathrm{~Hz}, 2 \mathrm{H}), 4.21$ (q, $J=$ $7.1 \mathrm{~Hz}, 2 \mathrm{H}), 1.32(\mathrm{t}, J=7.1 \mathrm{~Hz}, 3 \mathrm{H}) ;{ }^{13} \mathrm{C}-\mathrm{NMR}:\left(100 \mathrm{MHz}, \mathrm{CDCl}_{3}\right) \delta=170.2,161.2$, 159.2, 155.7, 132.7, 125.9, 118.6, 116.4, 109.9, 98.9, 87.0, 66.4, 62.6, 57.4, 14.5; MS: $(\mathrm{ES}+) \mathrm{m} / \mathrm{z}=308(\mathrm{M}+1)$, HPLC purity $(95 \%)$.

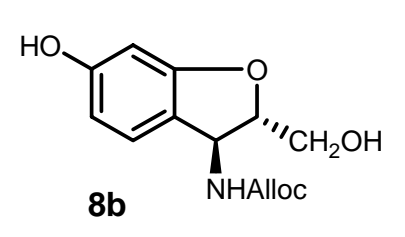

To an ice-cold $\left(0{ }^{\circ} \mathrm{C}\right)$ solution of $8 \mathbf{a}(617 \mathrm{mg}, 2 \mathrm{mmol})$ in dry THF (20 ml) $\mathrm{LiBH}_{4}(2 \mathrm{M}$ in THF, $2 \mathrm{mmol}, 2 \mathrm{ml}$ ) was added drop wise. The reaction mixture was allowed to worm slowly to room temperature over 3 hours after which saturated solution of $\mathrm{NH}_{4} \mathrm{Cl}$ was added to quench the reaction. THF was evaporated and the reaction was diluted with ethyl acetate, washed with brine, dried over $\mathrm{MgSO}_{4}$ and concentrated. Purification by flash chromatography (50\% ethyl acetate in hexane) afforded compound $8 \mathbf{b}(450 \mathrm{mg}$, $85 \%$ ) as a colorless oil. ${ }^{1} \mathrm{H}$ NMR: $\left(400 \mathrm{MHz}, \mathrm{C}_{6} \mathrm{D}_{6}\right) \delta=6.65(\mathrm{~d}, J=8.1 \mathrm{~Hz}, 1 \mathrm{H}), 6.22$ (s, $1 \mathrm{H}), 6.17$ (dd, $J=8.1 \mathrm{~Hz}, 2.0 \mathrm{~Hz}, 1 \mathrm{H}), 5.75-5.65$ (m, 1H), 5.11-4.86 (m, 4H), 4.41 (d, $J=$ $4.2 \mathrm{~Hz}, 2 \mathrm{H}), 4.32$ (d, $J=7.3 \mathrm{~Hz}, 1 \mathrm{H}), 4.26-4.23(\mathrm{~m}, 1 \mathrm{H}), 3.69$ (dd, $J=11.4 \mathrm{~Hz}, 5.0 \mathrm{~Hz}$, $1 \mathrm{H}), 3.62-3.53(\mathrm{~m}, 1 \mathrm{H})$; MS: (ES+) $\mathrm{m} / \mathrm{z}=266(\mathrm{M}+1)$, HPLC purity $(93 \%)$.

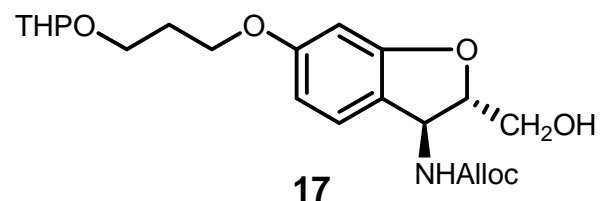

To a stirred solution of $\mathbf{8 b}$ (456 $\mathrm{mg}, 1.72 \mathrm{mmol})$ in dry DMF $(10 \mathrm{ml})$ spacer $(590 \mathrm{mg}, 1.90 \mathrm{mmol})$ dissolved in DMF (3 ml) was added slowly via insulated canula, followed by addition of oven dried $\mathrm{CsCO}_{3}(615 \mathrm{mg}, 1.90 \mathrm{mmol})$ at room temperature. Reaction was stirred for 17 hours at room temperature, filtered through celite and DMF was evaporated under reduced pressure. Reaction mixture was diluted with water and extracted with ethyl acetate. Combined organic layer was washed 
with brine, dried over $\mathrm{MgSO}_{4}$, filtered and concentrated. Purification by flash chromatography (35\% ethyl acetate in hexane) afforded compound 17 (500 mg, 71\%) as a white solid. ${ }^{1} \mathrm{H}$ NMR: $\left(400 \mathrm{MHz}, \mathrm{CDCl}_{3}\right) \delta=7.15(\mathrm{~d}, J=8.3 \mathrm{~Hz}, 1 \mathrm{H}), 6.50(\mathrm{dd}, J=$ $8.4 \mathrm{~Hz}, 2.0 \mathrm{~Hz}, 1 \mathrm{H}), 6.41$ (d, $J=1.9 \mathrm{~Hz}, 1 \mathrm{H}), 5.99-5.89$ (m, 1H), 5.33 (d, $J=17.2 \mathrm{~Hz}$, $1 \mathrm{H}), 5.25$ (d, $J=10.4,1 \mathrm{H}), 5.20-5.13(\mathrm{~m}, 2 \mathrm{H}), 4.62-4.57(\mathrm{~m}, 4 \mathrm{H}), 4.06(\mathrm{t}, J=6.6 \mathrm{~Hz}$, 2H), 3.93-3.84 (m, 4H), 3.59-3.49 (m, 2H), $2.07(\mathrm{t}, J=6.3 \mathrm{~Hz}, 1 \mathrm{H}), 1.83-1.80(\mathrm{~m}, 1 \mathrm{H})$, 1.73-1.70 (m, $1 \mathrm{H}), 1.60-1.52(\mathrm{~m}, 4 \mathrm{H}) ;{ }^{13} \mathrm{C}-\mathrm{NMR}:\left(100 \mathrm{MHz}, \mathrm{CDCl}_{3}\right) \delta=162.0,132.7$, 125.7, 118.6, 108.6, 99.3, 97.4, 91.9, 66.5, 66.3, 65.7, 64.3, 64.0, 62.7, 60.7, 56.3, 32.3, 31.1, 29.9, 25.8, 19.9; HRMS: (FAB) $\mathrm{m} / \mathrm{z}=407$ (M), HPLC purity $(>96 \%)$.

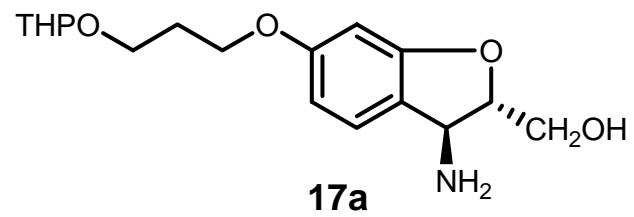

To a stirred solution of $\mathbf{1 7}$ (1.5 g, $3.7 \mathrm{mmol})$, in dry DCM $(75 \mathrm{ml}), \mathrm{Pd}\left(\mathrm{PPh}_{3}\right)_{4}(0.085 \mathrm{~g}, 0.074$ $\mathrm{mmol})$ and acetic acid $(0.5 \mathrm{ml}, 9 \mathrm{mmol})$ were added under argon atmosphere. The pale lemon yellow color of the solution was characteristic of the presence of palladium (II) complex. $\mathrm{Bu}_{3} \mathrm{SnH}(1.1 \mathrm{ml}, 4 \mathrm{mmol})$ was then rapidly and in one portion added to the stirred solution. After $5 \mathrm{~min}$, reaction became golden yellow indicating the presence of Pd (0). Reaction was diluted in DCM and extracted with agues sodium hydrogen carbonate solution. Organic layer was dried over $\mathrm{MgSO}_{4}$, filtered and concentrated. Purification by flash chromatography (10\% methanol in DCM) afforded compound 17a (1.2 g, 96\%) as a white solid. ${ }^{1} \mathrm{H}$ NMR: (400 MHz, $\left.\mathrm{CD}_{3} \mathrm{OD}\right) \delta=7.30(\mathrm{~d}, J=8.3 \mathrm{~Hz}, 1 \mathrm{H}), 6.54(\mathrm{dd}, J=8.3 \mathrm{~Hz}, 2.1 \mathrm{~Hz}, 1 \mathrm{H}), 6.46(\mathrm{~d}, J=2.0$ $\mathrm{Hz}, 1 \mathrm{H}), 4.62-4.61(\mathrm{~m}, 1 \mathrm{H}), 4.59-4.55(\mathrm{~m}, 2 \mathrm{H}), 4.07(\mathrm{t}, J=6.2 \mathrm{~Hz}, 2 \mathrm{H}), 3.92-3.85(\mathrm{~m}$, $2 \mathrm{H}), 3.73(\mathrm{~d}, J=3.9 \mathrm{~Hz}, 2 \mathrm{H}), 3.58-3.56(\mathrm{~m}, 1 \mathrm{H}), 3.55-3.48(\mathrm{~m}, 1 \mathrm{H}), 3.33-3.32(\mathrm{~m}, 1 \mathrm{H})$, 2.07-2.01 (m, 2H), 1.84-1.82 (m, 1H), 1.71-1.67 (m, 1H), 157-1.52 (m, 4H); HRMS: $(\mathrm{FAB}) \mathrm{m} / \mathrm{z}=323(\mathrm{M}), 307\left(\mathrm{M}-\mathrm{NH}_{2}\right)$, HPLC purity $(99 \%)$.

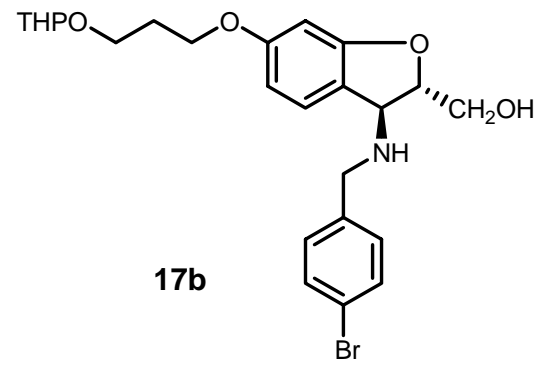

To a stirred solution of $\mathbf{1 7 a}(1.17 \mathrm{~g}, 3.6 \mathrm{mmol})$ in dry DMF (40 ml) was added $p$-bromo benzyl bromide (900 $\mathrm{mg}, 3.6 \mathrm{mmol}$ ), followed by addition of oven-dried potassium carbonate $(500 \mathrm{mg}, 3.6 \mathrm{mmol})$. The reaction mixture was stirred for 6 hours. DMF was evaporated 
and reaction mixture was diluted with water and extracted with ethyl acetate. Organic layer was dried over $\mathrm{MgSO}_{4}$, filtered and evaporated and concentrated. Purification by flash chromatography (30\% ethyl acetate in hexane) afforded compound 17b (906 mg, $51 \%$ ) as a white solid. ${ }^{1} \mathrm{H}$ NMR: (400 $\left.\mathrm{MHz}, \mathrm{CDCl}_{3}\right) \delta=7.5(\mathrm{~d}, J=8.5 \mathrm{~Hz}, 2 \mathrm{H}), 7.27-$ 7.23 (m, 3H), $6.61(\mathrm{dd}, J=8.3 \mathrm{~Hz}, 2.1 \mathrm{~Hz}, 1 \mathrm{H}), 6.43$ (d, $J=2.1 \mathrm{~Hz}, 1 \mathrm{H}), 4.75-4.73$ (m, $1 \mathrm{H}), 4.62-4.60(\mathrm{~m}, 1 \mathrm{H}), 4.40(\mathrm{~d}, J=3.4 \mathrm{~Hz}, 1 \mathrm{H}), 4.07-4.05(\mathrm{~m}, 2 \mathrm{H}), 3.96-3.92(\mathrm{~m}, 1 \mathrm{H})$, 3.88-3.80 (m, 3H), $3.74(\mathrm{~d}, J=5.4 \mathrm{~Hz}, 2 \mathrm{H}), 3.61-3.56(\mathrm{~m}, 1 \mathrm{H}), 3.56-3.49(\mathrm{~m}, 1 \mathrm{H}), 2.11-$ $2.05(\mathrm{~m}, 2 \mathrm{H}), 1.86-1.80(\mathrm{~m}, 1 \mathrm{H}), 1.76-1.70(\mathrm{~m}, 1 \mathrm{H}), 1.60-1.52(\mathrm{~m}, 4 \mathrm{H}) ;{ }^{13} \mathrm{C}-\mathrm{NMR}:(100$ $\left.\mathrm{MHz} \mathrm{CDCl}_{3}\right) \delta=161.6,161.3,138.5,132.0,130.4,126.1,121.6,119.7,108.2,99.4$, 97.5, 89.7, 65.7, 64.4, 64.3, 62.8, 61.1, 49.8, 31.1, 31.0, 25.9, 19.9; HRMS: (FAB) $\mathrm{m} / \mathrm{z}=$ $492(\mathrm{M}+1)$, HPLC purity (>95\%).

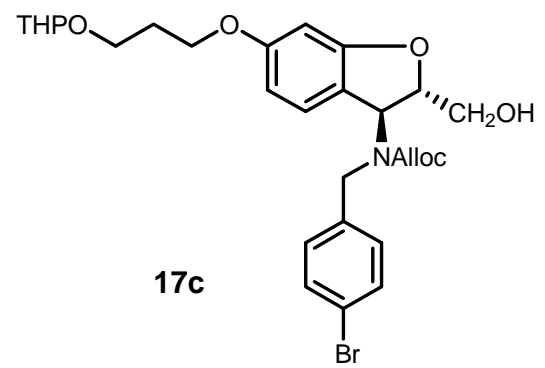

To a stirred solution of $\mathbf{1 7 b}(633 \mathrm{mg}, 1.23 \mathrm{mmol})$ in dry acetonitrile $(20 \mathrm{ml})$ was added allyl chloroformate $(0.150 \mathrm{ml}, 1.35 \mathrm{mmol})$ followed by the addition of DIPEA $(0.250 \mathrm{ml}, 1.35 \mathrm{mmol})$. Reaction mixture was stirred for 2 hours at room temperature. Reaction mixture was quenched by addition of water. Acetonitrile was evaporated and the resulting mixture was extracted with ethyl acetate. Organic layer was dried over $\mathrm{MgSO}_{4}$, filtered and concentrated. Purification by flash chromatography afforded compound 17c $(590 \mathrm{mg}$, $80 \%$ ) as a white solid. ${ }^{1} \mathrm{H}$ NMR: $\left(400 \mathrm{MHz}, \mathrm{CDCl}_{3}\right) \delta=7.35(\mathrm{~d}, J=8.3 \mathrm{~Hz}, 2 \mathrm{H}), 6.89$ 6.87 (m, 3H), 6.41-6.39 (m, 2H), 5.96-5.89 (m, 1H), 5.65-5.56 (broad m, 1H), 5.31-5.23 (broad m, 2H), 4.69 (d, $J=5.6 \mathrm{~Hz}, 2 \mathrm{H}), 4.62-4.60$ (m, 1H), 4.45-4.43 (m, 1H), 4.40-4.34 (broad m, 1H), 4.16 (d, $J=15.8 \mathrm{~Hz}, 1 \mathrm{H}), 4.05$ (t, $J=6.2 \mathrm{~Hz}, 2 \mathrm{H}), 3.96-3.92(\mathrm{~m}, 1 \mathrm{H})$, 3.90-3.84 (m, 1H), 3.73 (broad s, 2H), 3.61-3.55 (m, 1H), 3.54-3.49 (m, 1H), 2.83 (broad $\mathrm{s}, 0.5 \mathrm{H}), 2.10-2.04(\mathrm{~m}, 2 \mathrm{H}), 1.84-1.79(\mathrm{~m}, 1 \mathrm{H}), 1.76-1.70(\mathrm{~m}, 1 \mathrm{H}), 1.60-1.52(\mathrm{~m}, 4 \mathrm{H})$; ${ }^{13} \mathrm{C}-\mathrm{NMR}:\left(100 \mathrm{MHz}, \mathrm{CDCl}_{3}\right) \delta=162.0,157.1,137.7,132.7,131.8,130.1,129.5,127.1$, $121.5,118.7,114.9,108.4,99.4,97.3,89.4,67.2,65.7,64.2,62.8,61.4,60.2,53.9,47.2$, 46.9, 31.1, 29.9, 28.2, 27.2, 20.1, 17.9, 14.6, 14.0; MS: (ES+) m/z = $576(\mathrm{M}+1), 578$ $(\mathrm{M}+3)$, HPLC purity $(>98 \%)$. 


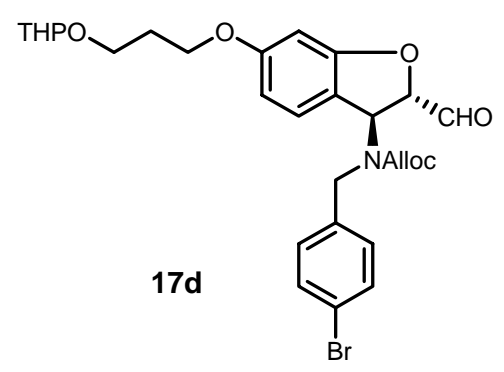

To a stirred solution of alcohol 17c (138 mg, $0.24 \mathrm{mmol})$ in dry DCM $(20 \mathrm{~mL})$ was added solid $\mathrm{NaHCO}_{3}(121 \mathrm{mg}$, $1.44 \mathrm{mmol}$ ) followed by Dess-Martin periodinane (127 $\mathrm{mg}, 0.3 \mathrm{mmol}$ ) at room temperature. The cloudy white solution was stirred at room temperature for 2 hours until the starting material was completely consumed and the substantially pure product appeared (monitored by TLC and MS), then the reaction mixture was quenched with 1:1 mixture of $10 \%$ aqueous $\mathrm{Na}_{2} \mathrm{~S}_{2} \mathrm{O}_{3}$ and saturated aqueous $\mathrm{NaHCO}_{3}$ solutions $(5 \mathrm{~mL})$. The reaction mixture was stirred for 10 minutes and poured into water $(10 \mathrm{~mL})$. The layers were separated, and the aqueous phase was extracted with DCM $(3 \times 10 \mathrm{~mL})$. The combined organic extracts were dried over $\mathrm{MgSO}_{4}$, filtered, and concentrated in vacuo. Since the material was substantially pure after work up, it was taken to the next step (olefination) without any purification.

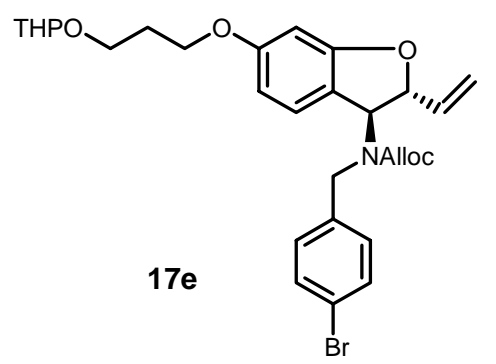

To a (Methyl)triphenylphosphonium bromide solution (343 $\mathrm{mg}, 0.96 \mathrm{mmol})$ in THF $(10 \mathrm{~mL})$ at $0{ }^{\circ} \mathrm{C}$, was added a solution of sodium hexamethyldisilazide (1M in THF) (480 $\mu \mathrm{L}, 0.48 \mathrm{mmol})$. The solution was allowed to gradually warm to room temperature and was stirred for 1 hour. The reaction mixture was then cooled to $0^{\circ} \mathrm{C}$ again and a solution of 17d $(0.24 \mathrm{mmol}$, crude material, considering $100 \%$ conversion has taken place during epoxidation) in THF ( $8 \mathrm{~mL})$ was added to it using a canula which was followed by addition of DIPEA ( $84 \mu \mathrm{L}, 0.48 \mathrm{mmol})$ at the same temperature. Reaction mixture was allowed to come to room temperature and then stirred at room temperature for additional 2 hours and then quenched by addition of saturated aqueous $\mathrm{NH}_{4} \mathrm{Cl}(3 \mathrm{~mL})$ and brine $(5 \mathrm{~mL})$, extracted with ethyl acetate $(3 \times 15 \mathrm{~mL})$, washed with water $(2 \mathrm{X} 10 \mathrm{~mL})$, dried over $\mathrm{MgSO}_{4}$ and concentrated to a yellowish solid. Presence of desired material in the crude product mixture was confirmed by MS at this stage with TLC having only two substantial spots. Apart from the desired product, the other spot was presumably due to triphenylphosphine oxide (as indicated by MS also) which, we thought will not interfere 
in the THP deprotection reaction (the following step). So, the crude material (17e, 796 $\mathrm{mg}$ ) was taken to the next step without any chromatographic purification.

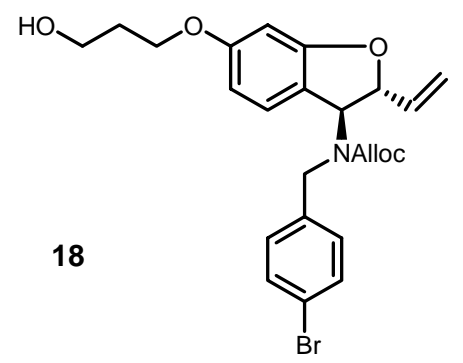

A solution of crude THP ether 17e (Considering 80\% accumulation of the desired product in the olefination step, $0.19 \mathrm{mmol})$ and PPTS (48 $\mathrm{mg}, 0.19 \mathrm{mmol})$ in ethanol (10 $\mathrm{mL}$ ) was stirred at $55{ }^{\circ} \mathrm{C}$ for 14 hours. The solvent was evaporated in vacuo. The crude material was then taken in DCM and subjected to purification by flash chromatography (40\% ethyl acetate in hexane) to afford 18 (47 mg, $40 \%$ overall yield in three steps starting from 17c) as a thick colorless oil. ${ }^{1} \mathrm{H}$ NMR: $\left(400 \mathrm{MHz}, \mathrm{CDCl}_{3}, 25{ }^{\circ} \mathrm{C}\right) \delta=7.35(\mathrm{~d}, J=8.32 \mathrm{~Hz}, 2 \mathrm{H})$, 6.946.89 (m, 3H), 6.42 (s, 1H), 6.39 (dd, $J=8.3 \mathrm{~Hz}, 2.1 \mathrm{~Hz}, 1 \mathrm{H}), 5.92$ (broad s, 2H), 5.67 $5.50($ broad m, 1H), 5.32-5.22 (m, 3H), $5.18(\mathrm{~d}, J=10.5,1 \mathrm{H}), 4.84$ (broad s, 1H), 4.69 (broad m, 2H), 4.45-4.35 (m, 1H), $4.14(\mathrm{~d}, J=11.0 \mathrm{~Hz}, 1 \mathrm{H}), 4.09$ (t, $J=5.9 \mathrm{~Hz}, 2 \mathrm{H})$, $3.87(\mathrm{t}, J=5.9 \mathrm{~Hz}, 2 \mathrm{H}), 2.05(\mathrm{tt}, J=5.9 \mathrm{~Hz}, 2 \mathrm{H}) ;{ }^{13} \mathrm{C}-\mathrm{NMR}:\left(100 \mathrm{MHz}, \mathrm{CDCl}_{3}, 25{ }^{\circ} \mathrm{C}\right) \delta$ $=161.8,156.7,137.9,135.5,132.7,131.7,129.7,129.0,126.9,121.1,118.2,116.8$, 115.4, 108.0, 97.0, 88.7, 66.8, 66.1, 63.7, 60.5, 46.8, 32.1; MS: (ES+) $\mathrm{m} / \mathrm{z}=488(\mathrm{M}+1)$, $490(\mathrm{M}+3)$.

${ }^{1} \mathrm{H}$ NMR: $\left(400 \mathrm{MHz}, \mathrm{CDCl}_{3}, 58{ }^{\circ} \mathrm{C}\right) \delta=7.34(\mathrm{~d}, J=8.2 \mathrm{~Hz}, 2 \mathrm{H}), 6.93(\mathrm{~d}, J=8.1 \mathrm{~Hz}$, 2H), 6.89 (d, $J=8.1 \mathrm{~Hz}, 1 \mathrm{H}), 6.42$ (s, 1H), 6.39 (d, $J=8.1 \mathrm{~Hz}, 1 \mathrm{H}), 5.98-5.86$ (m, 2H), 5.58 (broad s, 1H), 5.30 (dd, $J=17.0 \mathrm{~Hz}, 7.2 \mathrm{~Hz}, 2 \mathrm{H}), 5.22$ (d, $J=10.4,1 \mathrm{H}), 5.17$ (d, $J=$ 10.5, 1H), 4.85 (broad s, 1H), 4.69 (d, $J=5.4 \mathrm{~Hz}, 2 \mathrm{H}), 4.32(\mathrm{~d}, J=15.9 \mathrm{~Hz}, 1 \mathrm{H}), 4.16$ (d, $J=15.9 \mathrm{~Hz}, 1 \mathrm{H}$ ), 4.10 (t, $J=6.0 \mathrm{~Hz}, 2 \mathrm{H}), 3.86$ (t, $J=5.9 \mathrm{~Hz}, 2 \mathrm{H}$ ), 2.04 (tt, $J=5.9 \mathrm{~Hz}$, 2H); ${ }^{13} \mathrm{C}$-NMR: $\left(100 \mathrm{MHz}, \mathrm{CDCl}_{3}, 58{ }^{\circ} \mathrm{C}\right) \delta=162.2,161.9,156.5,138.1,135.6,132.9$, 131.6, 129.5, 126.9, 121.2, 118.2, 116.7, 115.8, 108.3, 97.4, 88.8, 66.8, 66.3, 64.0, 60.5, 47.3, 32.4; MS: (ES+) m/z = 488(M+1), $490(\mathrm{M}+3)$, HPLC purity $(99 \%)$.

\section{X-ray crystallographic data for Compound 8:}


Crystal data for sadf: $\mathrm{C}_{38} \mathrm{H}_{50} \mathrm{~N}_{2} \mathrm{O}_{16}, \mathrm{M}=790.80$, monoclinic, space group $\mathrm{P}_{1}, \mathrm{Z}=2$, a = 4.7879(6), $\mathrm{b}=35.801(5), \mathrm{c}=11.5963(15) \AA, \beta=90.618(3)^{\circ}, \mathrm{V}=1987.6(4) \AA^{3}$, density (calculated) $=1.321 \mathrm{~g} \mathrm{~cm}$. The data were collected at 173(1) K on a Bruker SMART CCD diffractometer using graphite-monochromatised Mo $\mathrm{K} \alpha$ radiation. The colorless crystal was needle-like $(0.60 \times 0.07 \times 0.03 \mathrm{~mm})$. Of 18805 reflections collected 7353 were unique $\left(\mathrm{R}_{\mathrm{int}}=0.07\right)$. Final $\mathrm{R} 1=0.060[\mathrm{I}>2 \sigma(\mathrm{I})]$ and $\mathrm{wR} 2$ $=0.132$ for all data.

\section{General Methods (Biological Assays):}

\section{Wound-Healing Assay}

NIH3T3 were maintained in Dulbecco's modified MEM (DMEM, Gibco) supplemented with $10 \%$ fetal bovine serum (FBS, Gibco), $2 \mathrm{mM}$ L-glutamine (Gibco) and penicillin $\mathrm{G}\left(200 \mathrm{U} \mathrm{ml}^{-1}\right.$, Gibco) in a humidified $37^{\circ} \mathrm{C}$ incubator at $5 \% \mathrm{CO}_{2}$. For wound healing assays, NIH3T3 cells were plated on fibronectin-coated $\left(10 \mu \mathrm{g} \mathrm{ml}^{-1}\right)$ dishes and serum-starved confluent monolayers were then scratched once with a pipette tip. Cells were then washed with PBS, refed in the presence of compound (or DMF control) and the initial wound was photographed. The wound was allowed to close for 16 hours and photographed again. The percent wound closure was calculated as the average distance between the two wound edges over the initial distance.

\section{Chamber Cell Migration Assay}

For quantitative migration assays, the cells were resuspended in DMEM containing $0.5 \% \mathrm{BSA}$ and added to the top of a Boyden transwell migration chamber pre-coated with fibronectin $\left(10 \mu \mathrm{g} \mathrm{ml}^{-1}\right)$ and allowed to migrate for 3-6 hours in the presence or absence of compound. Residual cells were removed from the top of the chamber and the filter was rinsed in PBS, fixed in 4\% PFA for 10 minutes and stained with DAPI $\left(0.5 \mu \mathrm{g} \mathrm{ml}^{-1}\right.$, Sigma). The cells that migrated to the underside of the filter were enumerated from 5 to 10 random fields using DAPI fluorescence. Cell counts were performed in triplicate for three independent experiments. 


\section{Immunostaining Experiments}

For immunofluorescence studies, NIH3T3 cells were plated on coverslips coated with fibronectin $(10 \mu \mathrm{g} / \mathrm{ml})$ and incubated overnight. The following day, monolayers were scratched as above and stained after 2-4h. Briefly, the cells were rinsed with PBS, fixed in 4\% PFA and incubated with tetramethyl rhodamine isothiocyanate (TRITC)phalloidin (Sigma) for 10 minutes. The samples were visualized with a Zeiss Axioscope100 epifluorescence microscope equipped with the appropriate filters and photographed with a digital camera (Sony Corporation HB050) using the Northern Eclipse software package. 


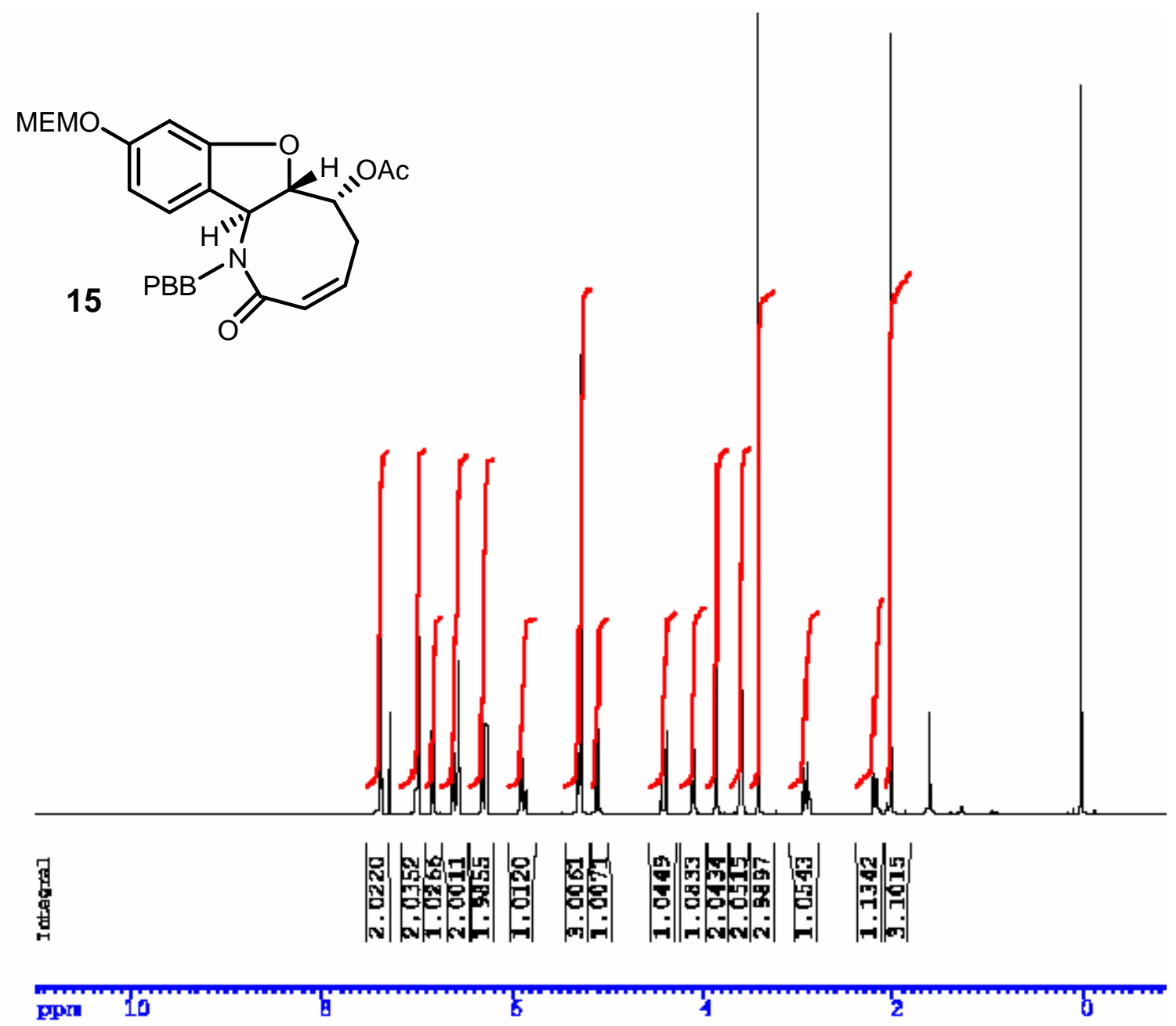




\section{H-H COSY}

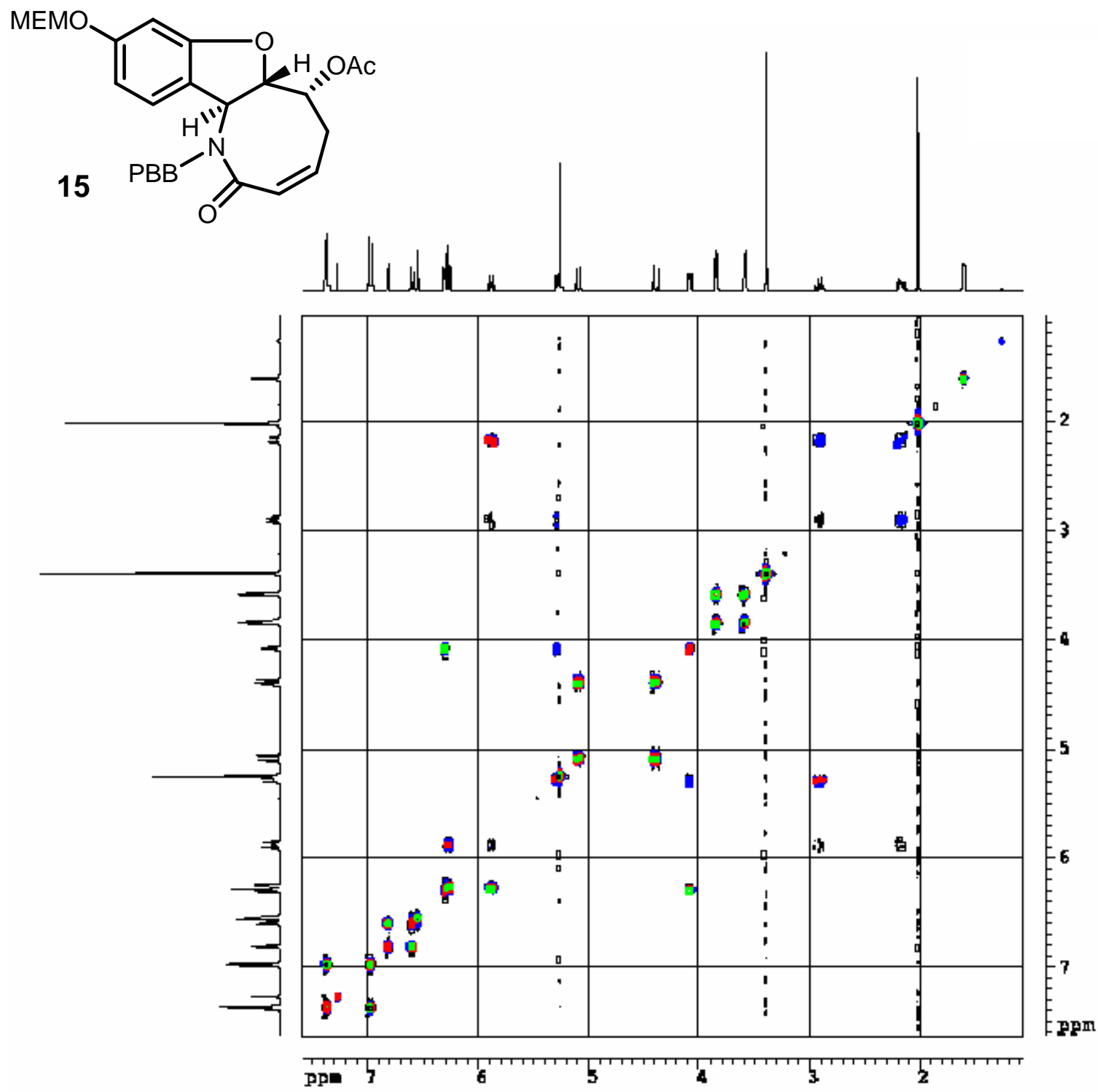




\section{NOESY}

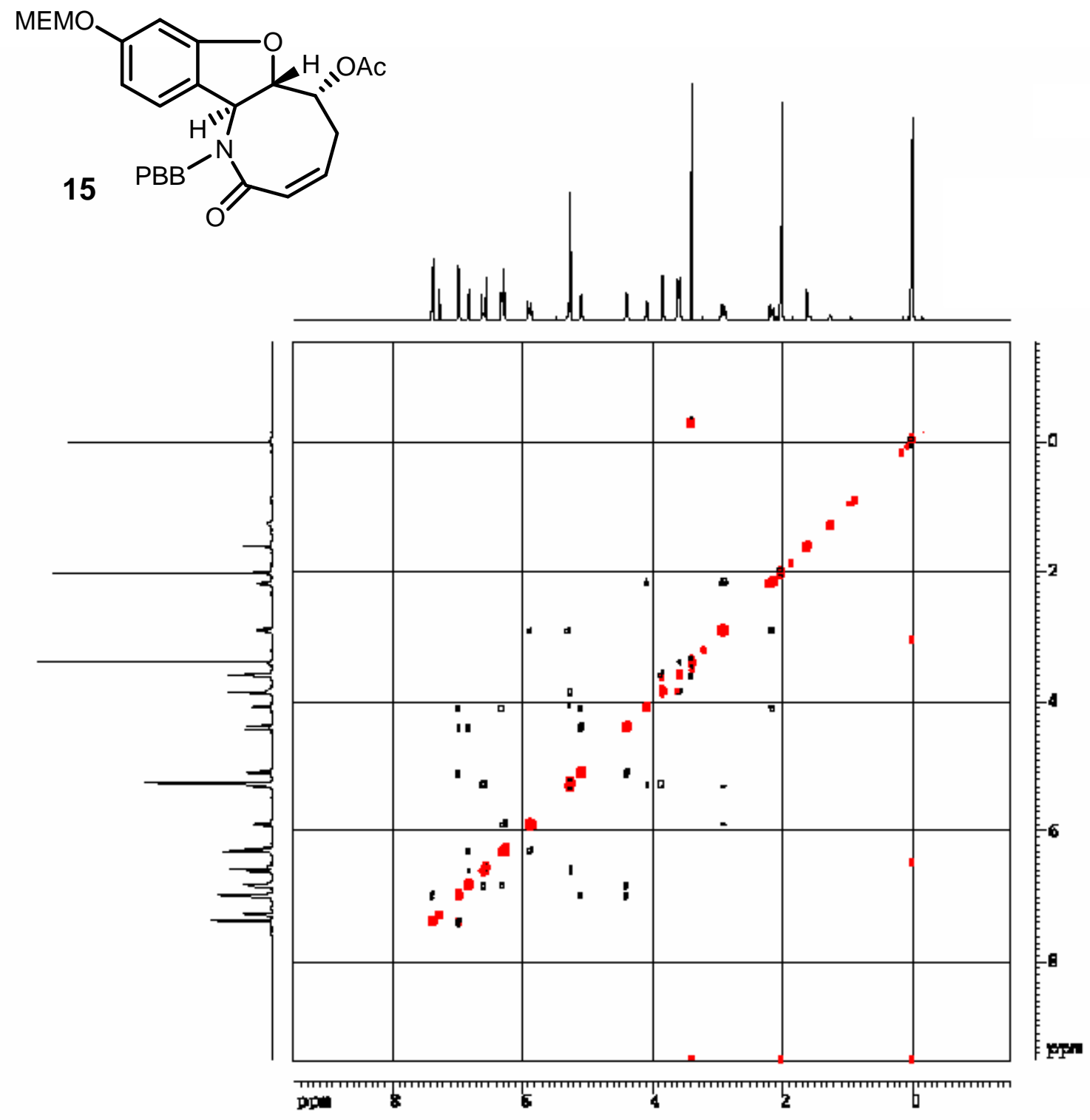


08/02/2008Supporting information - Benzofuran-derived Cyclic $\beta$-amino acid p no 29

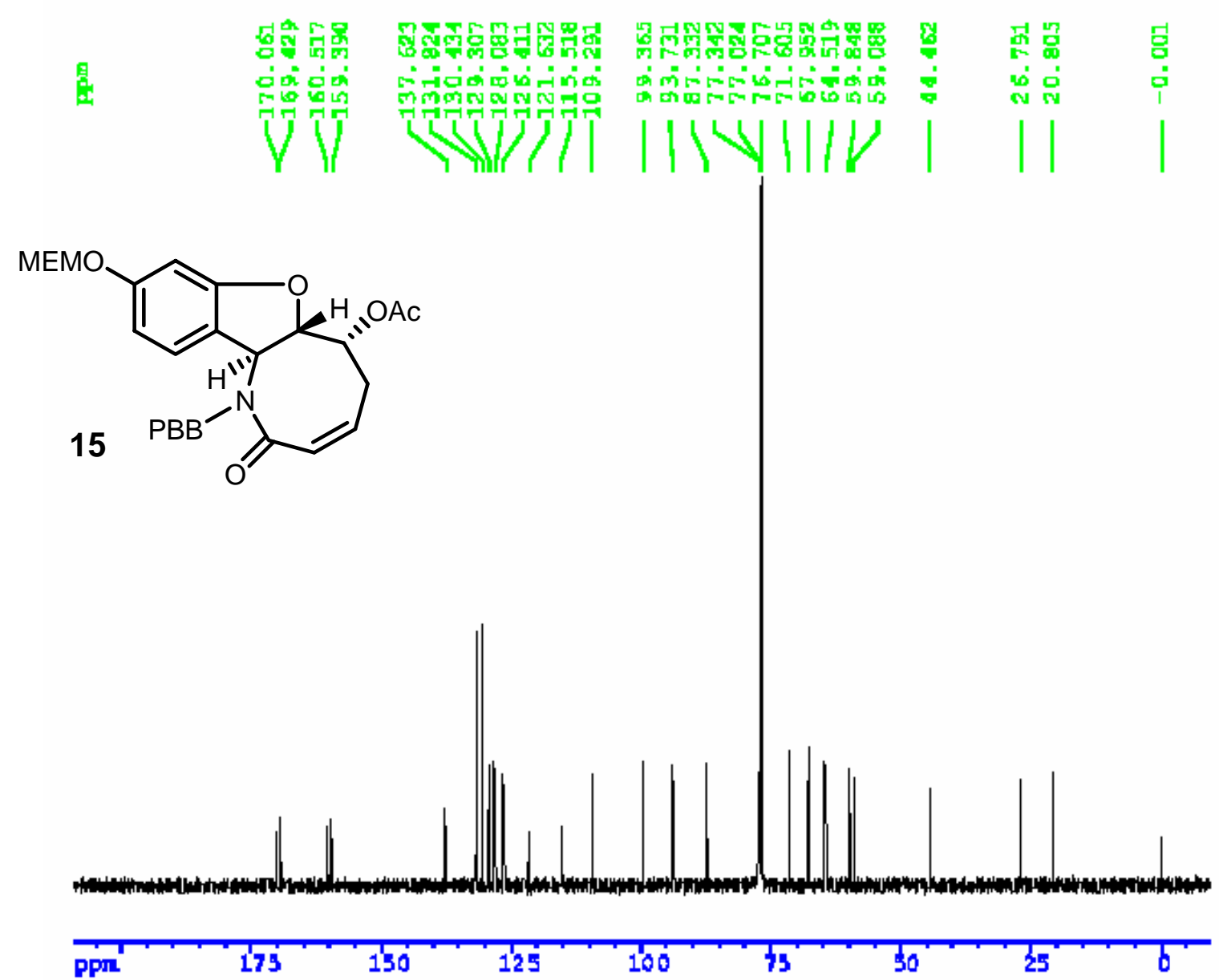




\section{HSQC}

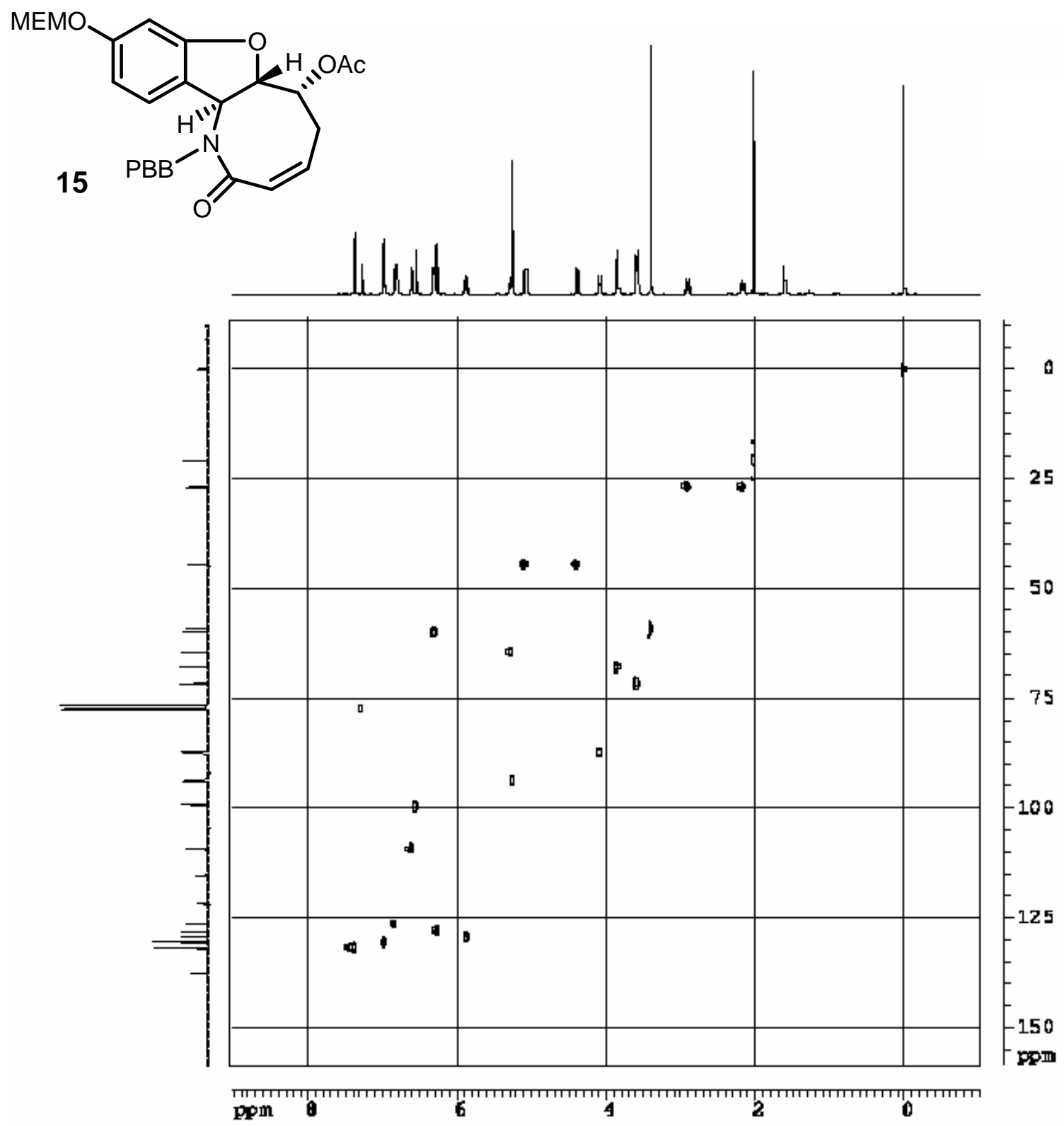




\section{HMBC}
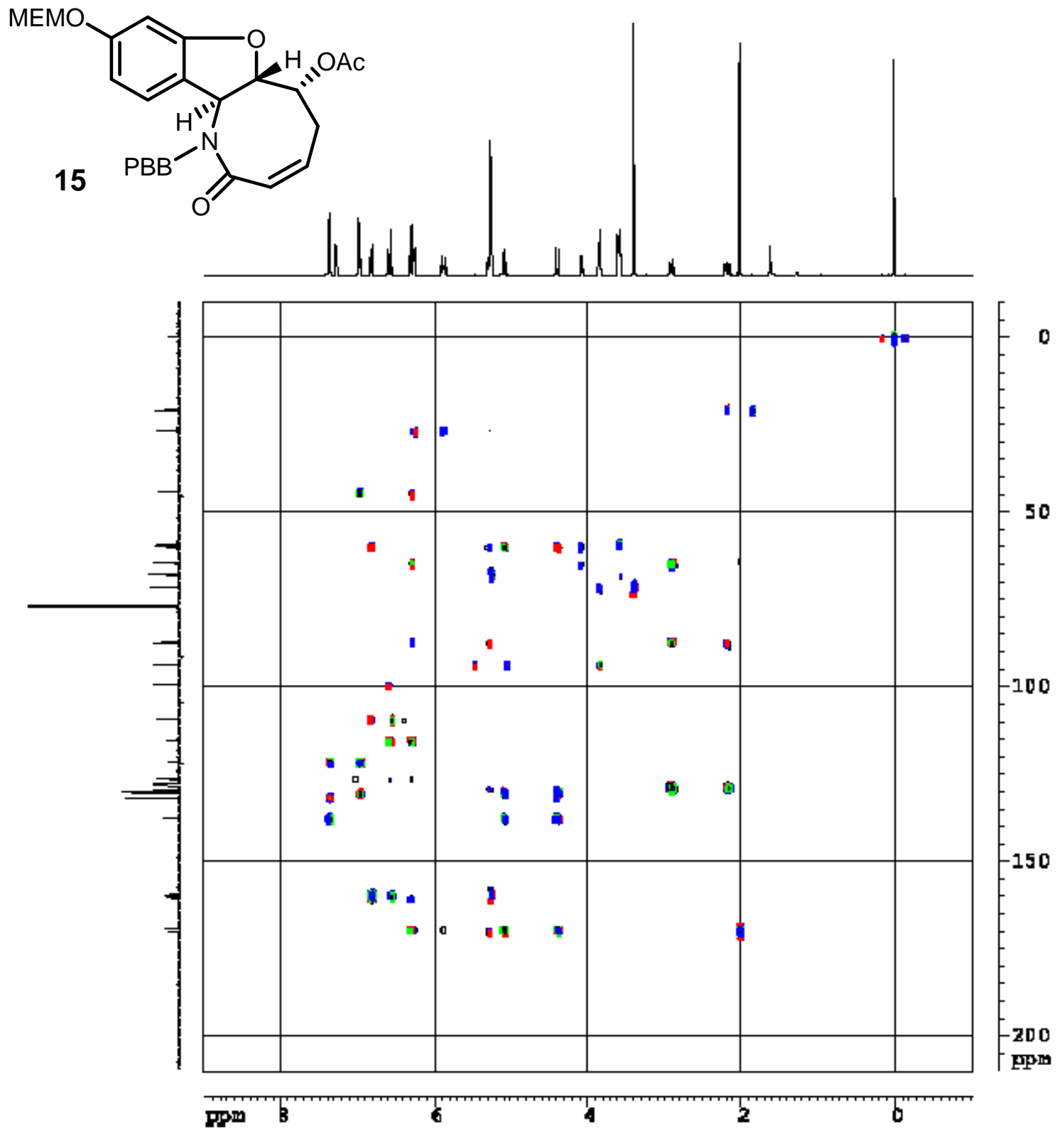

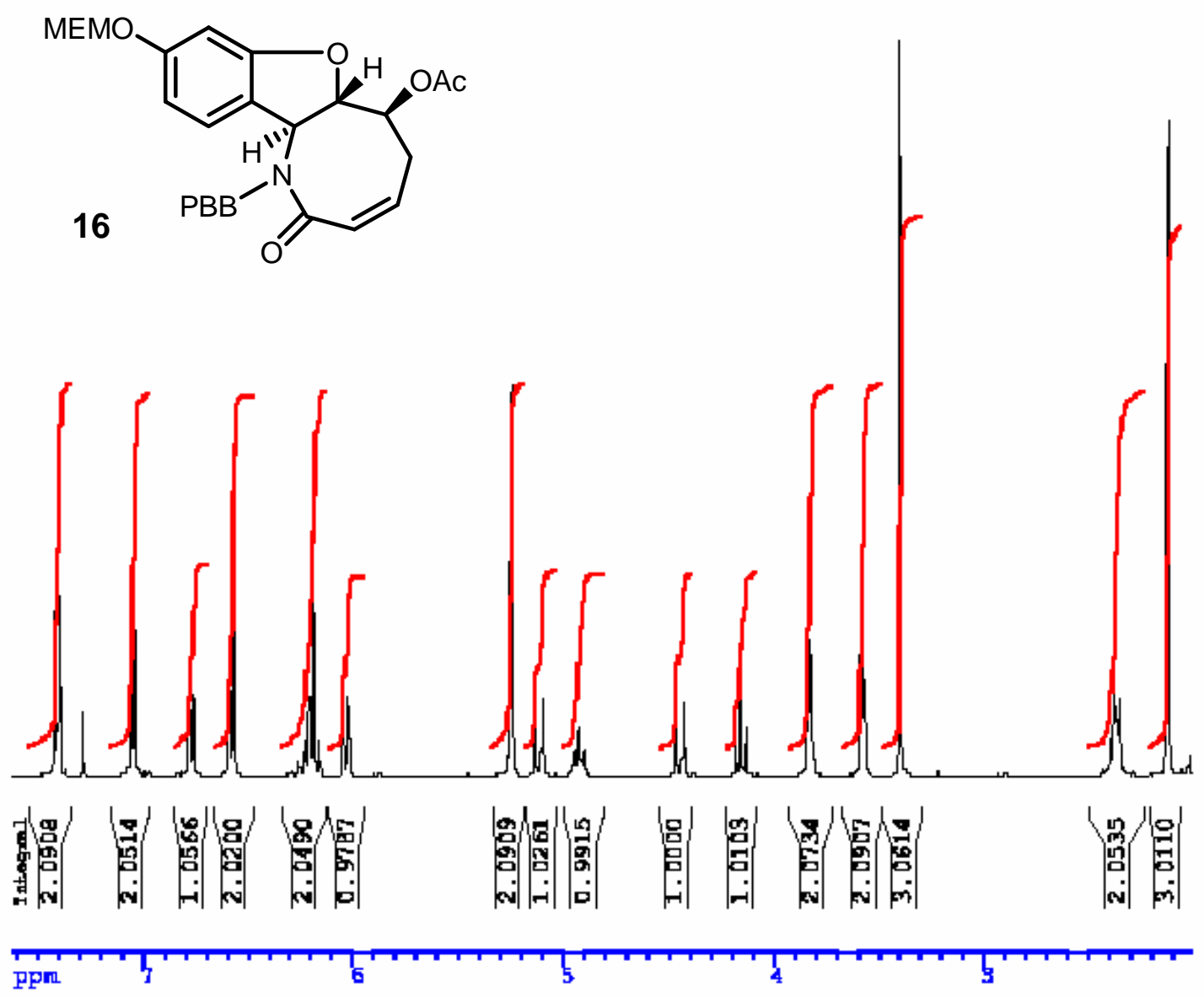


\section{H-H COSY}

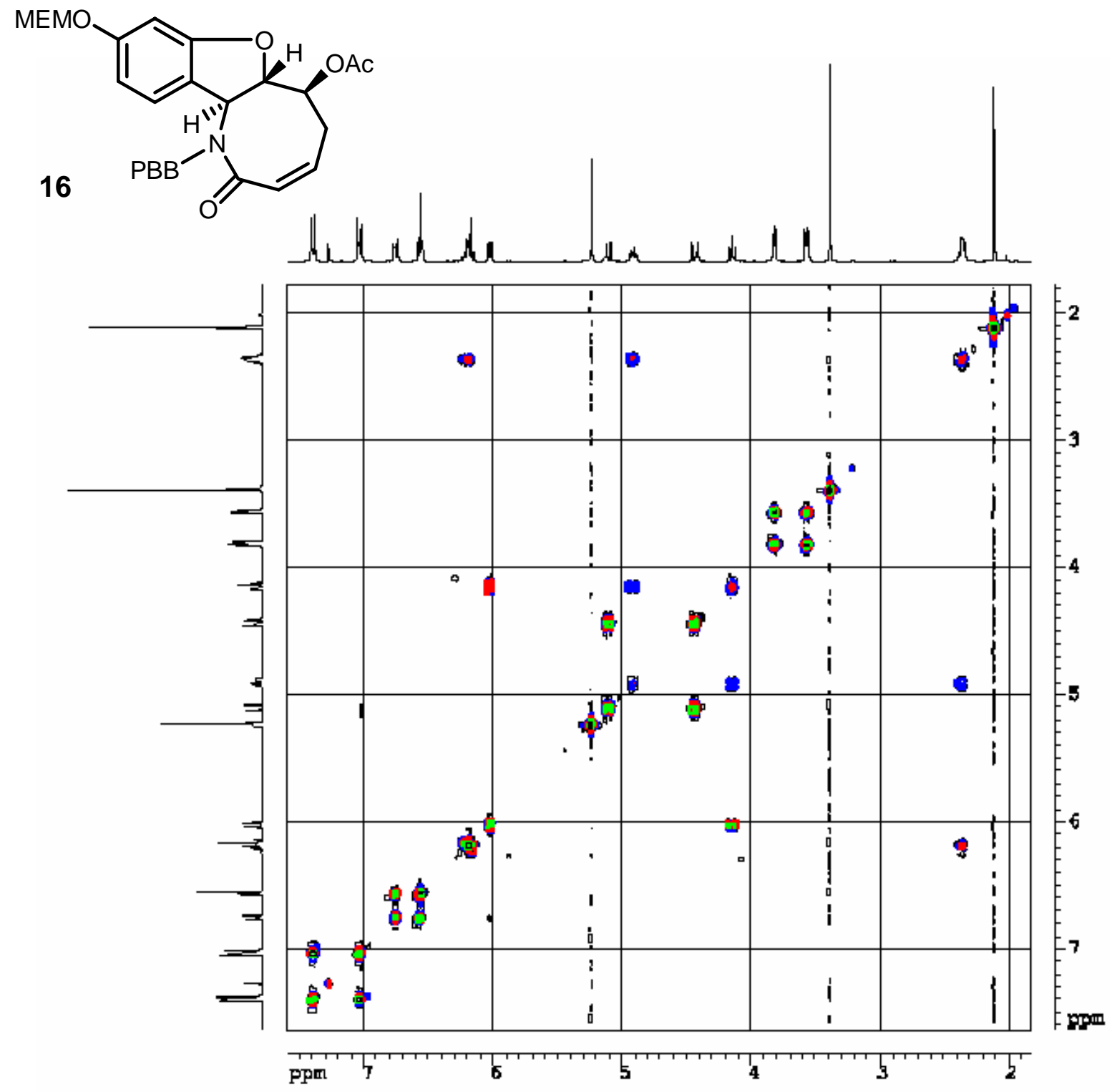




\section{NOESY}

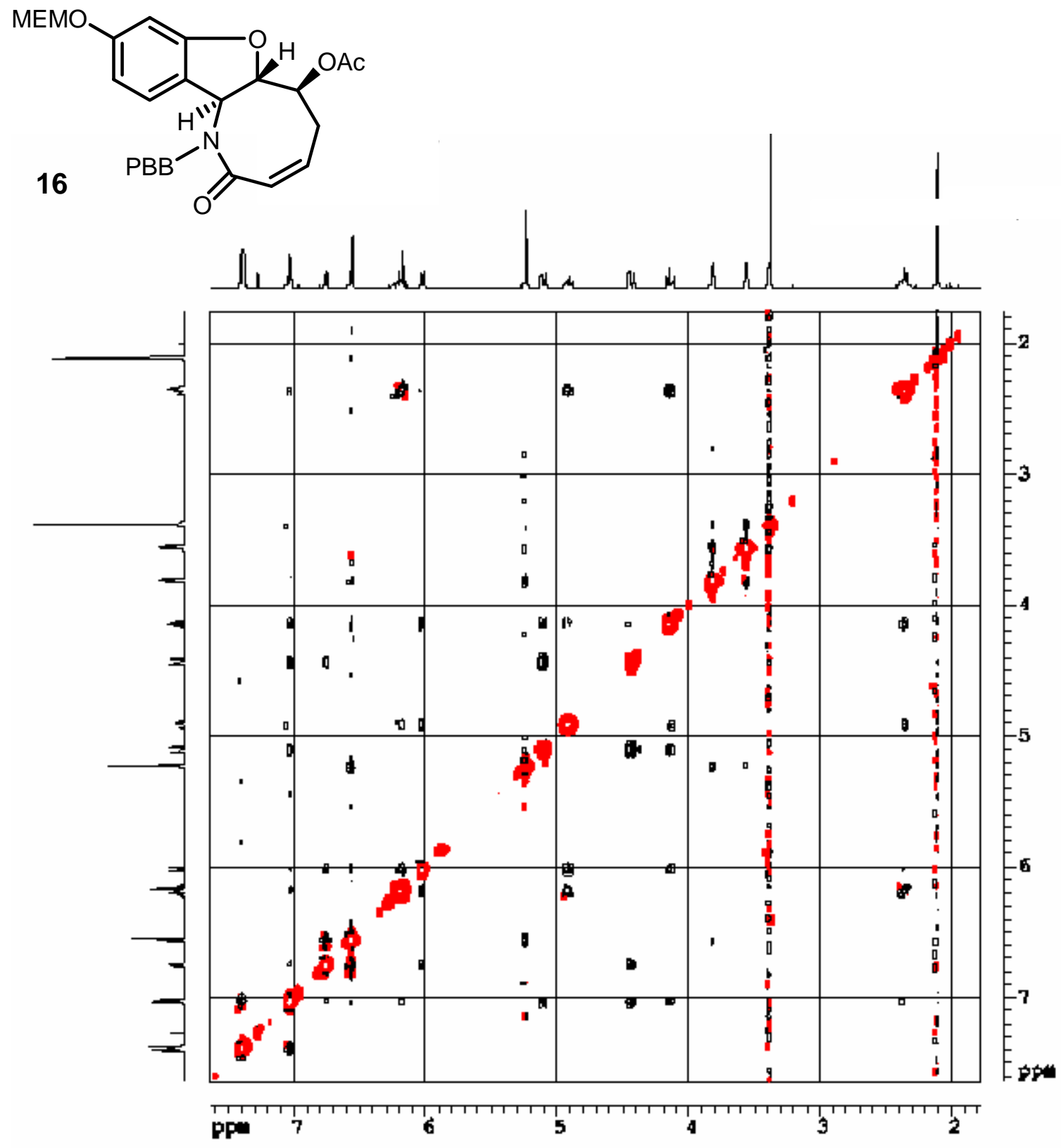


08/02/2008Supporting information - Benzofuran-derived Cyclic $\beta$-amino acid p no 35

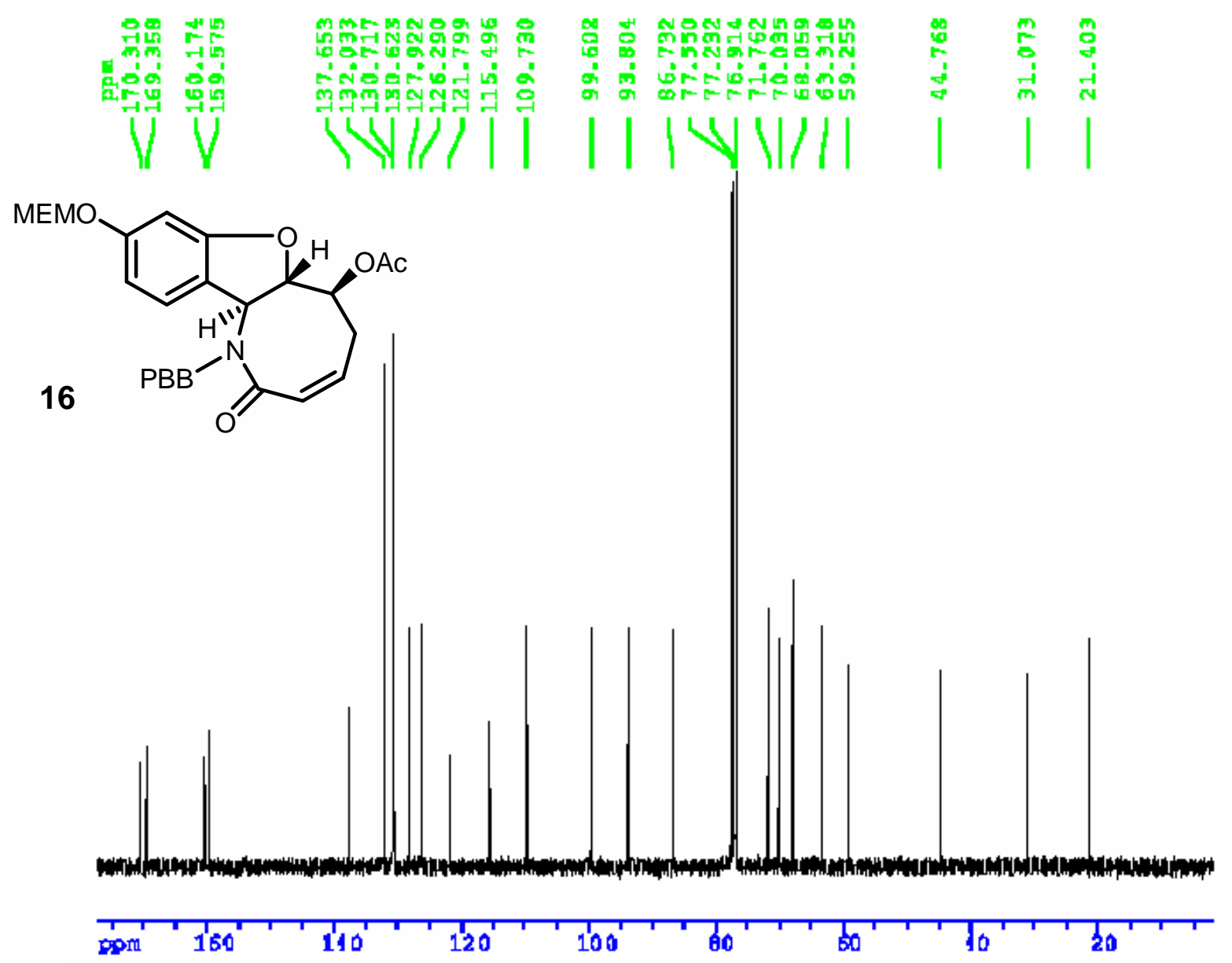




\section{HSQC}

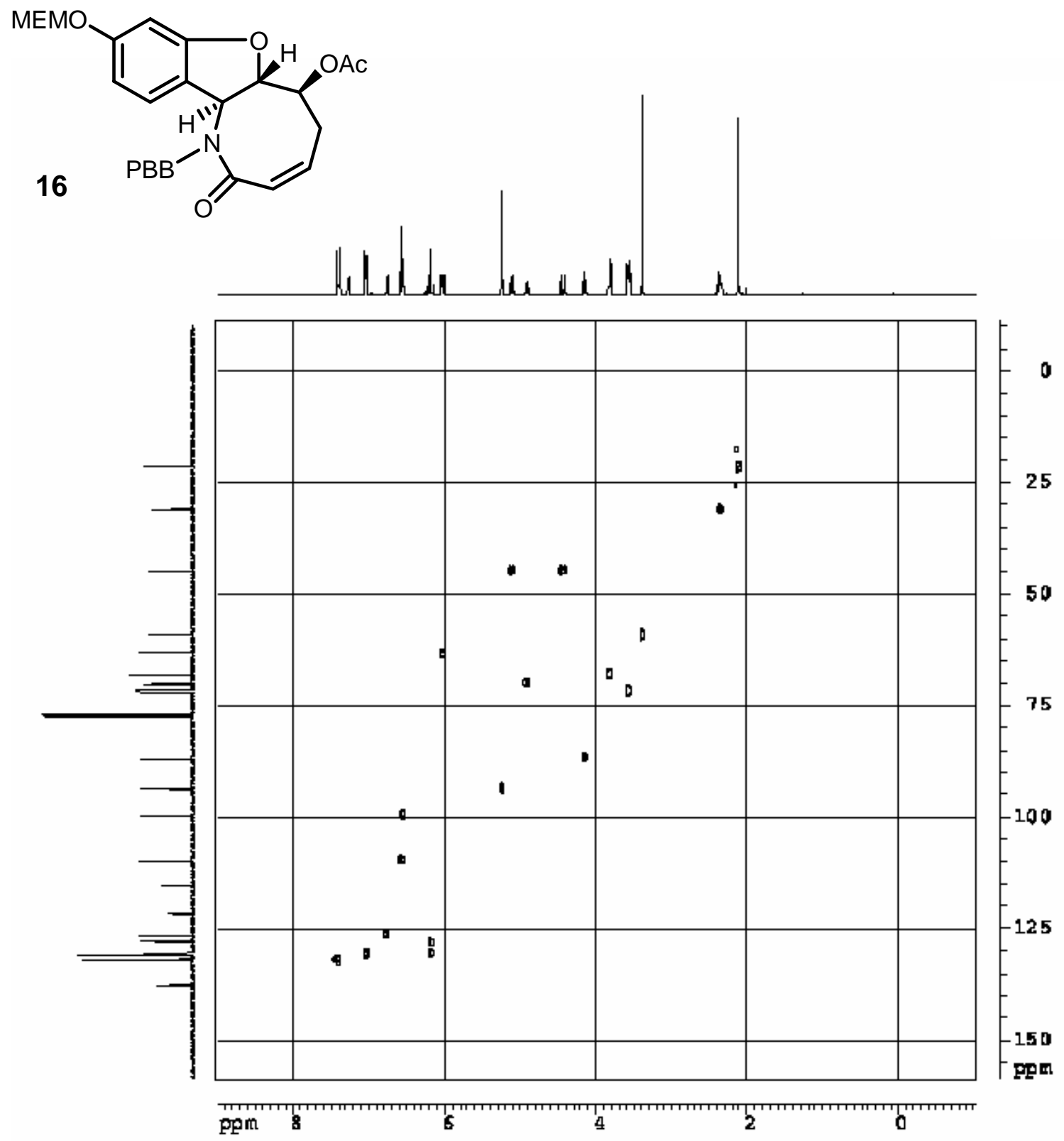




\section{HMBC}

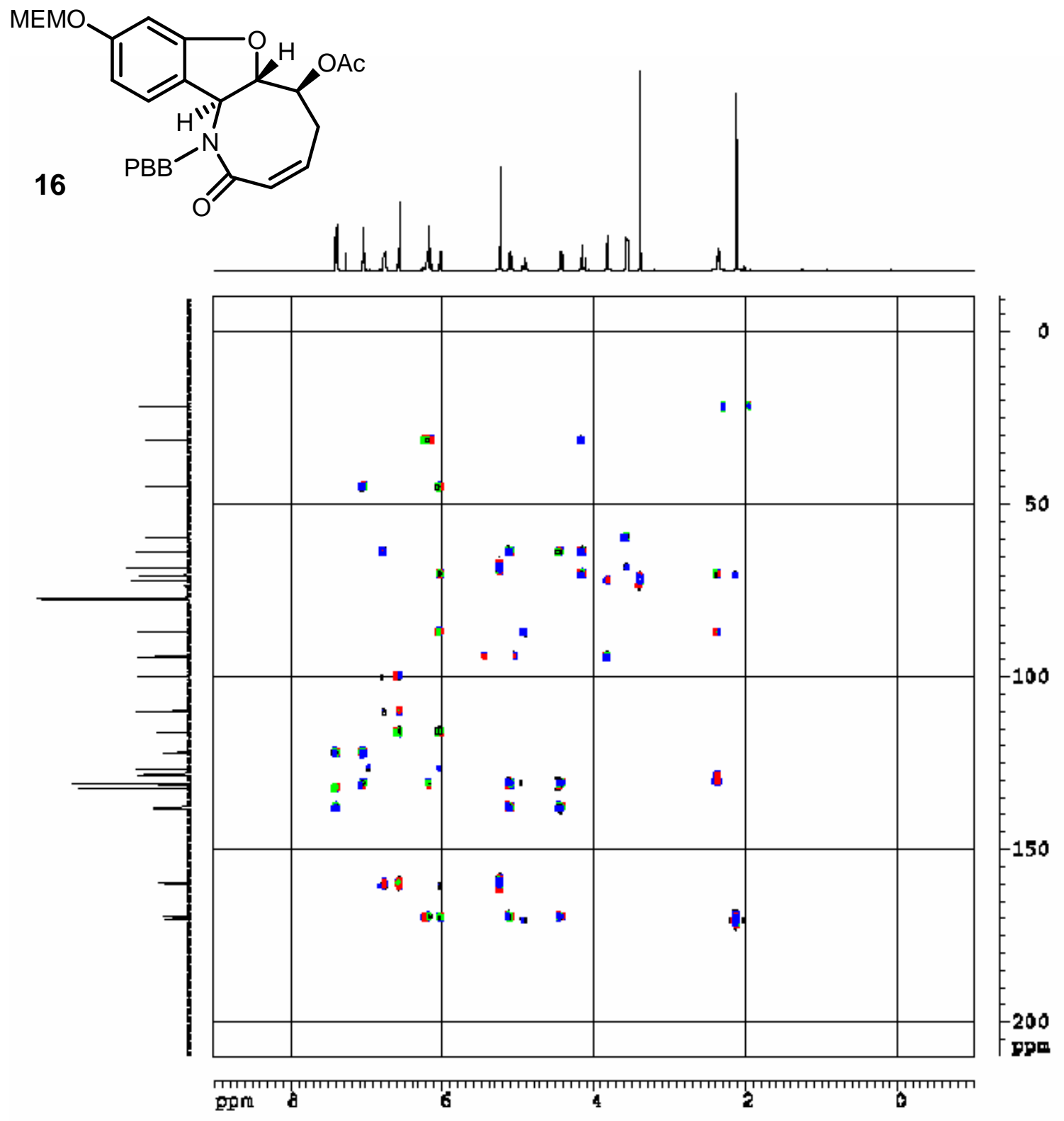




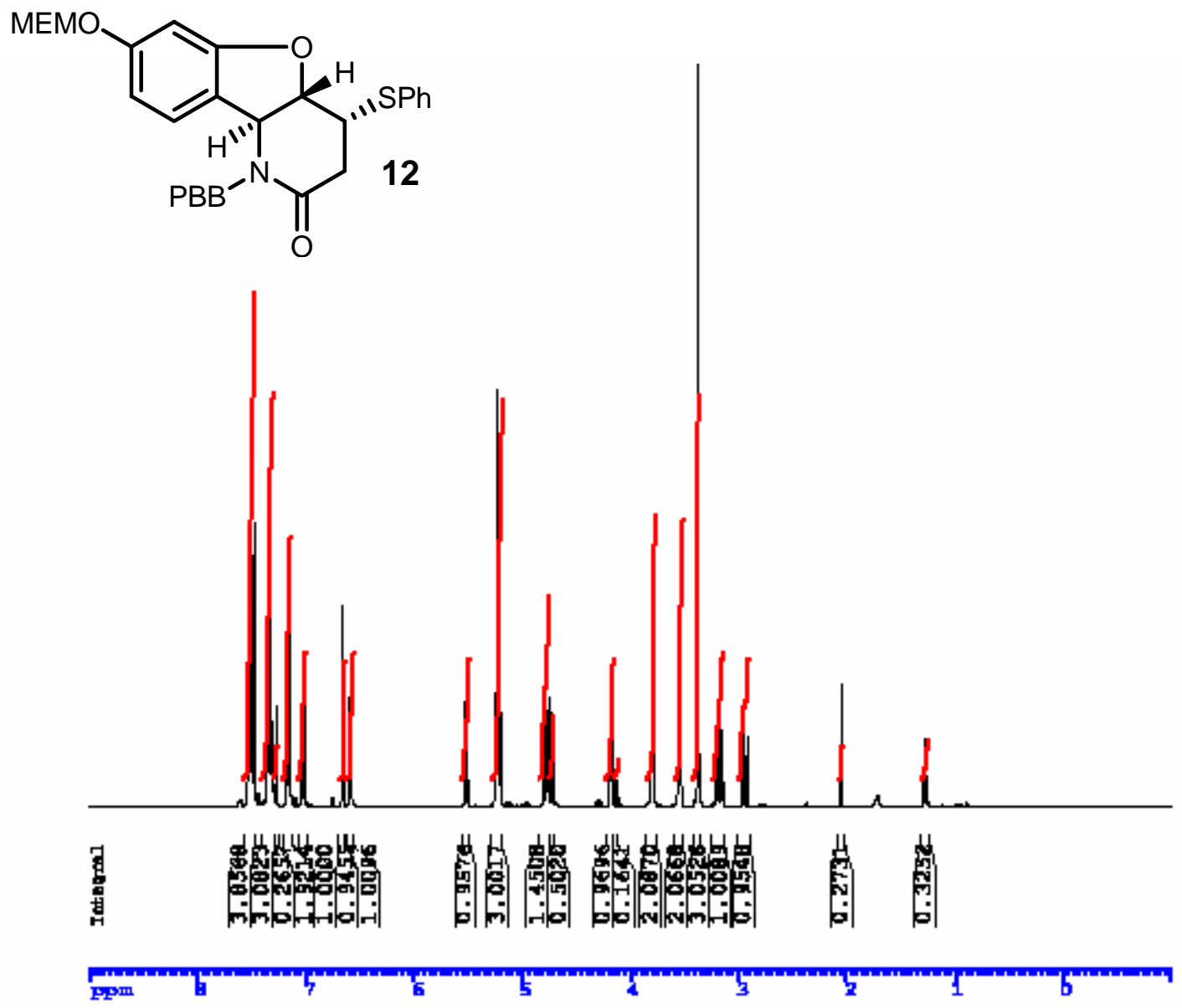




\section{H-H COSY}

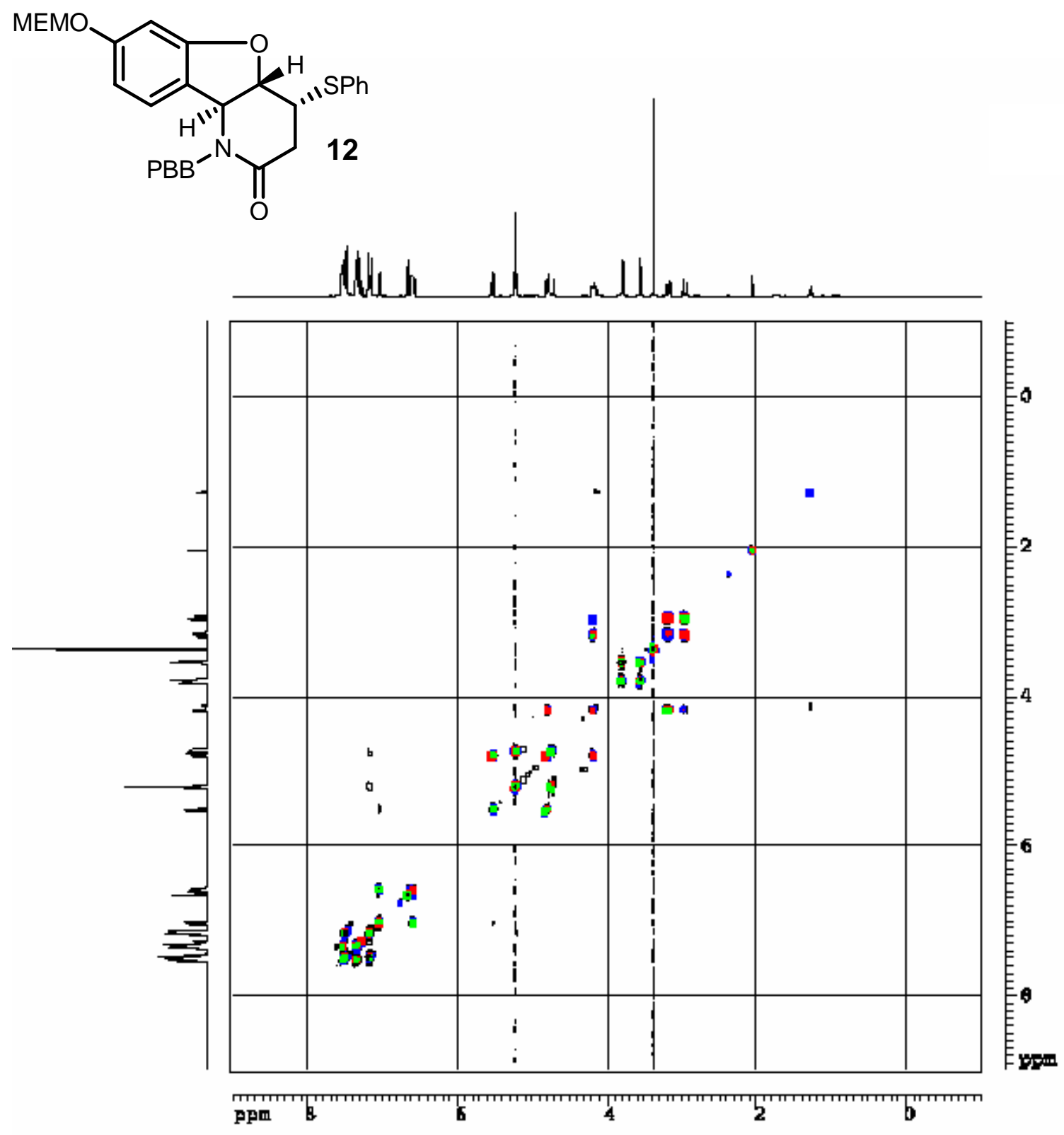




\section{NOESY}

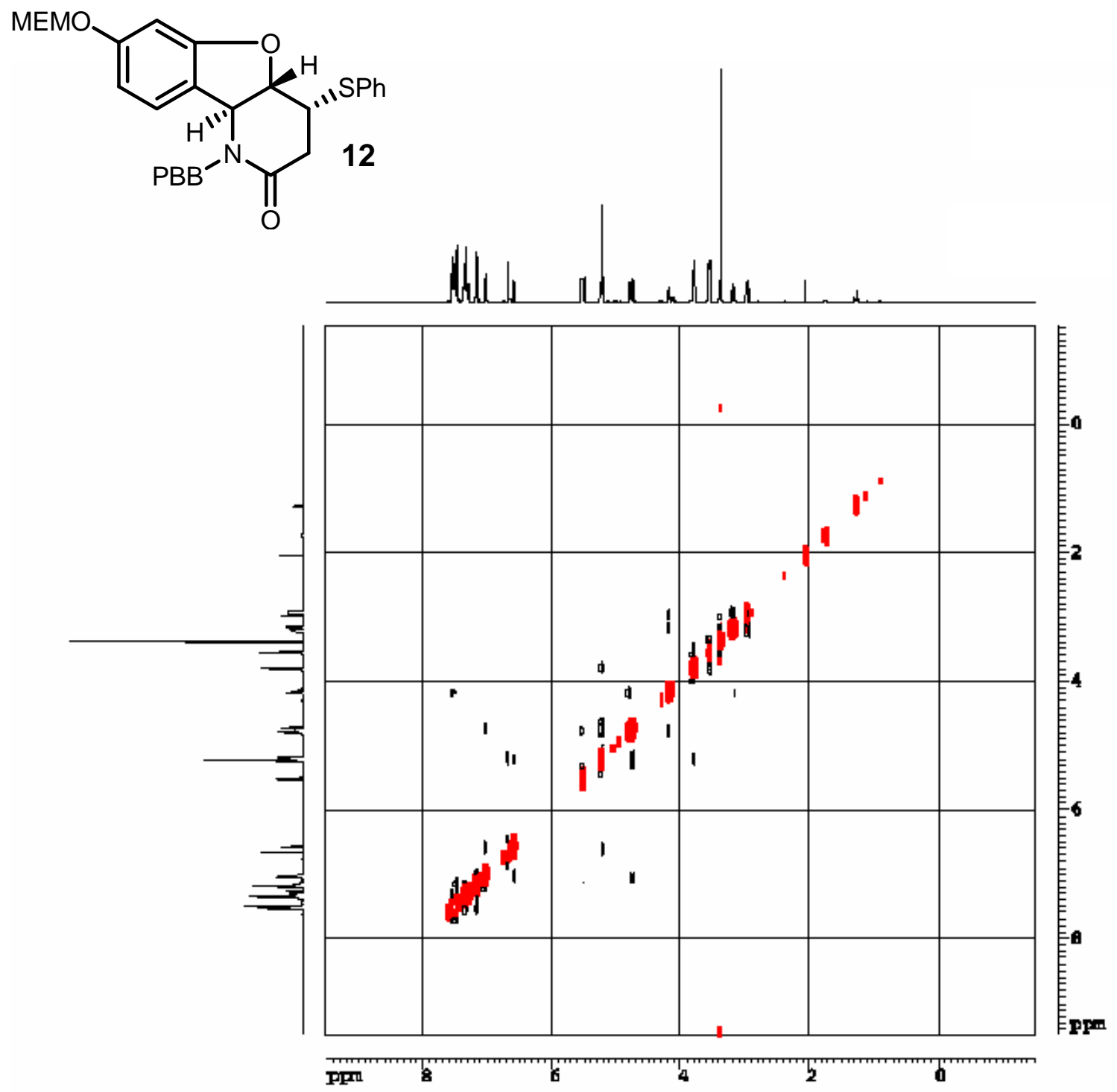




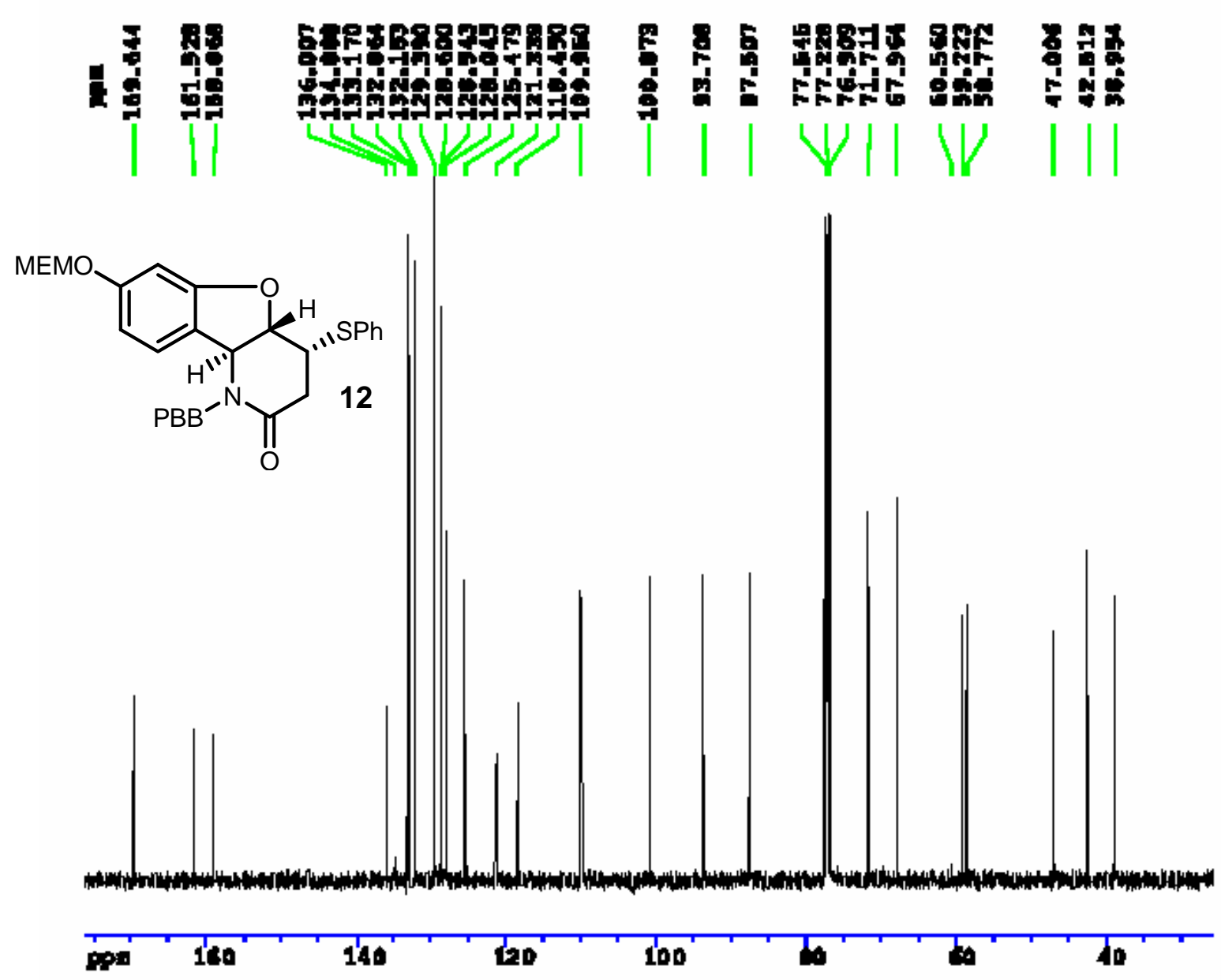




\section{HSQC}

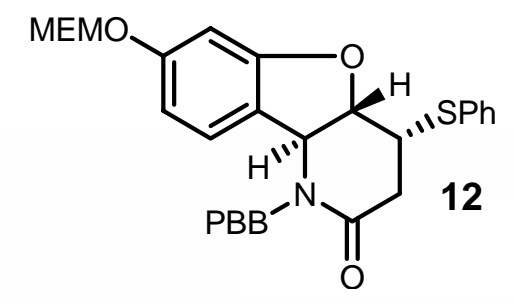

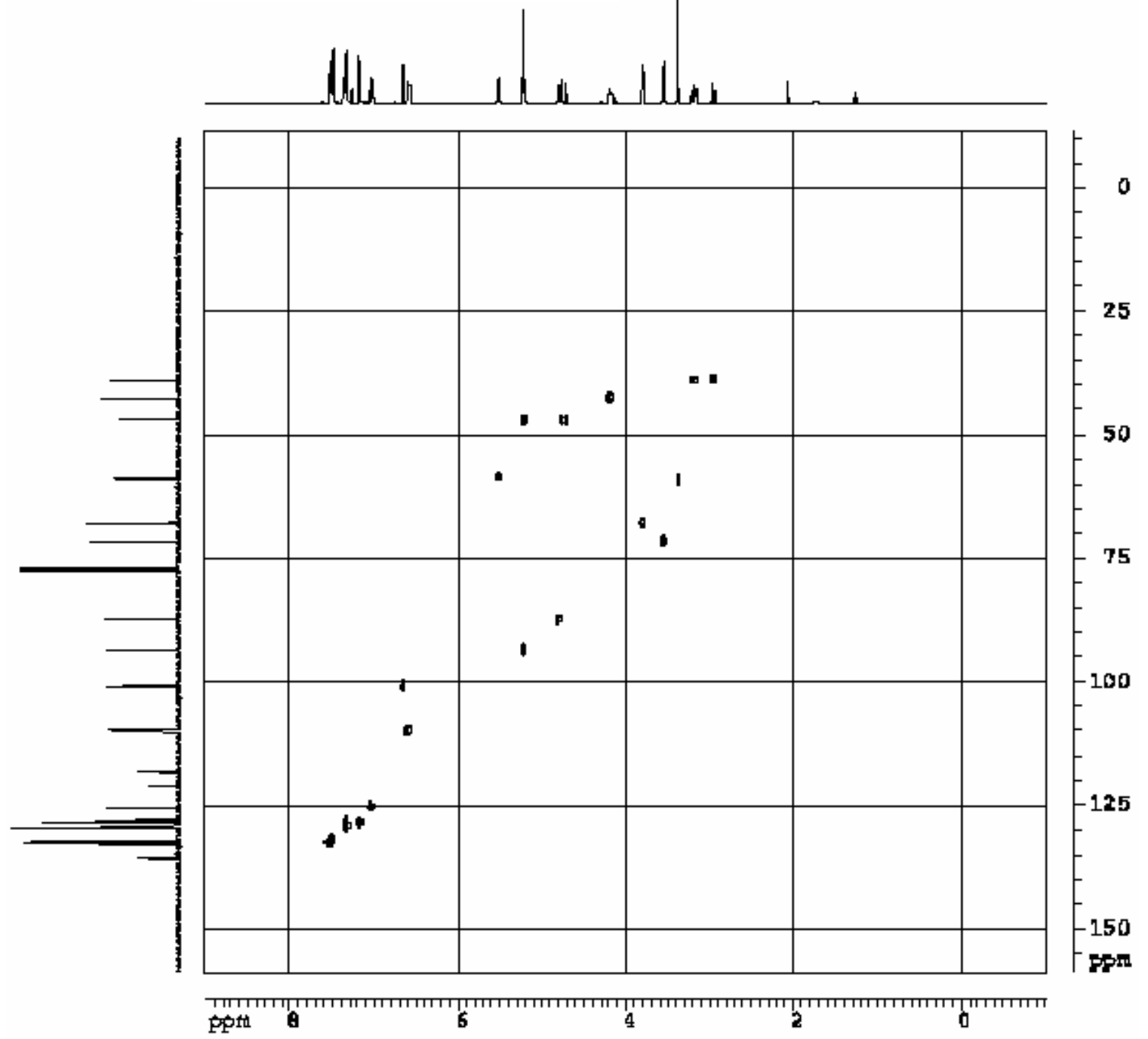




\section{HMBC}

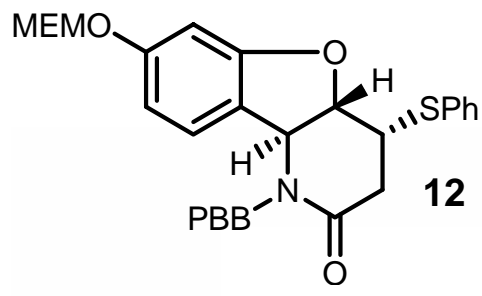

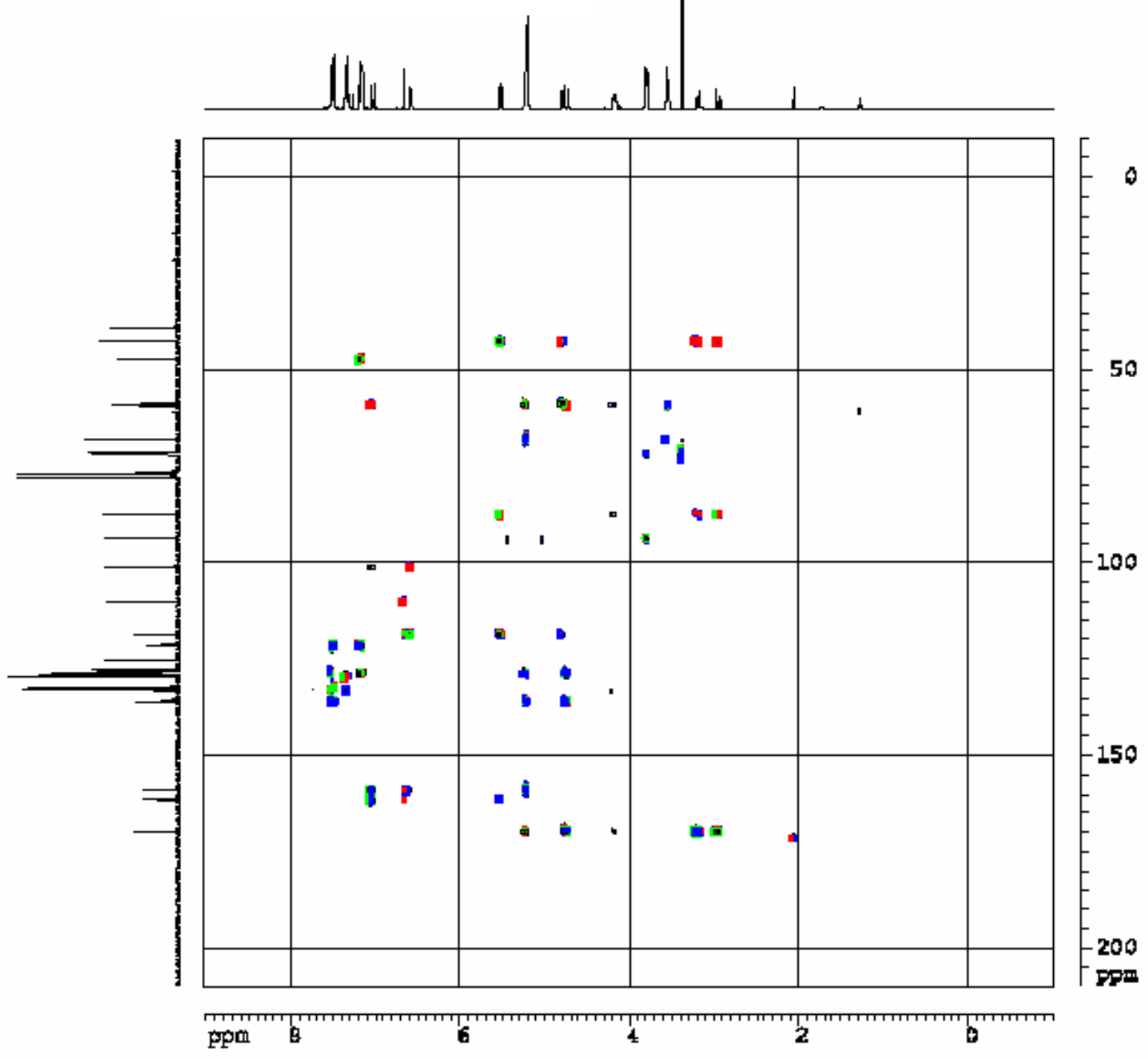




\section{H NMR $\left(25^{\circ} \mathrm{C}\right)$}

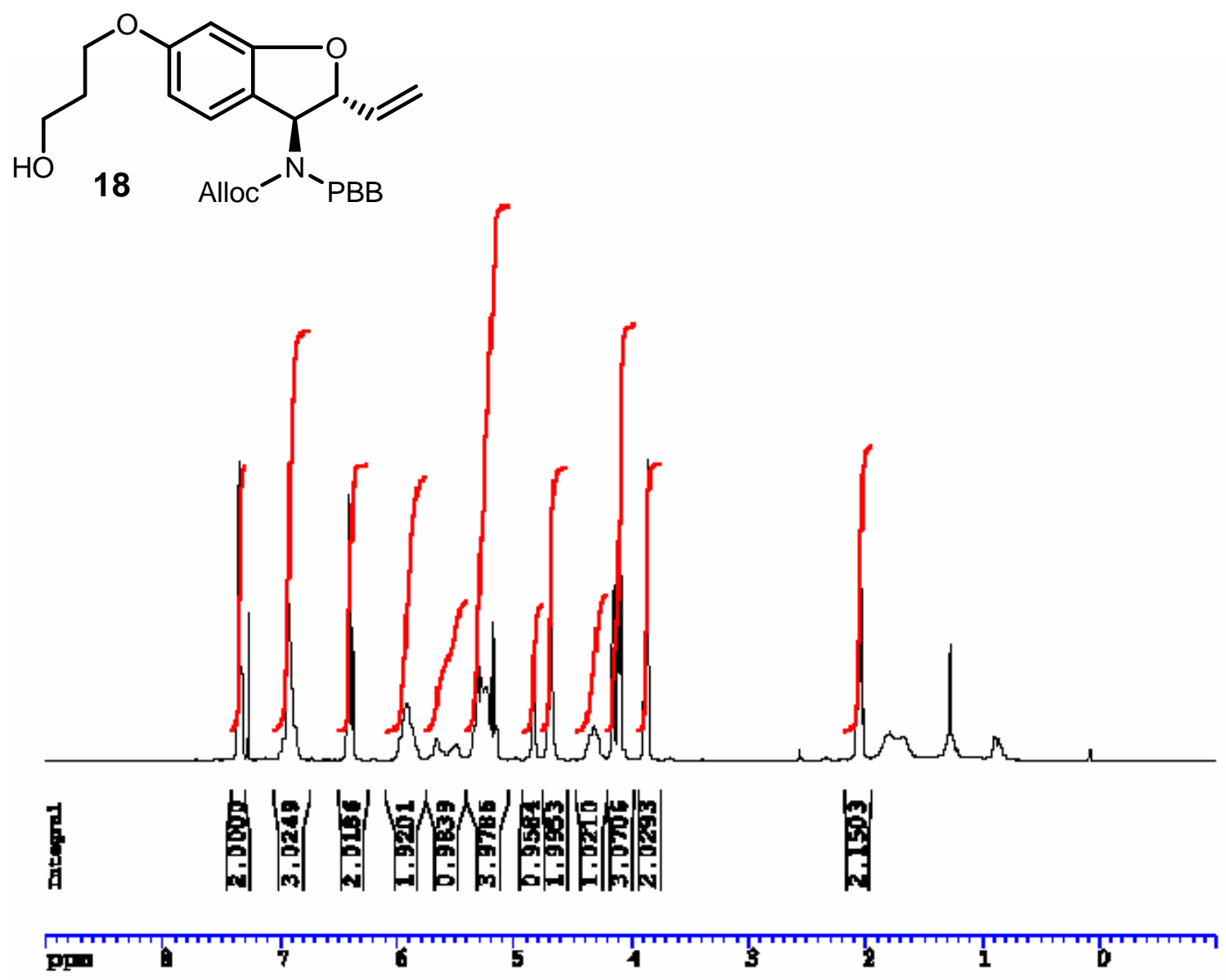




\section{H NMR $\left(58^{\circ} \mathrm{C}\right)$}<smiles>[R5]N([13CH3])[C@@H]1c2ccc(OCCCO)cc2O[C@@H]1C=C</smiles>

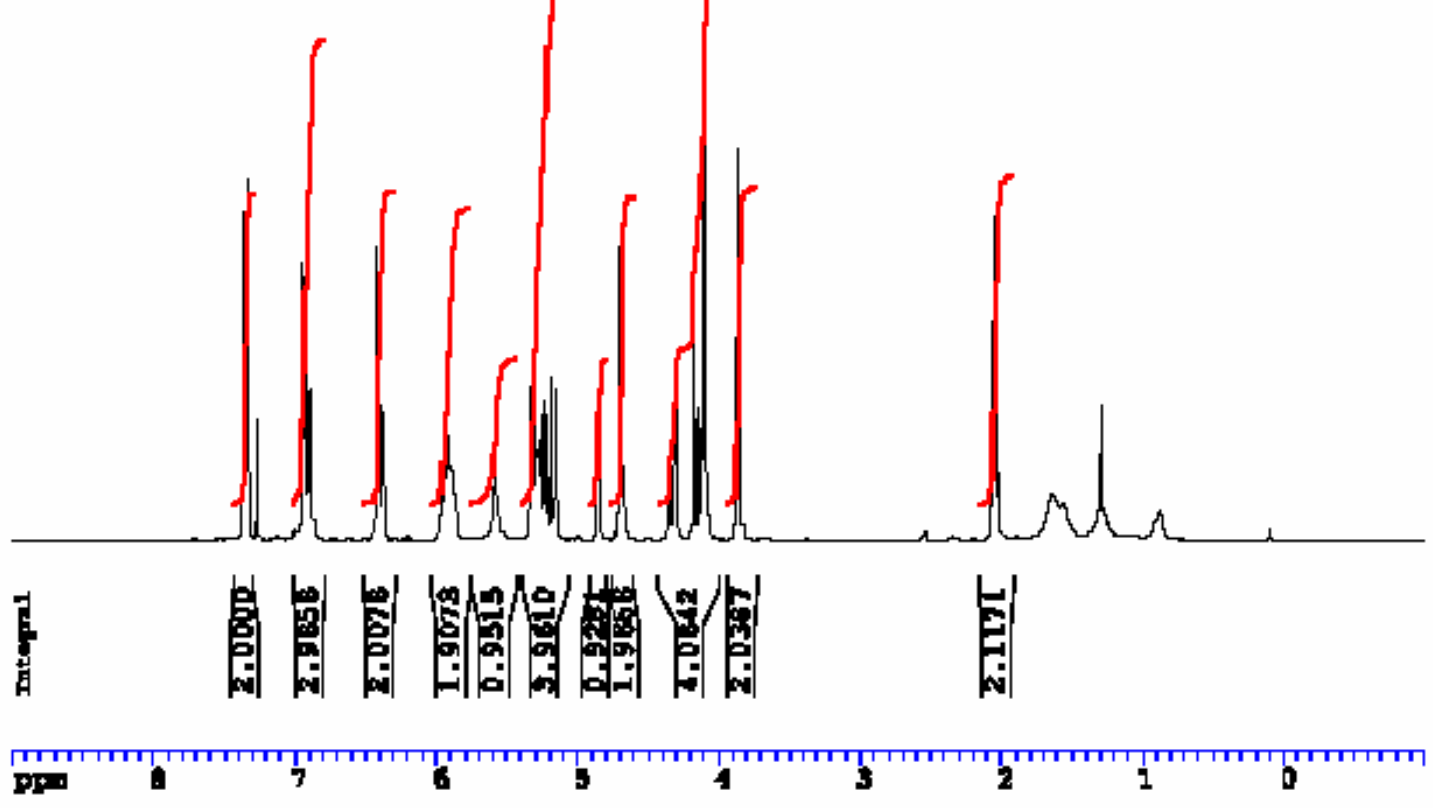




\section{C NMR $\left(25^{\circ} \mathrm{C}\right)$}

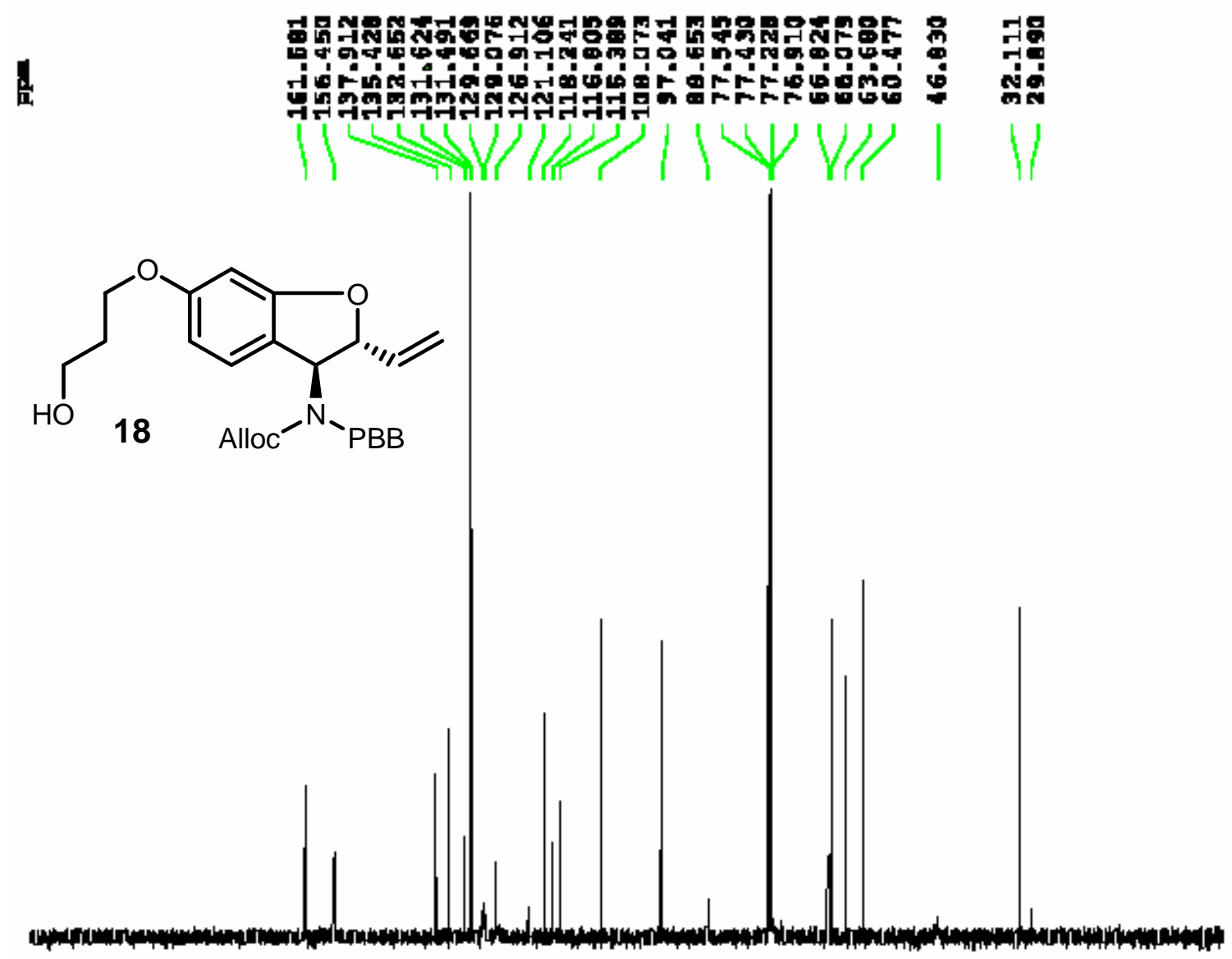

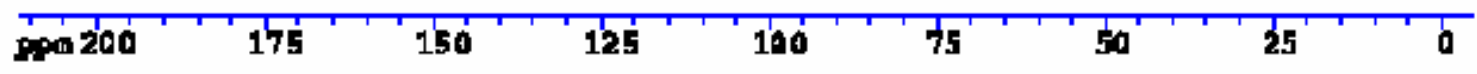




\section{C NMR $\left(58^{\circ} \mathrm{C}\right)$}

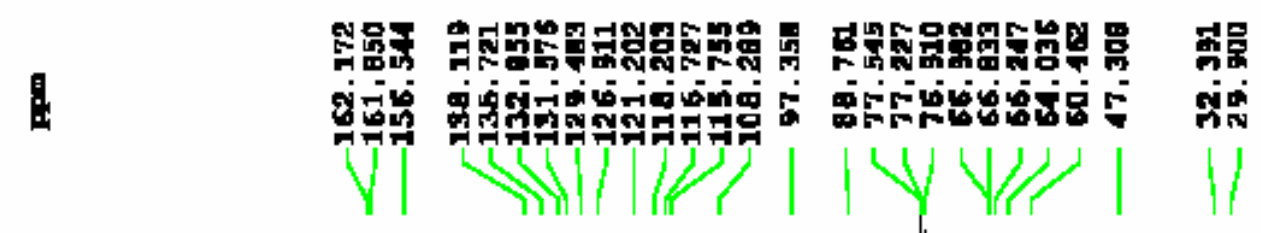<smiles>C=C[C@H]1Oc2cc(OCCCO)ccc2[C@H]1N(C(=O)c1ccccc1)C(=O)c1ccccc1</smiles>

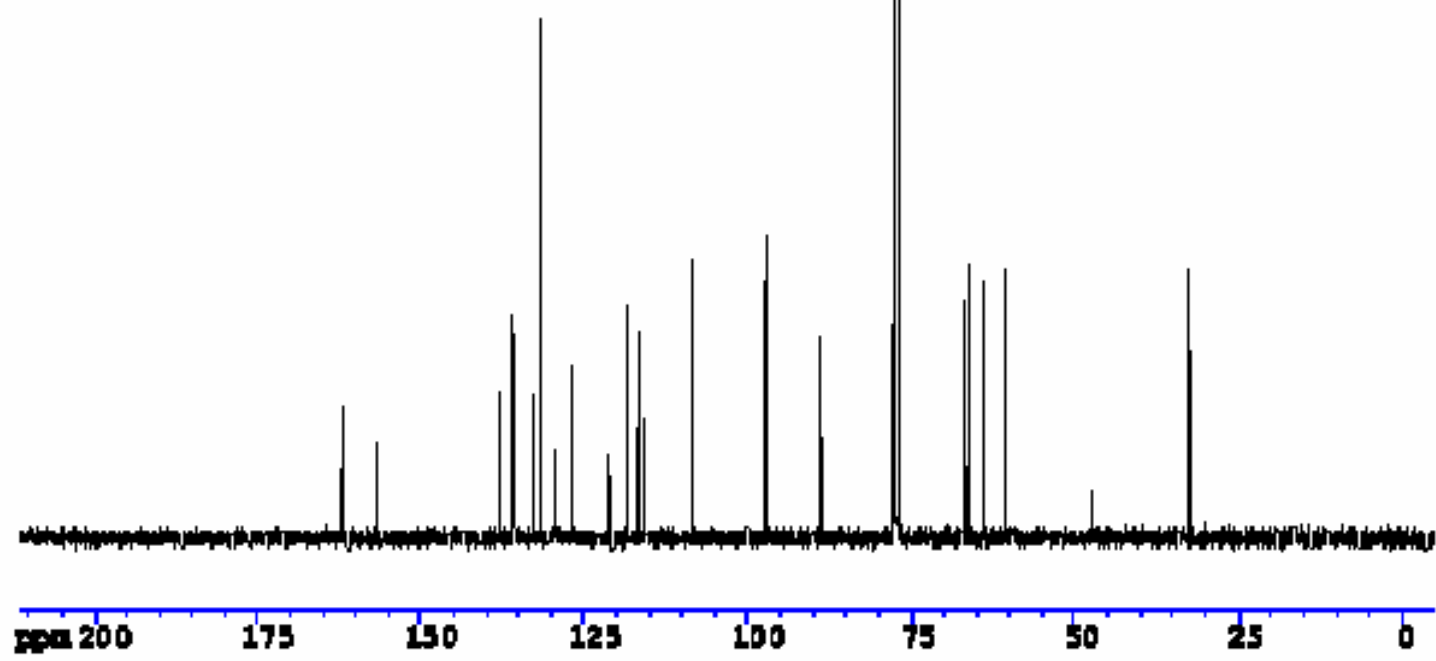




\section{H-H COSY $\left(58^{\circ} \mathrm{C}\right)$}

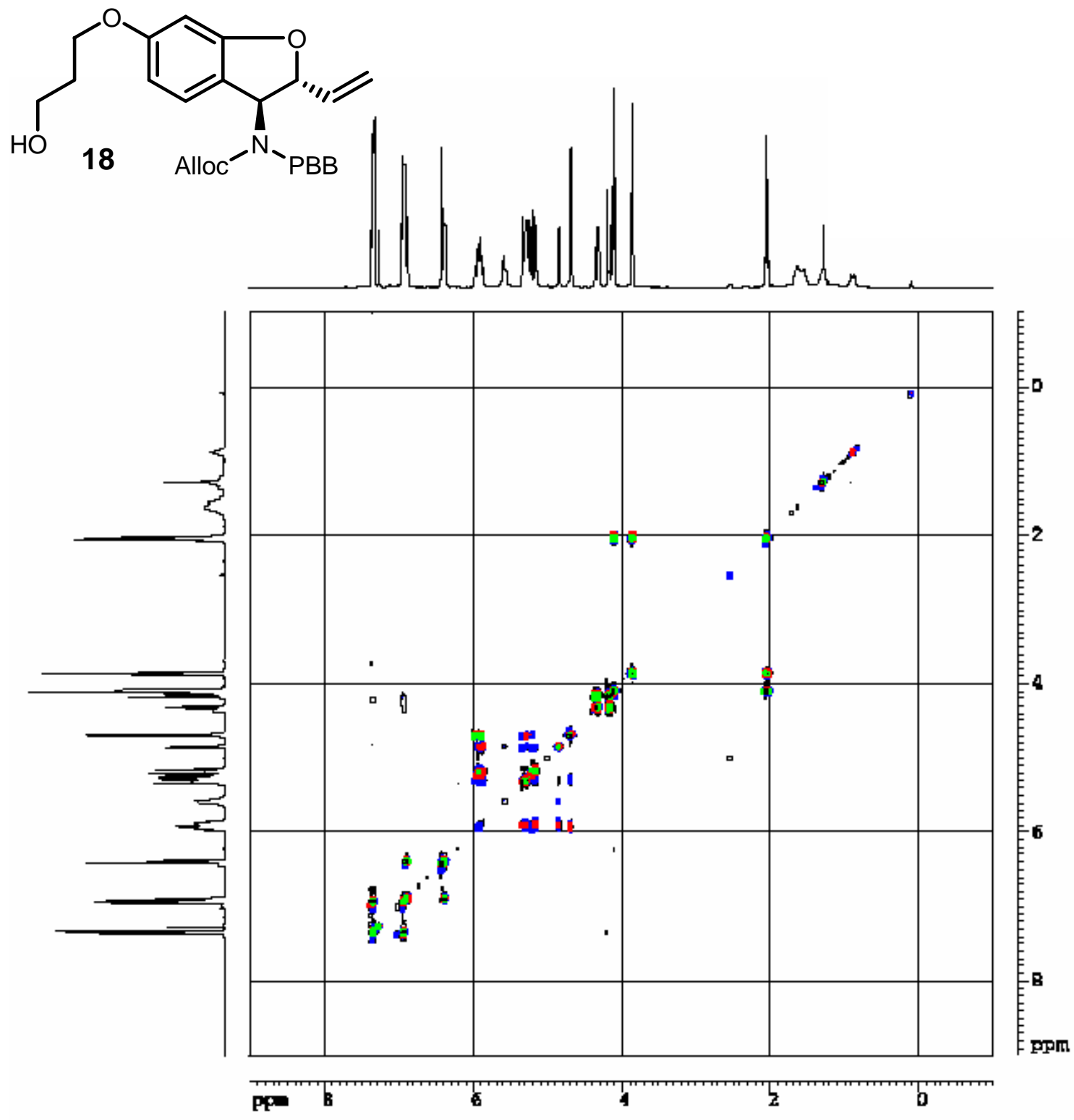




\section{HSQC $\left(58^{\circ} \mathrm{C}\right)$}
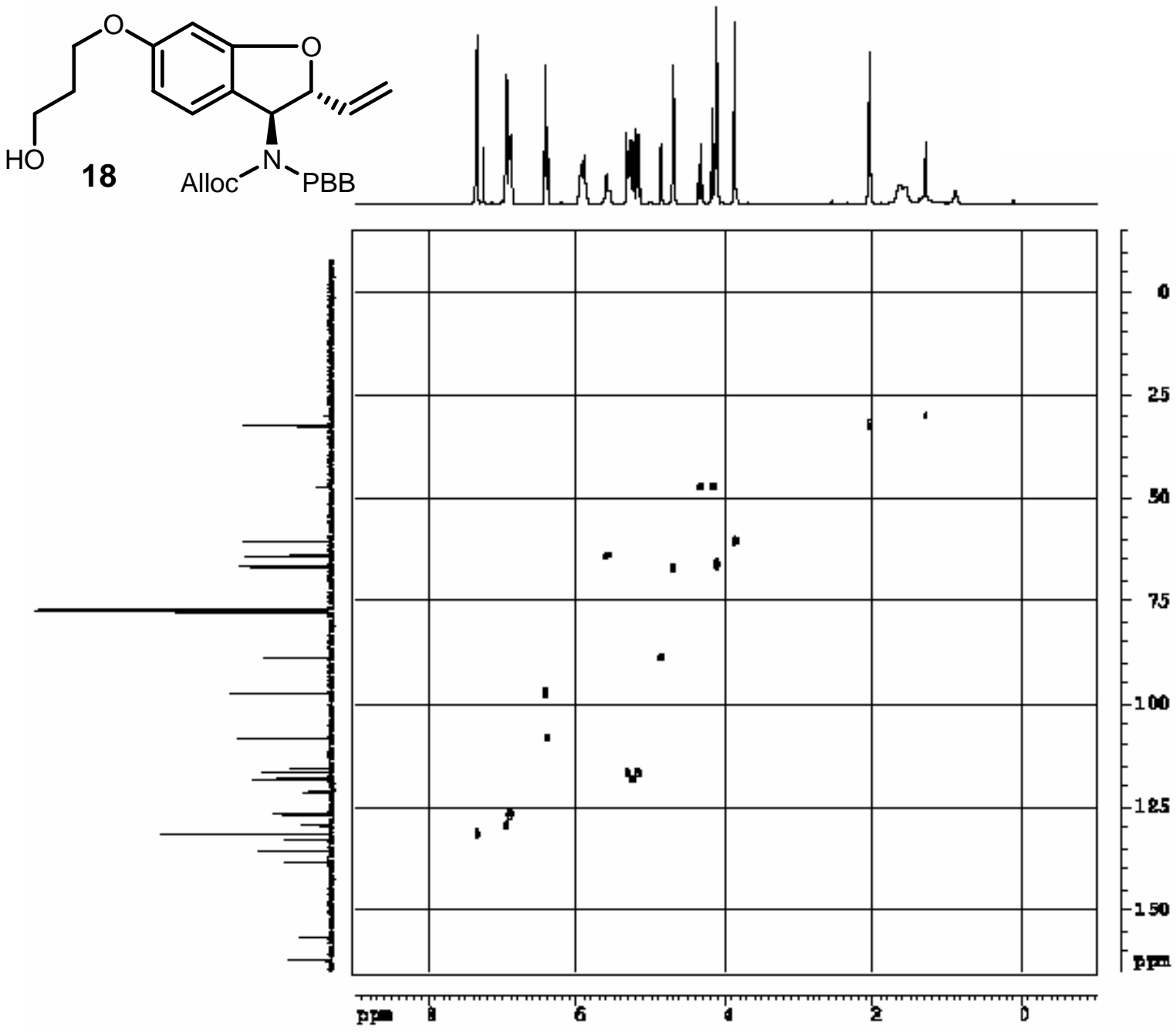


\section{TOCSY $\left(58^{\circ} \mathrm{C}\right)$}<smiles>[R5]N(C(=O)[OH2+])[C@@H]1c2ccc(OCCCO)cc2O[C@@H]1C=C</smiles>

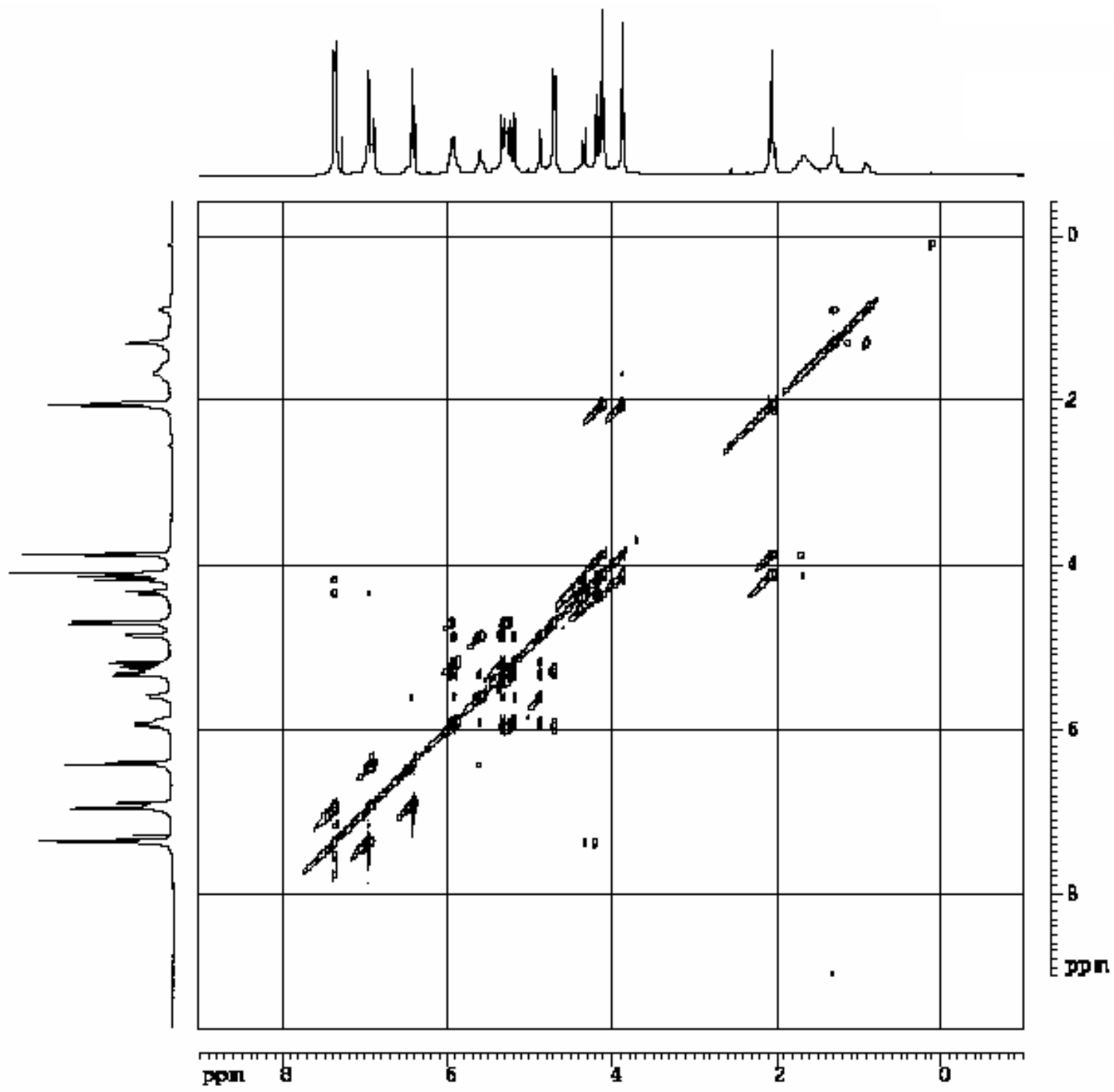

